\title{
A RESEARCH AGENDA FOR ACADEMIC PETROLEUM ENGINEERING PROGRAMS
}

A

REPORT

on

DEPARTMENT OF ENERGY GRANT DE-FGQ5-88ER75419

from

THE TEXAS ENGINEERING EXPERIMENT STATION

prepared by

JOHN C. CALHOUN, JR.

MARCH 31, 1990

\section{DISCLAIMER}

This report was prepared as an account of work sponsored by an agency of the United States Government. Neither the United States Government nor any agency thereof, r.or any of their employees, makes any warranty, express or implied, or assumes any legal liability or responsibility for the accuracy, completeness, or usefulness of any information, apparatus, product, or process disclosed, or represents that its use would not infringe privately owned rights. Reference herein to any specific commercial product, process, or service by trade name, trademark, manufacturer, or otherwise does not necessarily constitute or imply its endorsement, recommendation, or favoring by the United States Government or any agency thereof. The views and opinions of authors expressed herein do not necessarily state or reflect those of the United States Government or any agency thereof. 
Although the preparation of this report involved discussions with many porsons and is based on opinions and ideas that were gathered from those discussions as well as from survey instruments that were completed by petroleum engineering faculty members and other individuals, the content of this report is in no way intended to reflect the opinions of any person or groups of persons other than the author, who takes full responsibility for the statements, findings and conclusions of this report.

John C.Calhoun, Jr. 
A RESEARCH AGENDA FOR ACADEMIC PETROLEUM ENGINEERING PROGRAMS

\section{TABILE OF CONTENTS}

Chapter 1. Introduction $\ldots \ldots \ldots \ldots \ldots \ldots \ldots \ldots \ldots \ldots \ldots \ldots \ldots \ldots \ldots \ldots \ldots \ldots$

1.0 Purposes and importance

1.1 Scope of study

1.2 Manner in which the study was conducted

Chapter 2. The Background $\ldots \ldots \ldots \ldots \ldots \ldots \ldots \ldots \ldots \ldots \ldots \ldots \ldots$. $4 \ldots \ldots$. 4

2.0 The development of industry research in petroleum production

2.1 The development of academic petroleum engineering research

2.2. The funding levels for petroleum engineering research

2.3 Petroleum industry research associations

Chapter 3 The Scope of Petroleum Engineering Research ...................... 15

3.0 The domain of petroleum engineering

3.1 The subject matter organization of petroleum engineering

3.2 The elements of a petroleum engineering research agenda

3.3 The need for environmental access in petroleum engineering research

Chapter 4 Priority Research Topics and Technological Issues............Page 25

4.0 Survey of research issues

4.1 The faculty survey on research topics

4.2 The faculty survey on level of research activity

4.3 Survey of selected industrial leaders

4.4. Some key research issues

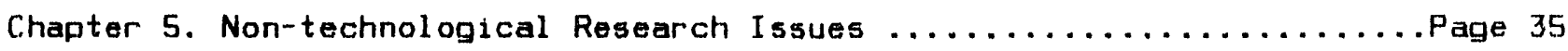

5.0 The faculty survey on non-technical issues

5.1 The faculty survey on cooperation, field data and special facilities

5.2 Non-technical issues from non-faculty sources

5.3 General attitudes and perceptions

5.4 Resources and organizational arrangements

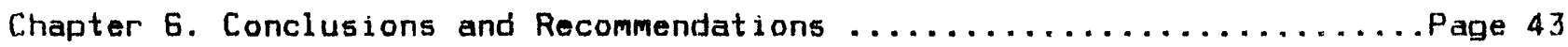

Appendices $\ldots \ldots \ldots \ldots \ldots \ldots \ldots \ldots \ldots \ldots \ldots \ldots \ldots \ldots \ldots \ldots \ldots \ldots \ldots \ldots \ldots \ldots$. $5 . \ldots \ldots$ 


\section{A RESFARCH AGENDA FOR ACADEMIC PETROLEUM ENGINEERING PROGRAMS}

\section{Chapter 1 -INTRODUCTION}

\subsection{PURPOSE}

The petroleum engineering academic community has an obligation to be able to advise the overall university community, the profession, industry, government agencies and the public at large as to the status of the technology of which it claims to be the academic guardian. This obligation is normally discharged through the directed programs of graduate study, the research activities, the programs of continuing education, the publications by faciulty and the participation of individual faculty members in professional activities, advisory groups and consultative positions. The fulfilment of the obligation becomes a collective response as the effort of each individual faculty member or petroleum engineering department adds to the total. There has been little occasion, however, for the petroleum engineering academic community to address this obligation as a consensus matter. The concept of developing a national research agenda for petroloum engineering represents such an opportunity.

The devolopment of a research agenda should be a direct way of portraying the scope of petroleum engineering, of identifying the critical technological issues faced by the profession, of elucidating the gaps between the existing research rosources and the neods, and of outlining a program of research through which the petroloum ongineering departments can be collectively of maximum service. Such an agenda would be of value to the profession of petroleum engineering. to industry and to government agencies, as well as to the faculty and students of the petrol eum engineering departments.

The purposes of the activity that led to this report, therefore, were

* to develop a statement to serve as a beginnning research agenda for the petroleum engineering academic community;

- to bring together representatives of the petroleum engineering academic community to recognize the importance of developing a consensus posture with respect to research; and

* to provide a document that will assist in portraying to industry, government agencies and others the problems and needs of the petroleum engineering departments for conducting research.

\subsection{SCOPE OF THE STUDY}

The questions that were to be addressed in the preparation of a research agenda included the following- 
1. What technological issues or problems are most critical for the advancement of petroleum technology?

2. What gaps exist in the knowledge structure of petrol eum techrology?

3. What non-technological issues or problems are critical for the advancement of petroloum technology?

4. What academic research programs should be mounted to deal with the issues and gaps that are identified?

5. What additional resuurces will be required by the petroleum engineering departments so that they can carry out the programs that are identified?

6. What actions are neoded on the part of the petroleum engineering departments, industry, government agencies or other entities to bring the proposed programs to fruition?

7. What communication and cooperation channels neec to be established or improved in order to gather data for answering such questions or to maintain $v i a b l e$ academic research programs and assemble the required resources and funding?

The scope of the activity on which this report is based, therefore, was intended to be sufficient to provide answers to these and similar questions. As background for addressing such topics, there needed to be some base of understanding as to the nature of petroleum engineering, as to the current status of research support and as to the role of various participants in the research arene pertaining to petroleum engineering. Chapters of this report provide short summaries of such backgrounds.

\subsection{MANNER IN WHICH THE STUDY WAS CONDUCTED}

This study was conducted by John C.Calhoun, Jr, under a grant from the Department of Energy, made to the Texas Engineering Experiment Station. The study was encouraged by the Assoclation of Heads of Petroleum Engineering Schools and was endorsed by that group. The Steering Committee, consisting of the institutional representatives who are 1 isted in Appendix 1-1, met at the headquarters of the Society of Petroleum Engineers in Richardson, Texas on April 25, 1989. At that meoting the conduct of the study was discussed, including methods for gathering opinions and the outline of a potential report. Also at that meeting presentations were received from industry persons about the several industrial research associations that were in being, which information was subsequently distributed to the heads of petroleum engineering departments. A summary of that meeting is included as Appendix 1-2.

Survey instruments, prepared for distribution to faculty members of petroleum engineering departments, were used as a method of obteining opinions about important problems and issues related to research in petroloum engineering. The instrument was sent to all faculty members who were listed in the publication of the Society of Potroleum Engineers titled "Petroleum Engineoring and Technol ogy Schools". The specific questions and responses are 
detailed in Chapters 4 and 5 of the report. A similar survey instrument was sent to selected persons outside of petroleum engineering departments, as is also detailed in Chapters 4 and 5.

0n July 10, 1989 a report was made to the heads of petroleum engineering departments, meeting at SPE headquarterts in Richardson, Texas. At that meeting several summaries of background information were distributed, preliminary responses from the surveys were discussed and plans were outlined for assembling small faculty groups to discuss the agenda. At that meeting, also, further information was distributed to department heads about the work of the industrial research associations.

A draft report was prepared, based on the results of the surveys, coupled with research statistics that were available in several reports published by the National Science Foundation, the National Petroleum Council and the American Society for Engineering Education. The draft report, dated September 12, 1989 was distributed to heads of petroleum engineering departments and was discussed at a meeting of the department heads held in San Antionio October 8 , 19891. Copies of the draft report were distributed also to persons who had responded to surveys and to others, the purpose boing to obtain feedback on the draft. A copy of the introductory page to the draft report is given as Appendix $1-3$.

In addition to these interactions with departments heads, a presentation about the study was made to the Education Council of the Society of Petroleum Engineers on September 19, 1989 in Houston, Texas. The study was described to members of the Council and they were given copies of the draft report. Three of the overhead displays, used in this presentation to emphasize the relevance of the study to SPE, are in Appendix 1-4.

Late in 1989, each department of petroleum engineering was contacted and was asked to designate faculty members who would be willing to attend small group meetings during January, 1990 to discuss specific topics within the report. Seven dates were set for the meetings, all to be held at the SPE headquarters in Richardson, Texas, with topics as follows-

January 9 - Logging. Characterizaton \& Formation Evaluation

January 15-Reservoir \& Well Systems

January 16-Recovery Processes \& EOR

January 22- Drilling \& Completions

January 23 - Production

January 29- Environment, Economics \& Related Matters

January 30- Optimization, Expert Systems \& Data Organization

All departments were furnished the schedule for these meetings and were invited to send as many individuals to participate as they desired (see Appendix 1-5). Invitations were also extended to selected persons from industry, including persons who were familiar with the industrial research associations. Lists of attendees at these meetings are given in Appendix 1-6.

After these small discussion meetings, the draft report was revised and a concluding chapter dealing with findings and recommendations was prepared. 


\section{A RESEARCH AGENDA FOR ACADEMIC PETROLEUM ENGINEERING PROGRAMS}

\section{Chapter 2- THE BACKGROUND OF RESEARCH}

\section{THE DEVELOPMENT OF PETROLEUM INDUSTRY RESEARCH}

A historical summary of petroleum ongineering research is given in Cliapter 17. Mistory of Petroleum Engineering, published by the American Petroleum Institute in 1961. The author, L.E.Elkins, notes the early work of the Pennsylvania Geological Survey, the U.S. Geological Survey and the U. S. Bureau of Mines and cites a figure of 145 research people employed in the entire petroleum industry in 1920.

Elkins describes the poriod prior to 1927 as that in which there was a recognition of research by the individual petroleum companies, with the establishment of field laboratories and/or certralized production laboratories to deal with operational problems. These early starts evolved into research departments and/or separate research corporate entities. The Gulf 0il Corporation established the Gulf Research and Development Company in 1927 and other companies followed its lead in succeeding yoars, a period given by Elkins as extending from 1927 to 1957.

The total extent of current industrial research in petroleum exploration and production is not catalogued. The 1988 National Petroleum Council Report, "Integrating R\&D Efforts", contains information on 38 responses to a questionaire that was sent to its mombers, twenty three of whom said that their organization conducted or supported exploration and production research activities. In response to a question that asked for the approximate year in which the company began its research, the replies showed that two companies had started their research by 1920, three companies in the interval 1921-30, three companies in the interval 1931-40, four companies in the interval 1941-50, three companies in the interval 1951-60, two in the interval 1961-70, two in the interval 1971-80, and four in the years since 1980. In short, all but five have been supporting research for twenty years or more.

Figure 2-1 shows the growth in reported expenditures for exploration and production R\&D, combining data cited by Elkins and data tabulated in the NPC report cited above. The text of the NPC report statos "Domestic upstream research is also being performed by privato research laboratories and companies involved with chemical, software, and goophysical activities, as well as by other oil and service companies not included in the survey. It is estimated that including those firms would increase private-sector domestic upstream research to more than $\$ 1$ billion from the $\$ 811$ million reported by the survey respondents."

It is difficult to assess the level of this research as it inight compare to other industries or areas of technolopy. However, the NPC report notes that in 1986 the corporate revenues from oil and gas production were $\$ 459,199$ million while the R\&D expenditures were 853 million, i.e. research expenditures were slightly 108 s than $1.5 \%$ of the total revenues. 
It is also difficult to assess the degree to which the support of research is distributed throughout the entire industry. An indirect assessment of the distribution can be gained by noting that the 1989 "USA Oil Industry Directory", published by Pennwalt, lists 26 separate companies in the tabulations of the top 20 companies in each of the categories of US liquids production, US 1 iquids reserves, US gas production and US gas reserves. The companies in these four 1 ists represent $92 \%$ of the 1 iquid reserves, $90 \%$ of the 1 iquid production. $74 \%$ of the gas reserves and $71 \%$ of the gas production. Although thase 26 compantes cannot be 1 dentifind as the 23 companios renortert

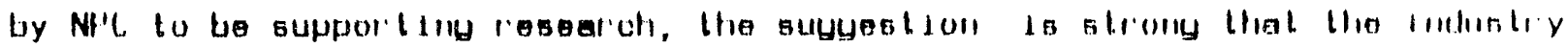
research is supported by the large companies that represent from $75 \%$ to $90 \%$ of the total industry activity.

The emphasis on research topics has varled over the years as needs have changed and emerging problems or technological opportunities have been recognized. In essence, much of the early research laid the groundwork for recognizing and defining the elements of reservoir engineering. Elkins states that "In the last years of the great economic depression, the term 'reservoir engineering' had not yet been coined and knowledge of this subject was meager and relatively undeveloped." Elkins goes on to note that in the two decades. 1935-1955, much research was done on petrophysics, physics of reservoir fluids and basic reservoir performance equations. In subsequent years the cycle of research emphasis has included such areas as the development of sophisticated formation evaluation techniques, the development of various EOR processes and mass transfer, the use of computers for simulation and operational control, the analysis of transient phenomena, the use of fracturing and other well stimulation methods, the improvement of drilling systems and the development of techniques for dealing with off-shore and other unfiendly onvironmental situations.

The NPC report gives the current distribution of funds in E\&P research as Exploration, 29\%; Research Characterization and EOR, 34\% and other Production, 37x. Elkins notes that $40 x$ to $50 x$ of the total E\&P research was spent on production in 1955. The lower relative percentage being spent on exploration research today is explained in the NPC roport as follows. "With the large quantity of oil currently considered as unrecoverable in the domestic reservoirs (estimated to be over 300 billion barrels), and restricted opportunities to explore in many of the frontier areas, it has become increasingly importarit to the nation and to the industry to improve recovery from the known resources."

\subsection{THE DEVELOPMENT OF ACADEMIC PETROLEUM TECHNOLOGY RESEARCH}

Petrolaum engineering rosearch in the academic community can be traced in part through the growth of the petroleum ongineering educational orograms. Much of the early research, however. involved fields of study other than petroleum engineering. Prior to 1950, there were very few doctoral programs in petroleum 
engineering, the majority of such doctorates having been produced in the last twenty years. ( see Appendix 2-2). Hence, the focusing of research programs within petroleum engineering departments is a relatively recent matter.

University involvement in the oarly development of petroleum production research was usually the result of individual contacts betweon faculty members and oll company personnel. However, in 1926, the American Petroleum Institute initiated a program that was to play a significant role involving the

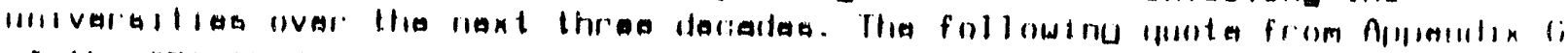
of the API 1943 volume on "Fundamental Research Un the Uccurrence and Hecuvery of Petroleum" gives the origin of this activity. - "On November 1, 1925, John D. Rockefeller, Sr. donated $\$ 250,00$ to the American Petroleum Institute for fundamental research in petroloum, payable $\$ 50,00$ per year over a period of five years. In January 1926 the Universal $0 i 1$ Products Company contributed a like amount for the same purpose. These two funds were expended by the Institute, with the advice and assistance of the Central Petroleum Committee of the National Research Council, in supporting fellowships at various university and government laboratories during the poriod July 1, 1926 to June 30, 1931." Among the early projects for the API fellowship support were Project 1-Generation of 011 In Rock by Shearing Pressures. Directed by Professor Warren J.Mead, University of Wisconsin;

Project 4-Origin and Enviromment of Source Sediments, with successive headquarters over five years at Scripps Institution of Oceanography, USDA, Chemistry department of Stanford University, the Agricultural Experiment Station of Rutgers University and the Frick Chemical Laboratory at Princeton; Project 5-Diatoms as a Source of O11, Directed by Professors Becking and Tolman of Stanford University;

Project 23-Limestones and Dolomites as Reservoir Rocks, Directed by Dean Daniels, University of Illinois,

Project 25-The Deturmination of Geothermal Gradients in 0il Fields on Anticlinal Structures, a project in threo parts, one at The University of Oklahoma, directed by Professor George and Dr. Gould, one at the University of Texas, directed by Profossors Sellards and Plummer, and one at the University of California, directed by Frofessor Uren;

Project 27-Displacement of Petroloum 0ils from 0il-Bearing Sands by Use of Selected Aqueous Solutions, Directed by Ur. Bartell at the University of Michigan;

Project 33-The Effect of Natural Gas Upon the Viscosity, Surface Tension, Adhesion and General Extrertability of Potroloum of Various Types. Directed by Dr. George of the University of Oklahomai and

Project 34- The LaPlace-Perrin Law of the Distribution of Suspensions, Directed by Dr. Millikan. California Institute of Technology.

One of the most famous and long-continuing of the API Projects was that conducted by Sage anci Lacey at the California Institute of Technology. Their research provided the framework for the understanding of the PUT behavior of petroloum reservoir fluids. 
Although the research program of the American Petroleum Institute contributed to the development of petroleum production technology, it did so largely through support of academic programs in departments other than petroleum enginering. The basis of research funding on which the academic petroleum engineering research programs were bullt came from other sources, primarily through a combination of state funding and fellowship support from individual companies.

Perhaps the earliost comprehonsive university research program in petroleum ongineering, per se, was that at the Pennsylvania State University. Two industrial groups, the Ponneylvania Grade Crude Oxl Association and the

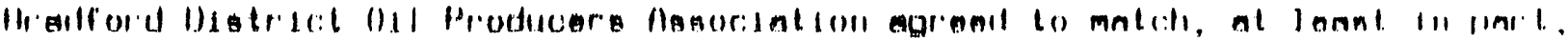
funds that were appropriated by the state legislature for conducting research to understand and improve the production of oil by secondary recovery methods. This program was begun about 1930 and continued for about three decades. It aitracted the attention of the large oxl companies outside of Ponnsylvania, some of whom contributed to the research funding on an annual basis. This program provided funds for the hiring of research staff, separate from teaching personnel, and for the support of graduate students. An industry advisory group existed for guidance of the program and annual conferences were held to report on the research. Projects, al though centered on secondary recovery, included geological and geophysical subjects, in addition to petroleum production and recovery topics.

In 1950, the Texas Petroloum Research Committeo was formed by agreement among the Texes Railroad Commission, the Toxas A\&M University and The University of Texas. This program provided funding for the two universities, through appropriations to the Railroad Commission. This program, like that at Penn State, enabled the hiring of separate research personnel and the support of graduate students. The support of this program by the Texas legislature, although never large, continued through 1987.

For several years in the post World War II era, the State of Illinois also conducted a state financed program in conjunction with the University of Illinois. This program, however, was phased out during the 1960 s as enrolments in petroleum ongineering programs waned.

University research programs in petroloum technology in both Kansas and New Mexico were initiated during the energy crisis years of the 1970s. In New Mexico,legislative funding provided for the creation of the Petroleum Recovery Research Center at the New Mexico Institute of Mining and Technology and the Center is now the largest state supported academic entitity for petroleum production.

Not only the initiation, but also the continuation of the petroleum engineering academic programs, for the most part, has been by means of internal university resources, prompted by local economic interests reflected in state appropriations, and supplamented by industrial fellowships, equipment grants, or similar contributions.

Petroleum engineering academic departmerits did not participate in the 
spurt in research growth of the late fifties and sixties that took place in other academic engineering areas. This lack was due to several factors, among them being the fact that there was no identifiable program of federal research support on which petroleum engineering departments could draw. Another important factor, however, was that the status of petroleum resources was not a public concern, e.g. there were no gasoline lines and large foreign deficits were not yet apparent. Legislators, as well as the public. felt that the industry had this need under control and would do any research that was necessary. Still another factor was that the development of the petroleum engineering graduate programs was embryonic. The industry had a concern primarily for baccalaureate graduates, rather than those with advanced degrees in petroleum engineering, and the petroleum engineering departments were oriented to this posture also.

It has been primarily since the energy crisis of the the early 1970 period, followed by the growth of the industry into the early 1980 period, with a subsequent decline and reorganization, that the research programs of the academic petroleum engineering departments have taken on an appreciable growth and focus. During most of the 1970 decade, they were swamped with an undergraduate student demand that consumed most of their energies. More recently, they have been making a tranisition away from predominantly undergraduate programs, have been moving to a broader interdiscipl inary involvement and have been focusing their programs on more basic issues.

Research in the field of petroleum engineering today is conducted in the institutions that have degrees in petroleum engineering and also in other departments in institutions that do not offer the petroleum engineering degree. The American Society of Engineering Education publishes an annual survey of research in engineering at academic institutions, the latest being in March, 1989. Appendix 2-3 is a listing of the projects from that survey, under the category of separately budgeted research, that can be identified as being petroleum engineering. A minimum of 274 projects are listed, with 46, e.g. 17\%, being in departments other than petroleum engineering. The majority of these other projects are identified as chemical engineering.

It should be noted that the projects in this list are those provided by the engineering college administrators who filed the reports for their institutions. Consequently, they may not exhibit the breakdown or emphasis that. would exist if the list had been compiled by a single group of petroleum engineers for all institutions or by individuals interested in exhibiting the details of petroleum engineering. For example, a communication from the University of Tulsa indicates that the sirigle areas listed for Drilling, Fluid Flow and Artificial Lift actually encompass seven, twelve and six individual. projects respectively.

The level of expenditures for this separately budgeted research at these academic institutions cannot be determined exactly. For those institutions in which the research is identified with petroleum engineering, the total annual expenditures are $\$ 10,274,935$. If one would assume that the projects identified with other departments were supported at the same average amount, the total expenditures would be estimated at $\$ 12,020,000$. However, it should be noted 


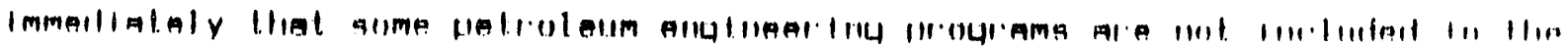

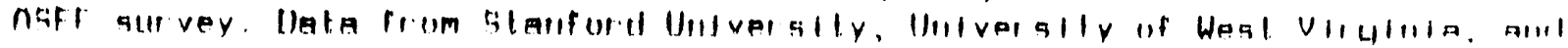
New Mexico Institute of Science and Technology do not appear in the ASEE publication.

Contributions from the academic research community to the petroleum literature have been substantial and have been greater than the relative level of the academic research expenditures would indicate when compared to the total industrial research exenditures. The API History gives a tabulation of the professional connections of authors of technical articles that were published on subjects pertaining to petroleum engineering by AIME, AAPG and API from 1914 to 1927. In that tabulation, $8.2 \%$ of the articles were shown as being identified with institutions of higher learning. For AIME articles alone the percentage was $9.2 \%$.

Examination of selected volumes of SPE Transactions indictate the following percentages of items in the respective Transactions that have at least one author identified with a US educational institution.

Vol $204(1955)-22 \times$

Vol $219(1960)-23 \%$

Vol $234(1965)-30 \%$

Vol $169(1980)-18 \%$

Vol $271(1981)-22 x$

Vol $281(1.986)-28 x$

Vol $283(1987)-30 x$

In the 1986 and 1987 SPE Transactions ( Vols 281 and 283), authors from a total of 25 different US educational institutions were noted. Sixteen of the institutions are recognized as having petroleum engineering programs, nine are not. Eighty percent of the articles that were identified were attributable to authors at institutions that are known to have petroleum engineering programs.

\subsection{FUNDING LEVELS FOR PETROLEUM RESEARCH}

As late as 1975, there was probably less than two million dollars total being expended on separately budgeted research by the petroleum engineering departments. The growth since that date has been roughly parallel with that for all of engineering and generally parallel with that for the industry.

Consistent data concerning research expenditures are difficult to assemble. Appendix 2-4 graphs the best available data from several sources for expenditures since 1975. The NPC data for petroleum industry research has been referenced in section 2.0. Data for separately budgeted research expenditures for all programs in engineering are taken from the ASEE annual reports in the journal "Engineering Education". Some data for academic petroleum engineering research is from the ASEE survey. More complete data for separately budgeted research expenditures was obtalned in a survey of petroleum engineering departments for a five year period, as reported in the "Report on DOE Grant DE-FG-88ER75419, October 1. 1988".

Following the publication of the March, 1989 issue of Engineering Education, a survey of those institutions not identified in the ASEE survey was 
made in order to provide a current figure for expendilures. Appendin $/$ i, ia a tabulation of the rosults. From this it is concluded that approximately $\$ 15,000,000$ is being expended in petrol eum ongineering departments. As is outlined in Section 2.1 , an additional $\$ 1.8$ million of research relative to petroloum recovery can be identified in engineering departments other than petroleum engineering. It should be noted that recent reports from petroleum engineering departments indicate that funding levels have increased appreciably. If so, the 1990 report of the ASEE should reflect the increase.

In order to place these research expenditures in perspective it is useful to make two sorts of comperisons. The first relates the level of petroleum engineering research to that for other onginearing programs. The second relates the level of petroloum engineering research to general research statistics of the nation.

The total reported separately budgeted research for all of academic engineering was reported to be $\$ 1.966$ Billion. Appendix 2-6 provicles a print out of some of the significant elements of this total, from which the following were derived-

$\begin{array}{lr}\text { Percent from Federal government } & 67.4 x \\ \text { Percent from other governments } & 11.0 x \\ \text { Percent from business \& industry } & 14.6 \% \\ \text { Percent from non-profits } & 4.8 x \\ \text { Porcent from other } & 2.2 x\end{array}$

Expenditures per total doctoral students $\$ 63,454$

Expenditures per professorial faculty $\$ 95,902$

Expenditures per doctoral degree $\quad 433,230$

PhD onrolments per profassorial faculty 1.51

PhD enrolments per total faculty 1.11

Percent of professorial faculty in

separately budgeted research

$63.7 x$

Porcent of enrolled graduate students

in separately budgeted research

25. 3x

Ratio of postdoctoral follows to graduate students in separately budgoted research

Ratio of postdoctoral fellows to professorial faculty in separately budgeted research .114

Detailed figures are not available for the petroleum enginearing portion of the surveyed research. so that the comparable ratios can not be computed. 
However, a fow comparisons can be noted. For example, the doctoral degrees in petroleum engineering roported in the survoy were 36, e.0. 0.79x of the total. This percentage (0.79x), applied to the total reported separately budgeted research would indicate that the petroleum engineering portion should be $\$ 15.5$ million, of which $\$ 10.5 \mathrm{mill}$ ion (67\%) would have been expected as the federal share of support. Actually, the total separately budgeted research for the reported petroloum engineoring programs was only $\$ 10,274,935$, five million less than the average engineoring program would suggest.

An oqually significant compartson is that, for petroloum engineering nrogramn. 785.4151 r rosmarch wan axpended por dnctornl degroe granted. cumpared to the average of 433,230 fur all of onglinering. Polroloum engineering would have needed over a fifty percent incroase to reach the engineering average. As a further comparison, it is known that for the petroleum engineering proprams no postdoctoral fellow positions exist. Clearly, the level of academic research funding for petroleum engineering lags that for engineering as a total fiold.

Sources of funding for petroloum engineering research programs w: documented over a five year period in the survey of departments that weis reported in the Report on DOE Grant DE-FG-88Ek75419. Federal sources accounted for $42 \%$ of funds, industrial sources for $41 \%$ and state sources for $10 \%$. In the figures given above for all engineering programs, the foderal and industry shares are 67\% and 15\%. In other words, the industry absorbs more of the funding load for petroloum engineoring and the federal government carries less. Twenty five percent of the total funding for petroloum engineering is represented in this shift. For academic petroleum ongineering research funding to be consistent with the avereje for all of engineering, the federal government should provide a significant increase in its level of funding support.

It has been only in relatively recent yoars that support from federal funding agencies has played any role at all in the research programs of petroloum engineering departments. If the National Scionce Foundation acknowledpod any concern in the past, it wae primarily through the support of their chemical engineering programs. The Department of Energy and its predecessor programs, as they considered engineering topics, tended to take a position that paralleled that of the oarlier API program. e.g. a philosophy that the research to be funded would be found in "fundamental" disciplines, not in an applied academic area such as petroloum engineoring was considered to be. Furthermore, fow, if any, of the government proprams were prepared to deal with research that involved actual reservoirs or field data.

Although there 18 still no evidence that the NSF is aware of the needs for support of academic research in potroleum engineering, there is some evidence that the DOE is becoming awere of the problom. The most recent awareness in DOE has been generated through the efforts of the Geoscience Institute for 0 il and Gas Recovery.

The current relative level of federal support to the academic area of 
petroloum engineering cannot readily be documented in federal tabulations. Report NSF 88-330, Foderal Support To Universities, Colleges And Selected Nonprofit Institutions, Fiscal Yoar 1987, contains general information for engineering and for its major fields, but no itoms appear for petroleum engineering. Foderal obligations to colleges and universities for R8D in 1987 were 987 million for all of engineering, the NSF portion of the total being $\$ 125 \mathrm{million}$. That same report indicates that $12 \mathrm{~m} 11 \mathrm{li}$ ion in federal funds was obligated to followships, traineeships and training grants, of which the NSF portion was $4.8 \mathrm{mill}$ ion. Conversations with leaders of the petroleum

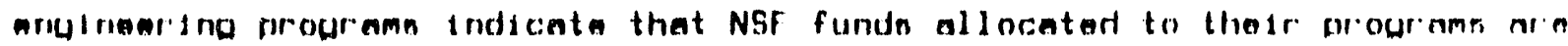
esentially zero.

It is also difficult to relate the level of academic petroleum engineering research to the level of research in industry or to the total national effort in this field. A Special Report. NSF 89-307, entitled International Science and Technology Data Update: 1988, contains some general data that might be considered in trying to evaluate a relationship. For example, non defense spending for R\&D in the US is cited as being 1.8\% of the GNP. According to the NPC report, cited above, 38 respondents reported $\$ 59$ billion in revenues from oil and gas production in 1986 and a research expenditure (E\&P) of \$853 million. This is an expenditure of $1.45 \%$ of revenues. On the other hand, it represents only the industry portion of total E\&P research. It does not take into consideration what the federal government may be spending on oil and gas research, which the NPC report estimates to be about 520 million.

The same NSF report indicates that $13 \%$ of the R\&D expenditures in the United States are done by higher education and $69 x$ by industry. If this ratio of 13/69 were to apply to E\&P topics, based on the level of industry expenditures, universities would have to be conducting obout $150 \mathrm{mill}$ ion in research.It is doubtful that the combination of geoscience and petroleum engineering research programs in universities, directod towerd E\&P subjects, would approach such a total. It certainly does not apply to the production portion of the E\&P, which is said by the NPC report to be $70 \%$ of the total industrial R\&D effort in E\&P.

The NSF report also gives a figure of $13 x$ for the relative amount of basic research in the US total. Based on the figure of 800 million for total E\&P research expenditures, this percentege would indicate that about $\$ 100$ million should be expected to be basic research in all E\&P and about $\$ 70 \mathrm{mill}$ ion in the production and EOR portions. As noted above, however, these floures do not take into consideration what the federal government may be spending on E\&P research.

It is generally accepted, from statistics on those segments of society that perform research, that over fifty percent of the basic research of the nation is done in universities. This statistic would indicate that university basic E\&P research should be well over $\$ 50 \mathrm{milli}$ ion and that university basic petroleum enginering research should be well over $\$ 35 \mathrm{million}$.

Finally, the NSF report tabulatos $6.3 \times$ of the total national R\&D as being separately budgeted academtc research. If the nation's total research in 
E\&P is \$1.3 billion,e.g. \$800 million industrial and $\$ 500$ million government, the separately budgeted acadomic E\&P research should be about $\$ 82$ million to measure up to the national averago.

It is of interast to note that the amount of anparatoly budueted aciminmil: research expenditures for petroloum ongineering programs over the periul of years showri in Appendix 2-4 range from about $0.5 x$ to $0.75 \%$ of the total industrial E\&P research oxpenditures and would be a smaller percentage if the federal E\&P expenditures were added to the total.

The significant observations from these various data sets and average statistical relationships are throe in number-first, that the relative amount of the total research being done by the universities in petroleum ongineering (and the related exploration fields) is less than that in other areas of national concern, second, that the amount of basic research being done in these fields is less than would be expected in other research programs, and third, that the federal government is funding less than it should be in these important areas, particularly in terms of support to basic research.

\subsection{PETROLEUM INDUSTRY RESEARCH ASSOCIATIONS}

In recent years, as petroloum engineering departments have become more active in seek ing research funds and as industry has reduced its level of research expenditures, several promising cooperative research arrangements have emerged. In one form, these arrangements are a consortium of companies who subseribe jointly to the support of a university research program. The initiative for such research programs almost always rests with the university itself. Detailed research proposals are prepared and are fresented to potential industrial sponsors, some of whom may decide to support the venture and some of whom may decline. Such proposals may include the commitment of matching research funds from the university or from a povernment source. These types of research programs are usually quite specific in their objective so that the justification for sponsorship and support can be clearly identified by a participant. However, they often may be multidisciplinary in nature and they often may originate in departments other than potroleum engineering. They may also be fostered as special Institutes or Centers in order to portray a unique identity.

The petroleum industry, perhaps partly as a means of dealing with the growing number of consortium ideas, has ovolvod a different type of cooperative mecharism for the purpose of providing a forum within which potential research projects can be discussed and the propress of on-going research projects can be reviewed. These cooperative groups now number four-

The Drilling Engineering Assoclation (DEA)

The Completions Engineoring Association (CEA)

The Petroloum Environmental Research Forum (PERF)

The Reservoir and Recovery Forum (RARF) 
These Associations are not-for-profit entities, organized for discussion purposes, with glidelines that avoid any anti-trust prohibitions on collaboration. The first one was the DEA, formed in 1983. The others are patterned after DEA. Representatives of the member companies that belong to an association meat, usually on a quarterly basis, to hear ideas for research

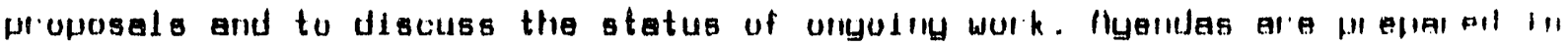
advance and thirty days notice is required in order to have an item placed on an agenda. Proposals must be in written form.

The Associations, as such, do not sponsor rosearch. If a proposal is of interest to a member company, that member, either alone, or in company with others, may enter into an agreement to support the research. The resulting project arrangoments is handled apart from the Association. An arrangement may take the form of a consortium, such as those that originate with the universities, or it may take some other form.

These Associations represent mechanisms through which university representatives can prosent research ideas to industry and can identify potential sponsors for a particular research program. Any non-member, such as a university professor, may present a proposal before a meeting of one of these associations by being sponsored by a member.

Appendix 2-7 is a copy of an early announcement of the RARF, formed in January 1989. At the time of the ennouncement there were 18 members. $A$ copy of the charter for the CEA is given in Appendix 2-8. Its membership list in March, 1989 was 15.

These Associations hold a ormat deal of promise for facilitating the industrial support of academic rosearch in petroloum engineering departments. At least one of them, the CEA, has taken steps to identifythe research needs in a broad sense and to outline important types of projects. In addition, the leader of the RARF has recently taken steps to convene a meeting of all the Association chairmen to discuss the appropriateness of interaction among themselves and with other groups that are interested in assessing research neods, such as the Association of Heads of Potroleum Engineering Schools.

Although it has been suggested that the petroloum companies might form a research entity, similar to the Gas Research Institute, for the purpose of having a "netional" offort in potroloum production research, the idea appears to be lacking in industrial support. 


\section{A RESEARCH AGENDA FOR ACADEMIC PETROLEUM ENGINEERING PROGRAMS}

\section{Chapter 3- SCOPE OF PETROLEUM ENGINEERING RESEARCH}

\subsection{THE DOMAIN OF PETROLEUM ENGINEERING.}

As a separate field of technology, petroleum engineering is not widely recognized or understood. Part of the reason for this poor recognition is the use of the descriptor, petroleum, which conveys the impression of engineering associated with a commodity rather than with a generic technology. It is a fact that very fow industries, outside the petroleum industry, have had reasons to become acquainted with the technology because there have been few reasons for any other industry to drill and operate wells. Hence, the technology has historically been of interest largely to the potroleum industry. It has also been a long term practice of the potroloum industry to hire engineers from other disciplines and convert them, through in-house education and experience, for use as petroleum engineers. This practice has tended to blur the differentiations between petroloum engineering and other branches of engineering.

The ongineering that is associated with the activities of producing petroleum includes the use of soveral engineering types in addition to petroloum engineering, chief among the others being chemical, mechanical, civil, electrical and goological. This situation is no different from that in other industrial fields. The unique element in the production of petroleum, that leads to the identification of the separate category of petroleum engineering, is the fact that petroloum occurs within and must be recovered from the subsurface environment. The practice of petroloum engineering concerns the subsurface onvironment of the earth and is subject to the boundaries and constraints of the goological sciences.

In this sense, petroleum ongineering might be best placed in perspective as being analogous to such other engineering fields as ocean engineering. aeronautical engineering, mining engineering, nuclear engineering. bio-enginoering and manufacturing ongineoring. In each of these instances, the technological domain is not characterized by any underlying goneric engineering science, as may be the case with mechanical, electrical and chemical engineering. Rather, the technological domain is characterized by the overriding importance of the nature of the environment within which the engineering knowledge must be applied.

There are no separate concepts of physics and chemistry that apply within the subsurface environment, any more than there are within the ocean environment, the atmosphere or living organisms. Nor, are there are different principles of mass or thermal transfer or of other engineering sciences. However, there are time constants, boundary values, and ranges of variables 
that are unique to the goological onvironment and to the processes of moving fluids within that onvironment. Each portion of the geological environment has its unique characteristics. There are no standard replications of specific system elements within the earth and heterogeneities will exist at all dimensions. It is the uniqueness of these individual situations that contribute to many of the engineering problems a petroloum engineer must face.

Petroleum engineering is one of the two technologies concerned with the development, conservation and use of the resources of the earth. The other is mining engineering. The specific part that falls to petroleum engineering is the development, conservation and use through well systems that permit fluids to be taken from, injected into or transmitted through the formations and reservisirs of the earth. By contrast, the specific part that falls to mining enginetring is the development, conservation and use through mechanical and structural systems that permit solid materials to be taken from or placed within the earth. Although there are times when these two technologies interlock, and although both dopend upon detailod knowledge of the geological environment. in general the teclinological hardware and software for the fields are quite distinct.

Although the technology of petroloum ongineering has been developed primarily through the use of the earth for the recovery of petroleum hydrocarbons, the technology has wide application. Among the other activities to which the technology is germano are the scientific exploration of the earth, the recovery and conservation of underground water resources, the recovery of thermal energy, the disposal of wastes, the storage of gaseous and liquid materials, the degasification of coal seams, the recovery of minerals through liquefaction or solution processes, the recovery of resources through underground gasification processes and the use of the formations of the earth as reactor systems.

\subsection{THE SUBJECT MATTER ORGANIZATION OF PETROLEUM ENGINEERING}

The subject matter that is germane to petroloum engineering can be seen in a general way through the organization of courses that make up the average petroleum ongineering zurriculum. The Society of Petroleum Engineers also uses a list of "technical interests" that categorizes the eloments of subject matter. Using the latter as a starting point, the following subject matter organization has been developed as a scheme through which the total scope of potential research might be onvisioned.

It is a fundamental aspect of the technology that wells be drilled and operated under controlled conditions. This leads to the major categories of Drilling and Well Oporations. Well Operations is chosen rather than the historical term. Production, to recognize the moro general aspects of the 
technology for being able to handle both inflow and outflow of fluids from the subsurface.

It is also a nocessary attribute of the technology for the goolugic onvironment to be measured, characterized and understood. This leads to the major category of Formation and Reservoir Characterization, which recognizes

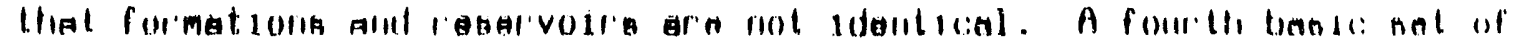
concepts encompasses the totality of Reservoir and Recovery Processes, whether natural or man-induced and whether encompassing the reservoir as a whole or in part.

The subject matter organization would not be complete, however, unless recognition is given to topics that appear as threads throughout all the basic areas, 1.e.expert systems, to topics that may be germane to a specific application, 1.e. to geothermal resources, or to lopics that come from a field with which an interaction might be needod, i, e. actic technology. These groups are headed Cross-Cutting Topics. Non-Hydrocarbon Technological Applications, and Interacting Technologios.

Following is the suggested organization of subjects, germane to petroleum engineoring. toward which academic research programs might be directed.

\section{DRILLING}

a. Equipment \& facilities

b. Operations

c. Materials

d. Measurements \& analytical methods

a. Well completions

f. Horizontal wells

o. Environmental controls

h. Real time monitoring \& managoment

\section{WELL OPERATIONS}

a. Production equipment \& facilities

b. Production materials

c. Formation, flow and pressure measurements

d. Well performance \& testing

e. Well maintainence

f. Woll stimulation

g. Formation damage

h. Artificial lifting

i. Horizontal well operations

j. Group well behavior

k. Environmental controls

1. Production monitoring \&anagement 

m. Injection monitoring \& manegement
n. Pre-injection operations
o. Post-production operations

3. FORMATION AND RESERVOIR CHARACTERIZATION
a. Moasurement \& evaluation equipment
b. Measurement techniques
c. Interpretative methods
d. Properties of rocks fluids
a. Characteristics of porous systoms with their fluids
f. Formation variability \& heterogonaity
g. Depositional and formation simulations
h. Formation data management \& economics

4. RESERVOIR \& RECOVERY PROCESSES

a. Comprehensive reservoir descriptions

b. Reservoir processes

c. Oil rocovery mechanisms

d. Enhanced oil recovery

e. Well/reservoir interactions

f. Reservoir \& well simulation

g. Natural gas reservoirs

h. Storage reservoirs

i. Data organization manegement

j. Reservoir development \& case histories

k. Reservoir evaluation \& reserve estimation

1. Reservoir managoment strategies

5. CROSS-CUTTING TOPICS
a. Computer development 8 use
b. Expert systems
c. Optimization techniques
d. Environmental issues
o. Risk assessments
f. Regulations \& safety
g. Education \& personnel development
h. Technological development \& technology transfer
i. Economics
j. Project planning \& management
$k$. Company organization \& management

6. NON-HYDROCARBON TECHNOLOGICAL APPLICATIONS
a. Scientific exploration of the earth through wells
b. Underground water resources
c. Geothermal resources 
d. Weste disposal in earth formations
e. Mineral rocovery through well systems
f. Degasification of mines underground formations
g. Wnderground heating, combustion or reartion processes through well systems

7. INTERACTING TECHNOLOGIES

a. Off-shore technology

b. Arctic technology

c. Conservation technology

d. Remote sensing technology

e. Hydrocarbon transportation technology

f. Resource development technology

\subsection{THE ELEMENTS OF A PETROLEUM ENGINEERING RESEARCH AGENDA}

Al though research in petroleum ongineering might be directed toward any part of the subject matter that makes up petroleum engineering, such a 1 ist does not readily adapt itself to outlining a research agenda. It is germane to seek a mor concise grouping of research elements that would serve to place the sum of such research into the acadomic perspective. To that end, the following elements for a research agenda are offered. Some of these elements will overlap those for other fields of technology. Some are different and are unique to petroleum ongineering. The separate elements are identified as-

* Materials, equipment,tools, instruments and measuring devices

* Mathematical and computerizad analytical methods

* Processes of mass transfor, thermodynamics and chemical exchange within well-bores, subsurface formations and associated equipment

* Knowledge of the components, characteristics and behoviors of geological formations and reservoir environments

* Structuro and performance of individual wolls and of composite systems of wells and reservoirs

* Management of wells to achieve desired objectives in the subsurface formations and reservoirs.

The first element, which will appear also on the topical lists of other technologies, constitutes the materials, equipment, tools, instruments, and measuring devices necessary to the pursuit of petroloum engineering. These are the hardware lements of any technology, without which the engineer can neither gain access to nor operate within the environmental domain of his practice. The research with respect to this element does not involve the petroleum engineer as a general expert in materials or in the fabrication of materials into equipment and tools, but rather in the development, fabrication and use for specific purposes under special constraints. The petroloum engineor should have a rosearch input into the purposes and conditions pertaining to the use, the static and dynamic conditions in the sub surfece and well-bore pertaining to 
the use, the quality of the performance during use, and the manner in which the use may interact with the total systom with which the petroleum engineer must deal. In this role, the petroloum ongineer, as a researcher, may become an innovator or an adaptor of materials and fabrications that are known in other fields. In pursuing this element of a research agenda, the petroleum engtneer is likely to be working in cooperation with technologists in materials, structures, mechanics, electronics, geophysics, remote sensing and similar fields.

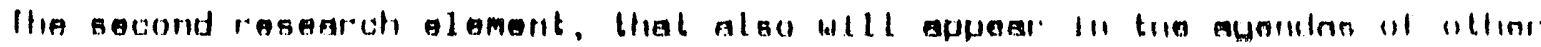
technologies, is made up of the mathematical or computerized methods of analysis, of history matching, of modelling, and of optimization, etc. These are the analytical techniques that are applicable to large, complex systems, with many variables and an incomplete number of individual data points, usually extending over long time periods. The research with respect to this el ement may also involve the petrol ium engineer as a user.e.g.relying upon others to develop the mathematical or computer technology. The petroleum engineer may aiso play a role as an expert in this field of research through adaptions and innovations, because the unique attributes of the petroleum ongineering problem to which his analytical offorts are addressed may require more than the general existing knowledge has to offer. Hence, the petroleum engineering contribution may be to the more general fleld of knowledge. In this portion of the research effort, the petroleum engineer is likely to be working in consort with mathematicians, statisticians, logicians, computer scientists and other technologists who are dealing with the analysis of similar large and complex systoms.

A third research element that will also be on the topical lists of other technologios encompasses the mass transfer, thermodynamic and chemical processes which the petroloum ongineer may oncounter. Such processes are fundamental to the technologies pertaining to both natural and man-made systems. The research with respect to this element will involve the petroleum engineer as an expert and innovator, in some respects, and as an adaptor in others. This element of research for petroleum ongineering focuses upon these processes as they occur within the context of the geological environment, the parameters of which may be outside the ranges normally encountered.

Contributions from such research may add to fundamental knowledge that is of interest to those concerned with these general processes. In this arena of research, the petroloum engineer is most likely to work cooperatively with the chemical ongineer.

A fourth element of research for petroleum engineering is identified as knowledge about the nature of the environment within which the practice occurs. Such resoarch will also be on the agenda for geological, geophysical or mining engineering. Although the rosearch interests of petroleum engineering may cover 
al aspects of this environmental nature, the fucus will be upon those environmental situations whose attributes have economic resource importance. The coverage of characteristics that are of concern is all inclusive,ranging in neture from the microscople to gross rogional properties, from molecular form to composite mineral aggregate, from mechanical and structural parameters to chemical and interactive properties. The research interests include the nature of all solids,fluids and geses within the onvironment and the manner in which these different kinds of materials interact with one another. The purpose of research may not necosserily be to determine why the enyironment exists as it does, which may be more the interest of the goologist who is working in this field, but rather to learn how to identify and measure the many characteristics that exist, to portray quantitatively the manner in which these characteristics vary throughout the onvironment and to understand how these characteristics may limit or offer offortunities to conduct operations within the environment for achievirg desired resource goals. In this element of research, however, the petroleum engineer will be an expert and a leader, but he must work closely with and share this leadership with the geoscientist.

The fifth research element, 1.e.the structure and performance of individual wells and of composite systems of wells and reservoirs, is unique to the field of petroleum engineering. This element encompesses a) an understanding of how a well is constructed and operated, o.g. the manner in which a well-bore penetrates the subsurface onvironment and is coupled both to the oarth's formations and to the surface of the earth so that fluid exchanges can be accomplished as desired, b) the messurements that can be made on the performance of a well and through the well on the movement and placement of fluids within the geologic formations, c) the measurements that can be made on the interactions among wells within a reservoir, d) the manner in which the performance of a reservoir will be reflected in the behavior of wells, and e! the mathematical or other techniques for analyzing the performance of wells and reservoirs. In this area of research the petroloum engineer must play a lead role. No technology, other than petroleum engineering, has a motivation to undertake this type of research or to assume a responsibility for the manner in which it is pursued.

The final element of the research agenda is that concerned with the technological manapement of a systom of wells within a reservoir(s) that constitutes a separately identifiable entity for design, use and control toward a resource objective. This element of research may have some general topics in common w. th other resource management fiolds, but for the most part it will be unique to petroloum engineering. Within this arena is research that pertains to the manner in which data are obtained and organized. When, in the life cycle of a well or reservoir, should certain data be obtained? How can the various types of data be interralated, correlated and used to reinforce the total analysis that is desired? The research directed toward optimization will encompass not 
only data acquisition but every operation that is involved in the procese of drilling and operating wells. It will also include the development of artificial intelligence to assigt in management and operational processes. Another part of this research area will be the consideration of alternate methods for developing a resource use, for supplomenting natural recovery processes and for conducting field tests or speciel projects through which decision meking can be enhenced. Topice for ressarch might elso cover concepts that apply to the most beneficiel use of a perticular subeurfece environment and to the manner in which particular prectices may ceuse a deterorietion or an enhencement of the general environment. This field of research is one in which the petroleum engineer must be the leader and innovator.

It is axiometic that one cannot predict beforshand the origins of the concepts that will ultimately prove to be the principal contribution to a particular research advance. The best research in any field will draw upon ideas from the total universe of knowledge, as may be appropriate to the course of the investigation that is being pursued. Contributions from other technologies, al though more obvious for some of the above elements of research than for oihers, should always be sought and should be an integral part of a research plan.

For an academic research agenda, the most appropriate point of view is the achievement of a knowledge goal, but other points of view should not be ignored, such as that of problem solving. A problem generally reflects symptoms of a particular situation that exists and an examination of the problem may be needed in order to recognize the underlying lack of knowledge that needs to be filled. Likewise, the development of a new diagnostic or analytical technique may appear to have a limited objective, but the process of development may open up new ways of combining existing elements of knowledge. Whatever may be the motivation for the research, in the final analysis the primary objective of an academic research agenda is to advance the scope of knowledge that is germane to the practice of petroleum engineering. The above list of elements provides a way to group these knowledge goals.

\subsection{THE NEED FOR ENUIRONMENTAL ACCESS IN PETROLEUM ENGINEERING RESEARCH}

A primary deterrent to the conduct of research in petroleum engineering is that the environment is not readily accessible to the researcher. This is a problem that is faced by many fields, such as medicine, agriculture and other bio-related professions, by meteorology, oceanography and other geo-related professions and by the general fields of technology dealing with outer space. The general dilomma has been resolved in various ways by these other professions, but remains a problem in the profession of petroleum engineering.

The medical profession, for example, has university research hospitals at 
its disposal. The medical researcher may conduct research programs that involve living persons and 1 arge populations as well as 1 aboratory experiments in which no patient is involved. Similarly, university agriculturai research programs include animal communities, experimental farms and other natural situations as well as theoretical and laboratory experiments. The academic oceanographic community includes research programs that are conducted from shipboard or by remote sensing for sampling of and measurement within the environment in a planned fashion. Researshers in epace and aeronautical engineering are able to conduct experiments on vehicles in the actual environment.

The needs of petroleum engineering to do research within the enviroment of practice have many similarities to these other fields, but similar opportunities for the researcher to have access to the real environment do not exist. The knowledge elements outlined above include such things as the manner in which the geological environment constrains or alters a particular measurement or process, the manner in which specific hardware or materials can be coupled successfully with designated subsurface situations, the indirect methods of making measurements on the nature of the earth's formations and reservoirs, and the need to measure, analyze and control an entire operation that occurs only within the confines of the earth itself. Theoretical and laboratory studies may indicate certain types of performances for wells and reservoirs, but planned research opportunities to vorify such studies are not available. The verification must be limited to comparisons with observed behaviors that may also include the influences of a wide range of other factors.

In most of the professions, the solution to the problem of environmental access for research purposes has been solved by recognizing that there is a public need for such research to be done, followed by the set-aside, with public funds, of facilitios that provide the environmental capability. A desirable first step for petroleum engineering would be to achieve a general public acknowledgement of the need to conduct petroloum engineering research that is in the public interest. A set-aside facility to provide environmental access would be a more difficult matter, however. Fow of these other areas that have provided such facilities heve dealt with quite the same proprietary situation that is found in petroleum engineering.

Petroleum reservoirs are ouned and operated for private enterprise purposes. Diversion of these operations for research purposes would be somewhat equivalent to asking an individual or a population to divert their living to serve medical research needs. In the medical system, the answer has not been found in such diversions. It has been achieved in soveral other ways, such as a) in the pooling of data and experiences from many individuals and populations, b) in voluntoer participation in organized rosearch, usually supported by public funds, by individuals with common critical health problems, and c) in the public funding of diagnostic centers for specified areas of 
medical knowledoe. Discussion is neoded in order to identify some such similar mechanisms that will provide eccess to the onvironment for petroleum engineering researchers in the acedemic community.

In summary, laboratory work, theoretical studies and computerized analyses, are insufficient for the complete academic petroleum engineering research agenda. Such offorts are being aided more and more by the availability of data from actual operations and subsurface situations through which the results of such activities can be verified. Still lacking are the opportunities to do research based on the desion of experiments to be carried out within the roal environment, on programs of designed diagnostic observations within operating situations, or on the composite pooling of data from a wide variety of real situations. 


\section{A RESEARCH AgENDA FOR ACADEMIC PETROL.EUM ENGINEERING PROgRamS}

\section{Chapter 4- TECHNOLOGICAL ISSUES}

\subsection{SURVEY OF RESEARCH ISSUES}

The identification of key technological issues in petroleum engineering was approached in several ways. Topics in the literature, the subject organization at conferences and SPE Forums, and survey articles have all been useful. Appendix 4.1, for example, gives the list of topics for SPE Forums for ten years, indicating the issues thought to be most timely by the organizers of the Forums over that period of time.

A survey form was sent to all petroleum engineering faculty to obtain a consensus viow of that community. The survey instrument, and the letter that accompanied it, are reproduced in Appendix 4.2. There were 35 completed responses received, which is a return percentage of less than $20 \%$. In Appendices 4.3 through 4.9 the replies to the survey questions are tabulated. In the following paragraphs, and in Chapter 5, the results are summarized.

A survey form was sent also to selected members of the National Academy of Engineering who were identified as petroleum engineers and to soveral SPE members who have been engaged in the organization and conduct of SPE Forums. The detailed responses from these surveys are given in Appendices 4.10 and 4.11 and the results are summarlzed in the following paragraphs, with some comments al so in Chapter 5.

\subsection{THE FACULTY SURVEY ON RESEARCH TOPICS}

Two different questions wero posed. One asked for the most important technical problems. The other asked for the most imporTant research topics. The responses, which closely paralleled one another, are tabulated in detail in Appendices 4-3 and 4-4. The responses are summarized as follows.

1. Reservoir Characterization-

Reservoir description, definition or characterization, and the companion question of heterogeneity are pervasive as important topics for research. The coverage includes improved and new measuring techniques and methods, better reliability, in-situ methods, and reduction of costs. Characterization is wanted at all scales of the reservoir, particularly between wells, and to satisfy all types of applications. The questions about heterogeneity include understanding its nature, now ways to measure and define it, representing it at various scales in the resorvoir, including mathematical models, and how to predict it. Special need is cited for characterization of fracture systems and for measuring formation characteristics through cased holes and between wells. Applying such technology to horizontal wolls is a subject for which study is al so suggested. 
2. Drilling-

In the areas of drilling and woll completion, a strong emphasis is made for research to be directed at the reduction of costs, thereby providing more access to reservoirs. Attention to the drilling of horizontal holes, including their logging, casing and comenting also was stressed. Improvements in MWD and in computer controlled drilling, improved $r i g$ safoty, environmental safety, improved cementing techniques are all singled out as important. Drilling in deeper water, including riser technology, and technologies for drilling in all hostile environments will need specific research. Formation damage is an issue calling for basic studies directed at the development of quantitative methods in order to predict, control and eliminate it. Drilling and completion techniques need to be improved in mature reservoirs with reduced pressures. Geomechanics (rock mechanics) applications should be studied for both drilling and completions applications, including better mothods for identifying fracture orientation and designing fractures for non-homogeneous situations. Inexpensive logging techniques are neoded to characterize fracturing in mature reservoirs. Well stimulation technology, in general, needs to be improved, including the use of computer models and the field use of computers and automated equipment.

\section{Production-}

Reduction of costs is also pinpointed for petroleum production research, not only for remote and hostilo situations and for older wells, but elso for routine operations. The need is cited for research using mathematical optimization methods on production operations, including the development of software for optimization workstations. The use and reliability of computers in fiold operations is a companion issue, with the development of expert system techniques for real time monitoring and ovaluation. Methods should be developed to include more ties between production and reservoir concepts not only with respect to design and operation of facilities, but also with respect to monitoring and evaluation. Improvement and cost reductions should be sought in artificial lift methods through facility design, mechanical efficiency improvement and process automation. Multiphase flow metering improvement needs include new methods for metering and modeling of multiphase behavior. In particular, the multiphase flow problems in long sub-sea pipelines need to be studied. The need is noted also for research to apply or analyze standard production techniques in horizontal or deviated wells. General production research noeds that are named cover subjects such as corrosion, sour gas design, improved lightning protection and well damage from sanding, paraffin and other causes. Research is also suggested on the environmental aspects of production, including the handling of produced waters and the possible development of subsurface spaces to carry out production operations in densely populated regions.

\section{Reservoir Engineering}

The overriding issues with respect to research on reservoir problems arise 
out of questions about the nature of the reservoir itself and how to quantify that nature. There is an emphasis that geoscience knowledge must be combined with engineering knowledge to achieve the research goals desired. Some research is called for at the level of fundamental concepts of petrophysics and the cilloractions of rocks and fluids, lncluding toplcs such as the mechenical properties of rocks, microfracture development, wettability, low wetting phase saturations \& high capillary pressures, and multi-phase flow. Research should correlate in-situ petrophysical properties with measured properties in cores and inferred properties from well logs.

A greater emphasis in reservoir research seoms to be called for at the level of combining fundamental concepts into the total reservoir picture. These needs include studies of non-equilibrium and time dependent processes in disordered media, the proper averaging and scale-up of properties at the pore-level and core level to the well level and field level and the development of simulators that combine these elements. The research that is proposed includes the study of complex reservoirs by teams of specialists and the combining of geological interpretations, core analyses and well analyses into an integrated framework. Research that will improve sweep efficiencies and mobility control is called for. Other reservair research that is proposed includes the identification of actual flow channels within the body of the reservoir, the analysis of reservoir benefits inherent with the use of horizontal wells, reservoir analysis based on data from horizontal wells and the improvement of simulators and computer models.

\section{Oil Recovery-}

With respect to oil recovery per se, and recovery methods, primary research emphases are pointed toward reducing the amount of residual oll, knowing where the remaining oil is located in a reservoir, and reducing the costs of oil recovery methods. Research for locating existing oil is suggested through research on cross-well logging, the use of reservoir models, and the interactions between transport processes and heterogeneity. For dealing with mobilization of remaining oil and control of the displacement process, research is suggested on new methods of mobiization, on the use of foam and on general methods to retard breakthrough and prevent vertical sweep imbalances. Research that is desired on EOR processes includes the improvement of existing methods and the development of new methods. Although no specifics are given for the latter, the research should build on basic geoscience understanding, rock mechanics and the behavior of rock-fluid systems. The impact of heterogeneity on EOR processes is a dominant theme, including research into recovery methods that are less sensitive to heterogeneity. Other research facets in this respect include the advantages of initiating EOR methods earlier in the life of a reservoir. more accurate quantitative predictions for EOR mothods in the field, and surfactants to match a larger variety of reservoir conditions. Research also is called for on heavy, or low gravity, oils, including the improvement of thermal methods, and on the improvement of stimulation methods to permit the 
development of low permeability formations. One general research effort that is suggested would involve detalled surveys of existing reservoirs to assess the potential for additional oil recovery. Another would classify recovery methods with emphasis on economic factors as a guide to further research areas that would reduce costs.

6. Cross-cutting Topics-

Among the issues that pervade all research suggestions, the most obvious pertains to the need for broader computer use with associated software and the development of expert systems. The expression of need for research into more sophisticated simulations is balanced by a similar recognition for research to develop models based on the limited data that is usually available. The organization of existing technical data is itself cited as a research need. Other general issues that pertain to all research are the need to be aware of improving the oconomics, and incorporating environmental considerations into all facets of petroleum technology. Technology transfer also is cited as an important element in research, including research into methods for borrowing from other fields and the wider application of techniques that exist within the field.

\subsection{THE FACULTY SURUEY ON LEVEL OF RESEARCH ACTIVITY}

One question asked if the levels of activity in the faculty member's special fields of research were as great as they should be, and if not, what levels of increases were nooded. For the most part, the responses indicated a need for an increased level of activity, sometimes estimated as high as $500 x$. One commentator pointed out that the question is not so much the level of activity as it a need for a greater focus toward basic research and a higher quality of research. A summary follows and the detailed responses are given in Appendix 4-9.

Estimates on the need to increase the level of research in reservoir characterization and definition ranged from none to five fold, with the predominant voices somewhere around a need for doubling. Particularly noted was the need for funding for new tools and new ways to process data. Mare institutions and more faculty were said to be needed for work in formation evaluation.

Four separate estimates, ranging from $50 x$ to $500 x$, were given for the need to increase research in drilling.

In most aspects of production related research, the expressed need was also large. Artificial lift is said to need double the research activity. The production logging estimate for increase is also 100\%. Multiphase flow in pipes and well bores needs ranged from $50 x$ to $200 \%$. Well stimulation, an area in 
which few faculty were said to be working, was estimated to need up to a $300 x$ increase. No numbers wero offered for incroase in matters dealing with horizontal wells, but a need for more support was indicated.

In many of the areas categorized as reservoir engineering, the level of research was indicated to be sat isfactory. However, increases in research were noted to be desirable for improving mobility control (300x), wettability (100x), fluid mixing in porous media, hot and high pressure gas reservoirs and reservoir management. An increase is also called for on reservoir questions that involve hoterogeneity and characterization.

A substantial increase in the level of research is the theme for recovery methods, particularly for thermal recovery and miscible flooding. Some sentiment is voiced for no increase in research at the laboratory scale but for research with field data and on a field scale.

From a general point of view, considerable increase in activity is called for in research that involves optimization, expert systoms, artificial intelligence and petroleum economics.

\subsection{SURVEY OF SELECTED INDUSTRIAL LEADERS}

Industrial leaders in two categories were contacted for viows about research issues, - members of the National Academy of Engineering identified as petroleum engineers and members of SPE whis were active in organizing or leading recent SPE Forums. The replies from these surveys are detailed in Appendices 4-10 and 4.11. The following paragraphs summarize the comments with respect to topics of importance. Chapter 5 summarizes some of the comments on non-technical issues.

The reduction of drilling costs is cited as an important topic, not only as a general matter but spocifically to increase the amount of in-fill drilling and to speed up the potential use of horizontal holes. Cost reduction through lighter weight and smaller equipment is also suggested. A more general topic cited for drilling research is a better understanding of the entire system of interactions between mechanical forces and rocks during the drilling process. Environmental impects are also noted as an important area for research, particularly the reduction of impacts through research on oil-water-gas mixtures and their separation.

A greater emphasis is placed on reservoir characterization research than on any other single subject. The separate topics range from fundamental studies on rocks to overall reservoir tomography. Cooperative programs involving engineering and the geosciences are called for, using geophysical, geological, conventional logging, core data and well performance information. Greater 
attention to "peostaticstics" is callod for. Now and improved tochniques are said to be needed. Some questions also are volced as to the capabilities of existing students and faculty to pursue such programs. One respondent noted "This effort, however, calls for a level of interdisciplinary research that I have not yet seen professors willing to undertake."

Research topics of importance that are cited with respect to the area of reservoir and recovery include wettability research and the effects of wettability on 100 interpretation as well as on flow in fractured rocks that would include two phase flow considerations. The improvement of reservoir simulation, from one point of viow, stresses a cooperative engineoringmathematics effort. Another point of viow emphasizes the inability to simulate heterogeneities adequately. Still a further reply notes that ". reservoir engineering must include the science of production geology in its fabric". Research suggested on improved oil recovery encompasses vertical sweep and mobility control, the need to find dilute aqueous surfactant systems, methods of oil recovery other than chemicals, tight gas reservoirs and tar sands recovery.

In generalizing upon the importance of research topics, one respondent observed that "Most fields in the U.S. are in the EOR mode. Therefore, we should be concentrating on research programs pertaining to EOR". By way of explanation this was said to include reservoir characterization, wettability and simulation research. Another comment identified some of the elements for making revolutionary impacts as "1) more realistic description of the 'plumbing' of reservoirs so we will know where fluids are flowing and what we are dealing with, 2) direct detection, or at least a lot more insightful inference, of where the romaining oil is, 3) much improved field-wide predictions of reservoir performance that account for the important details of reservoir description, and 4) much lower cost methods to drill up fields on close spacing".

\subsection{SOME KEY RESEARCH ISSUES}

From the composite replies, comments and inputs that have been received, it is possible to identify research issues that dominate the current analysis of needs. Following is a listing, organized under five subheadings-

1. The basic nature of reservoir rocks and their fluids and the interactions among rocks and fluids.

* Although a porous system can be characterized by individual parameters, such as porosity and permeability. there is no overall measurement system by means of which one pore matrix can be identified as being distinguishable from all other pore matrices. For this reason, also, there is no measure, except through the change in the value of individual parameters, to express the heterogeneity of a porous matrix as it may vary from place to place. Further, 
because there is no way to quantify the individual porous matrix, there is no way to construct a measure for a composite system that may be a mixture of numerous individual pore matrices. Fundamental work is needed on individual and composite systems of porous rocks, similar to the type of pioneer work that was done on individual and composite gases through early PVT studies.

* The mineralogic composition of rocks is a basic descriptor that may correlate with basic parameters of the porous system itself or with the rock-fluid interactions. Improved descriptions are desired from which better quantitative correlations need to be developed.

* When two or more fluids occupy a porous matrix, the relative position of one fluid to the other within the pores will be determined by the surface forces that are operative, a behavior identified generally as wettability. Although some of the variations in fluid behavior within a porous matrix that are due to wettability have been identified, there does not exist a full understanding of how wettability may vary within a porous matrix, how it may be measured under all circumstances, particularly in-situ, and how it will affect the basic measurements that depend upon rock/fluid interaction.

* Basic parameters of a porous rock as well as the distribution of fluids within the rock are inferred from logging measurements. The analytical methods on which these inferences are based assume a knowledge of the basic nature of the interactions between the rock and the contained fluids. There is need for a broader elucidation of how different assumptions concerning the rock/fluid interactions would lead to differont interpretations of both basic parameters and fluid distributions.

- For the most part, sampling of a reservoir through coring is done without regard to statistical methods for sampling. Selection of cores for detailed examination and study is highly subjective. In general, the number of individual samples that are studied in detail is small. There is need for greater attention to the question of appropriate sampling and for detailed examination of a greater percentage of the samples that are available.

* Rock properties are generally determined after a sample of the rock has been brought into the laboratory. Improved methods are needed for determining in-situ properties of the rock, such as compressibility, thermal conductivity, poissons ratio, porosity, permeability and formation resistivity factor.

- The chemical nature of reservoir fluids should be studied in greater detail and correlations should bo sought between the chemical nature and other porous sytem parameters such as the nature of interactions between rocks and fluids.

\footnotetext{
2. Characterization of a reservolr and its fluids in both a microscope and macroscopic sense

* The complexity of hydrocarbon reservoirs is such that there are no two identical in all respects. They must be viewed as individuals. Variation of character may exist at all scales, from the overall size and shape of the reservoir to the nature and arrangement of the microscopic pores and the fluids
} 
they contain. Satisfactory tools and methods for measurement of reservoir character at all scales do not exist, nor are satisfactory correlations available among the many measurements that can be made.

* The measurement of the properties of a reservoir are made by a sampling that is limited to the well bore itself or by instruments within the well bore that sense the nature of the geological environment immediate to the well bore. lssues here are (a) the need for seris lng measurements that peneliale wrealor. distances into the geological environment, perhaps involving several wells or well-to-surface arrangements, (b) the improvement of quality control and correlations among the many different $k$ inds of logging measurements that are posstble; and (c) greater quality control in coring and improved analysis that can be related to the basic nature of porous systems and their contained fluids. A particularly important measurement that is needed is one that will identify the location of remaining oil within a reservoir.

* The term, heterogoneity, is used loosely to denote different $k$ inds of variabilities within a porous system, ranging all the way from differences in individual parameters,e.g. permeability, to differences in reservoir performance,e.g. sweep efficiency. There is need for better definitions of heterogeneity as it pertain to variations within the porous system itself or to variations in the nature of rock/fluid interactions.

Hydrocarbon reservoirs are a product of geological processes and forces. Insufficient attention has been given to the description of a reservoir that may be derived from or understood through research into these geological processes and forces.

*The analysis of geological environments by stochastic methods has been applied in only a minimal fashion to the environments of hydrocarbon reservoirs. Research into the improvement of the stochastic methods, per se, and to their application to local reservoir environments is needed. There is need for the development of new methods that will yield appropriate quantitative expressions of composite or average reservoir properties that can be derived from the point measurements that are available.

3. The transports, transfers and displacements that occur within reservoirs * Al though proposed methods for enhanced oil recovery are generally understood in principle, they are not understood as they occur within specific geologic formations. The instability of a displacement front within a porous system,generally described as "fingering", is exacerbated by heterogeneities within the formation in some recovery processes more than in others. Reductions in the amount of instability may mean the difference between a successful recovery process and a failure. There is need to examine the impact of natural variations within geologic formations on the mass transfer processes that are being imposed on the system.

* The exact recovery of oil that will be achioved from a given oil containing formation is an unknown quantity. Tests are necessary to empirically determine the recovery for each core sample, lot alone for the entire 
reservoir. Part of this inability rests in the fact that there is nos sillule measurablo parameter that expresses the transfer capacity of a porous system. No overall scale exists to measure the capacity of the porous system to yield its oil, even with an idealized displacement process. Research is needed to develop a differentiating oil recovery capability for individual porous systems, so that the prediction of an average recovery for a complex reservoir can be derived from an analysis based on the specific situation rather than on an analogy to other reservoirs.

\section{Gaining, controlling and malntaining the access to underground reservoirs}

* The critical issue in drilling is drilling costs. Operational access to the earth through wells is an expensive activity, without which no other petroleum engineering operations can be performed. Any improvement in total access, or in the quality of wells that are drilled, will broaden the scope of all other operations. Reduction in overall drilling costs by five percent, for example, means that five percent more footage can be drilled with the same expenditures. Incremental advances may be found in more durable materials, more efficient drilling surfaces, better mud circulating systems, improved systematization of the elements of the drilling process or other facets of the activity. Step advances may be found in the development of now drilling strategies such as the use of horizontal holes through a producing formation or the drilling of numerous reservolr entry holes from a central main well. An interdisciplinary approach to the topic of drilling would be highly desirable.

* Drilling is usually done in remote locations where those in operational charge have to act without outside advice and without real-time technological analyses. Excessive costs may be involved due to on-site errors and mis-judgements. This situation could be alleviated by the dovelopment of artificial intelligence technology and expert systems for on-site use and by the development of improved real-time computer linkages betwen $r$ ig operation locations and contral analytical locations.

- As reservoirs age it is important to be able to maintain the oconomic life of low productivity wells. By maintaining wells in active status, more options will exist for additional recovery. Any technology that will reduce operating costs or eliminate extraneous operational activities will extend the total amount of hydrocarbon rosources that can be recovered. Issues that are germane to this topic include handling of large amounts of water, sand production, paraffin problems, corrosion and lifting of small volumes of liquid.

* 011 and gas will be produced in the future at parts of the earth in which the environmental constraints are more severe than have yet been encountered. These constraints may take the form of deep ocean waters, arctic locations, or extreme depths within the earth. These are places in which surface conditions or subsurface temperatures and pressures are beyond the present limits of drilling and producing technology. Meeting the limitations of these constraints will require research on many aspects of drilling and producing technologies. 
5. The overall performance, analysis and management of a reservair

* Where is the remaining recoverable oil within a reservoir. Although material balance considerations and other techniques may provide fairly accurate numbers for the unrecovered hydrocarbons, existing methods of analysis are poor in providing an accurate description of how the remaining hydrocarbon is distributed throughout the reservolr. Research is needed on methods to improve the knowledge of that distribution and to be able to assess its change over time.

- There is a need to systematize the measurement, diagnosis, modeling and decision making processes that are attendant upon developing and managing a petroleum reservoir. The available technological tools are too often used without reference to the whole. Each reservoir is different from every other reservoir and should be manoged as an individual. Research is needed to bring together the several parts of the technology into an integrated format.

- The formations of the earth and the fluids they contain are essentially physico-chemical systems. The conduct of fluid operations within the earth, which is the essence of petroloum technology, should be highly dependent upon the chemical nature of the formations, the fluids that are being moved and the interactions among them. Past research has emphasized the physical nature of reservoirs and operations. Future research should consider the chemical nature more thoroughly.

*Even though we have valid mathematical models for most of the recovery processes in the laboratory, we fall short of being able to predict the performance of processes in the fleld. The problem may be an inability to express the known fiold circumstances in appropriate mathematical form, or it may be in a failure to recognize the dependency of the recovery processes on changes in field circumstances. Research is needed to elucidate which of the characterizing features of a field situation may be the most dominant. 


\title{
A RESEARCH AGENDA FOR ACADEMIC PETROLEUM ENGINEERING PROGRAMS
}

\author{
Chapter 5- NON-TECHNOLOGICAL ISSUES
}

\subsection{THE FACULTY SURVEY ON NON-TECHNICAL. ISSUES}

The survey of petroleum ongineering faculty included several questions that were intended to explore their attitudes and concerns for issues that were not technical in nature. In response to a question that asked the faculty to identify general problems that restrict their ability to address the most important research issues, the principal topics that were named concerned the level of funding (or lack thereof), poor federal support, inadequate industrial relationships, the quality and number of students and general administrative deficiencies. These replies are detalled in Appendix 4-5.

Virtually overy response mentioned funding as a problem in some manner, the level of funding being characterized as insufficient for almost every research component, e.g. for student support, for roleased time and research staff, for technicians, for equipment, for upgrading laboratories, for fundamental and innovative research and for applied research. The opinions stressed the relatively low level of individual projects, 0.9 . $\$ 10,00$ to $\$ 50,0$ and the difficulties of obtaining long term funding. Lack of equipment was noted as a special concern in some instances. One faculty member noted that "lack of expensive, sophisticated equipment prohibits intelligent experimental studies".

Both industry and government sources of support were said to be lacking. The rationale for the low level of support was noted in several different ways, Q.g.petroleum engineering "has no home in major funding organizations such as NSF"; "petroleum engineering is not recognized as a stand alone discipline by NSF and other government apencies":"in harmony with the oconomic times, industry support is very erratic"; "the federal research dollars are controlled and spent by EOR groups primarily staffed by chemical engineers who do not have a grasp of the other areas of petroleum engineering"; "there is the perception by personnel of these (government) agencies that if any relevant petroleum engineering research needs to be done it will always be done by the industry or should be supported entirely by the industry".

Industrial relationships, per se, were said to be a problem in several respects. One major concern expressed inadequate interaction on applied research programs and lack of cooperative research support. The need for more industrial joint involvement was said to be particularly applicable to service companies. Another major area for comment was the lack of good data ( "what data is available is propriotary") or lack of access to reservoir and production data. One noted that "we have a difficult time getting low cost 'public domain' seismic data to work with". 
Perhaps the most pervasive concern, however, was directed at the numbers and quality of students. The question of insufficient numbers of graduate students was linked to the supply of undergraduates, to the perception of petroleum engineering as a narrow field, to a flagging industry and to the lack of industry incentives for degrees beyond the baccalaureate. A concern for quality of uraduate otudents was expressed in terms of poor quality compared to other disciplines, an insufficient background in mathematics and engineering sciences for petroleum engineering students. Low number of students from the U.S. and a limited market for PhD petroloum ongineers. These problems were felt to be amenable to solution through funding support for high quality graduate students.

Problems were also seen in the more general arena of program concept and administration. One faculty member noted as important the "lack of consensus national energy policy". Another noted that "Lack of a well focused national petroleum research program results in unreliable funding and cyclical effects on research priorities." Another said "I believe consistency of long term commitment is the most pervasive and damaging problem.... I understand the institution's inconsistency because it is a result of inconsistent signals from the private sector and other public sectors." Another noted problem was the overriding interost of univorsity administrators in research grants and the emphasis on quantity of rosearch papers. Still another problem identified was the lack of appreciation for the use of graduate students as "researchers in training". Further problems cited were the lack of a coordinated research program to bring new ideas to the field for testing and the lack of a unified direction among researchers in common areas. The only solution offered for some of these problems was the existence of more research chairs.

5. 1 THE FACULTY SURVEY ON COOPERATION. FIELD DATA AND SPECIAL FACILITIES

The faculty survey posed three other questions auxiliary to the subject of research topics, one dealing with the need for research faculties to have better access to field data, one dealing with the desirability for research cooperation among faculties at different institutions and one dealing with the potential need for "national" type research facilities. Detailed responses to these questions will be found in Appendices 4-6, 4-7 and 4-8. The following summary gives the sense of the responses.

With respect to the question concerning the "critical need for petroleum engineering faculties to have better access to fleld data..". the responses were positive, 24 to 9 . The gist of the need was expressed in several ways, for examplo-

* Laboratory scalo tests do not necessarily reflect real problems.

* Many production research projects cannot be reduced to lab size and require full scale equipment. 
* End products of research are usually models used to enhance our understanding of a physical set-up. To test the validity of and field applicability of these model s one needs current data that are owned and controlled by industry and usually nonaccessible.

"I think we have become too "scientific" and have focused on the analysis of laboratory and theoretical studies. As a rosult of this attention on the micro and synthetic worlds we have strayed in both research and instriuction from the ranl world of oxploitation of resourcos.

With respect to the question about the need for " petroleum engineering faculties to work cooperatively among institutions", the responses were primarily positive, 25 to 8 , although many in favor raised questions of logistics, size of projects and administrative overhead. Some key comments were-

* I feel strongly that goology and engineering should be better integrated in our research

* We are generally small in numbers and need cooperation to be able to establish " critical mosses" to work on any specific problem.

" Make better use of specialized knowledge to solve large national problems.

* That would enhance communication between petroleum and other engineers and scientists, a badly needed interaction.

On the question about the desirability of facilities of a "national" character for petroleum engineering, the responses were rather evenly divided. However, the explanations accompanying the negative responses of ten indicated an assumption that such facilitios would be owned and operated by a government agency, which was not intended to be a condition of the question. Those who visualized that such facilities would be important gave the following as examples-

* X-ray, NMR and CAT scanning equipment

* Supercomputers, mathomatical modelling and three dimensional graphics systems

* High pressure, computerized loop facilities to study multi-phase flow behavior

* Cored wells with known hetorogeneities to run new logs and formation evaluation tools

* Industry scale drilling facilities

* Full scale facilities simulating well hole geometry during drilling and production operations.

One response pointed out that the most useful such facility would be a comprehensive data base, which also speaks to the auxiliary question on data accessibility. Responders also pointed out that the success of such facilities would require methods for "integrating" the research programs of the more "elite" research schools with other institutions, which speaks also to the auxiliary question dealing with cooperation among institutions. 
The responses also pointed out that existing facilities, such as those for multiphase flow at the University of Tulsa and a "model" facility for petroloum goophysics at Stanford University could be useful on a general access basis.

\subsection{NON-TECHNICAL. ISSUES FROM NON-FACULTY SOURCES}

The following summary of non-faculty views is based on the detailed responses that are given in Appendices 4-10 and 4-11. The goneral thrust is that academia and industry must work closer together, that the effort must be interdisciplinary, that university research must be more relevant and that industry must give more support. At the same time there is voiced a concern that industry research is geared more to operations than to the generation of new technology and that the university petroleum engineering groups may be lacking in quality.

The preponderance of views is that access to field data is needed for the effective conduct of universly research. Although it is recognized that there is some research for which field data may not be necessary, the broader view is that university resoarch should not be limited by lack of fileld data and that in some instances the research that is needed cen not be done without access to field data, particularly in the area of reservoir charecterization. One respondent observed that "Much of petroleum engineering is emperical and statistically derived, making it difficult to further develop the technology on first principles in a building block manner.... Application of a single idea or concept ombodied within a complex system may be difficult to say the least, and often cannot be verified because of multivariable effects".

On the peneral matter of a research plan,one observor pointed out that the selection of a research propram was one of the most important steps and that at least 10\% of research efforts should be directed toward that end. Another noted that "university resoarch can load to worthwhile immprovements in technology that are ovolutionary in nature" but to make revolutionary impiacts "we are somehow going to have to drastically change the way we manage and produce oil reservoirs". Other comments noted a need for more long range research programs, more research oriented professors and departmental programs besed on individual strengths.

\subsection{GENERAL ATTITUDES AND PERCEPTIONS}

Equally important to the manner in which faculty viow their research role and their abilities to fulfil the role are the general attitudes of academia, industry, government and the general public. The responses of faculty indicate that they are aware of the importance of these attitudes.

A primary general attitude regarding rosearch in potroleum production technology is that fow are willing to accept the idea that public funds should 
be spent on research in this domain. It is considered to be the realm of private enterprise. It is viewed as leading only to greater profits for oil companies or royalty owners. There is an absence of the viow that the public has a large stake in advancing the knowledge system that applies to the existence of petroloum and its recovery.

A second general misconception exists in the academic world. Traditional scientists and engineers find it hard to identify "generic" topics that are unique to petroleum production technology, believing that the "generic" issues all lie within some other field, e.g. in thermodynamics, mechanics, geology otc. They fail to see the total system of petroleum production technology, or its environmental aspects, as they do with some other technologies, $\theta . g$. as they might see ocean engineering or bio-engineering for example. Part of the reason for this misconception is that petroleum is only about one percent of the total engineering community. Another reason for the misconception is that potroloum engineering researchers are slow to reach out to other academic fields for cooperative work.

There appears also to be a general attitude within the petroloum industry rosearch laboratories that the academic petrleum onginoering departments are not of very high quality, and that they do $108 s$ than adequate research.

Industrial laboratories have been administered in large part by non-petroleum engineers. For the most part, also, these laboratories have been protective of their continued existence and heve been less than favorable to the allocation of industrial funds outside their own orpanizations.

A general attitude that is allied with all of these perceptions is that the National Science Foundation, and other government agencies that support academic research do not recognize the technology that deals with fluid processes within the formations of the earth as a separate technological systom. Although the NSF identifies bio-engineering systems, environmental systems, ocean resource ongineoring systoms and natural hazard systems as distinct units it does not seo fit to recognize as a disctinct unit the comparable complex system that makes up the technology of moving fluids into and out of the earth through wells. Even the DOE, which has a responsibility for fossil fuel matters, does not rocognize the uniqueness of the technology.

These perceptions are all reinforced by the historic posture of both academic and government communities, as well of other concerned groups, to defer to the petroloum industry as the authoritative voice and arbiter for questions dealing with research in the technology. No professional society voice, no acadomic voice, no government agoncy voice has been able to overcome this deference. The result is that there is no objective consensus that has been achieved through dialogue among all concerned elements, both public and private. Such a consensus is needed. 


\subsection{RESOURCES AND ORGANIZATIONAL ARRANGEMENTS}

There is some question as to whether the facility and manpower resources of the petroloum engineering departments are sufficient to meet the challenges for maintaining U.S. leadership in this important area of international competitiveness. Petrol oum ongineering departments, in general, have not been able to assemble faculties and facilities of the sophistication and size of those that characterize other engineering research fields. A concern for this matter is reflected in many of the survey responses. Al though many elements enter into the resource equation, two are emphasized as being particularly germane to building and maintaining the quality of academic petroleum engineering. The first is a continuity of commitment, the second is an adequate level of funding. If these elements are met, and they are inter-related, it is presumed that any deficiencies in quality of faculty, facilities or students can be overcome.

Petroloum engineering departments have been plagued by the continuity question for many years, primarily because of the cyclic nature of undergraduate enrolments, which in turn is tied to the general welfare of the domestic petroloum industry. For a period of twelve years or more. prior to 1985, the petroleum engineering departments were under tremendous prossure from all sides to produce large numbers of students with B.S degrees to support the energy growth of the nation. Manpower resources that might have been directed to building up graduate programs and research programs were consumed by attention to undergraduate problems. Since 1985, undergraduate enrolments have fallen drastically and some university administrations are considering the termination of their petroloum ongineering departmonts.

For a program, such as petroloum engineering, that represents a relatively small portion of the total engineering onterprise, continuity within the university community will depend more upon its role as a graduate and research program rather than its contribution as an undergraduate program. This is a matter, however, on which no consensus position exists so far as petroleum engineering is concerned. Industry is still placing its emphasis upon undergraduate degrees. Government funding agencies give minimal recognition to the field for research support. The petrol oum engineering departments, themselves, are just emerging from the period whon they have been buried under the concerns of undergraduate programs.

Unfortunately, the research funding support also has been below the average for other engineering fields. The departmental programs accordingly have developed less research than they might have initiated with higher levels of support. This theme is clear from faculty responses and is documented in chapter 2 of this report. As has been noted above, part of the reason rest in 
the fact tht dopartments wore too heavily committed to serving undergraduate demands to give proper attention to research activities. More fundamentally, the reasons for the low support level can be found in the general attitudes and perceptions which have been outlined in Section 5.3. These attitudes and perceptions will need to change before adequate funding levels can be achieved.

These matters of achieving a focus for program continuity and of dealing with the perceptions and attitudes that affect funding levels can be resolved only by group action. Leadership of the petroleum engineering academic community is essential, and the Association of Heads of Petroleum Engineering Schools, which has recently been formed, should undertake such loadership. However, the support of many other factions will be needed, including that of industry, of appropriate government agencies and of the Society of Petroleum Engineers.

Within the context of the totality of petroleum ongineering programs that are assured continuity and are supplied with adequate funding, other important resource and organizational questions need to be considered in detail, the following being among them.

- A greater recognition is needed by the academic petroleum engineering groups that more multidisciplinary approaches are necessary for some of the large research problems. These approaches might be very informal, or they might take the form of formal Centers through which the multidisciplinary thrust is recognized and implemented, such as a Center for Reservoir Characterization that would coordinate the efforts of engineers, geoscientists, statisticians, computer scienctists, otc.

* Modern laboratory facilities need to be acquired, not only to permit research that is at the leading edge of technology but also to point the way to the development of new instruments and now applications. Acquisition of large scale instruments, in particular, which may be beyond the capacity of a single institution, ought to be considered on a consortium basis. The same consortium consideration should be given to special facility installations that aro dedicated to a large system of problems, such as those associated with drilling.

* It is essential that relationships be developed with industry through which large amounts of data from many companies can be assembled for research purposes. Any data that is made available for research purposes is done at the pleasure of those who own the data. Although some data are made public through regulatory channels, such data is usually unsatisfactory for research uses. Companies will usually try to supply data, if they are asked, when an appropriate use has been outlined. The logistics of gathering comparable data from many companies is usually prohibitive, however.

* There should be some development of mechanisms through which the academic researcher in petroloum production technology may obtain access to the 
real environment of wells and reservoirs for research purposes. Many of the substantive research questions that need to be tackled require the same $k$ ind of entry to the environment as is supplied in the fields of oceanography, meteorology, agriculture, otc. Public research funds ought to support such access. Perhaps the use of wells or fields, just prior to abandonment, could be diverted to research purposes for short periods of time. Or, perhaps a limited program of drilling and production, specifically designed for research purposes, should be generated.

* A greater number of U.S.students need to be brought into the graduate programs of petroleum engineering. One approach might be to examine the greater use of graduates from other disciplines as graduate students in petroleum engineering. This matter is tied to how the multidisciplinary characteristics of research programs are viowed. 


\section{A RESEARCH AGENDA FOR ACADEMIC PETROLEUM ENGINEERING PROGRAMS}

\section{CHAPTER G- CONCLUSIONS AND RECOMMENDATIONS}

6.0 The intent of this study was several fold, e.p. to elucidate the problems and issues relative to rosearch in the acadomic petroleum ongineering community, to identify the koy research topics and directions that should be of concern to the petroloum engineoring departments, to initiate discussions among faculty and others relative to focusing the field of academic petroleum engineering research, and to provide a document for use by the petroleum engineering departments as a basis for discussions with industrial and government groups responsible for making decisions on the allocation of resources for research. The study was able to touch upon some these issues and problems only in an exploratory manner. Therefore, some of the conclusions and recommendations are directed at the goal of achieving an ongoing consideration of these mattors. Other conclusions and recommendations suggest specific courses of action at this time.

The degree of urgency about these issues that is felt by the petroleum ongineering academic community stoms from at least four considerations- the uncertainties for the continued existence of petroloum orgineering academic programs, the changing needs of the domestic petroleum industry for technology to produce our remaining hydrocarbon resources, the need for the nation to maintain its historic international lead with respect to petroleum technology, and the need for establishing a coherent understanding of the technologies that make up subsurface well systoms ongineering. All of these factors point toward the need for concerted actions that involve the academic institutions, the petroleum industry and public agencies.

6. 1 The status of the acadonic petroleum engineering community does not appear to be as strong as it should be after more than a half century of existence in graduate study and research. This academic field has expertenced a relatively low level of research funding, a virtual absence of support for research as a matter of public interest, an industry demand for students that has been concentrated at the undergraduate level, and a stronger emphas is among many faculty on consulting rather than on research as a means of advancing their individual competencies and careors. These forces have mitigated against the development of strong research roles for the petroleum engineering departments and against the development of a role for potroleum ongineering departments to be an integrative influence for petroleum technology within the academic community.

The petroleum engineering departments have been followers in research, for the most part, rather then leaders, tending to think of their collective role from a single disciplinary point of view. In recent yoars, basic research, so 
necessary for advancing applications, has beon lacking. In addition, the major emphasis has been upon mathematical and computer oriented activities, with experimental capabilities having been abandoned for the most part. To a large degree, these postures are a consequence of the primary allegiances that the departments have maintained with respect to the petroleum industry. Not only have the departments looked to industry for the hiring of their graduates and for primary research funding, but also for emphasis upon now technology directions and areas of application.

As a consequence of these many factors, there is little to be found in the way of a group posture within the petroleum engineering departments with respect to basic research needs. It follows that there is also little in the way of a community approach to developing the capabilites that may be necessary to meet those needs. In total, the petroleum engineering departments represent one to two percent of the nation's academic engineering effort. Without a national approach that unifies the departments, the future of these programs may be more dependent upon forces outside the technology than on forces within it.

The following paragraphs enumerate several needs pertaining to the lack of cohesiveness and state several general recommendations for action that are suggested for the petroleum engineering academic departments.

* Although the departments may have different individual nesds, their most fundamental common need is for the petroleum ongineering departments to act in concert with respect to the role of potroleum engineering within the academic community and the presentation of that role to the world outside the university.

* A major need is for the petroleum engineering departments to clarify the uniqueness of the technological area that they represent within the academic community. The name "petroleum engineering" will continue to be a barrier, but no satisfactory substitute is apparent.

- There noeds to be a better internal understanding within the petroleum engineering community of the academic petroleum engineering research programs that they have in being, of the resources that are avallable, of the research interest of the faculties, and of the opportunities for cooperative research programs that might involve the petroloum engineering departments.

Toward meeting these need, the following are recommended-

THE ASSOCIATION OF HEADS OF PETROLEUM ENGINEERING SCHOOLS SHOULD

a) CREATE A SUB GROUP OF ITS MEMBERS WITH SPECIFIC RESPONSIBILITY TO FORMULATE A PROGRAM FOR ADVANCING THE COMMON UNDERSTANDING OF PETROLEUM ENGINEERING RESEARCH PROGRAMS. NEEDS AND POTENTIAL AMONG ITS MEMBERS.

b) COMPILE AN INUENTORY OF THE SPECIAL FACILITIES, CONSORTIA AND CAPABILITIES FOR RESEARCH AT THE VARIOUS UNIVERSITIES IN ORDER TO PORTRAY THE OPPORTUNITIES FOR COOPERATIVE RESEARCH PROGRAMS AND JOINT USE OF FACILITIES. c) APPOINT FACULTY COMMITTEES, REPRESENTING ALL THE DEPARTMENTS, THAT WILL 
MEET PERIODICALLY TO DISCUSS THE STATUS OF ACADEMIC RESEARCH AND RESEARCH NEEDS IN DIFFERENT ASPECTS OF THE TECHNOLOGY, .9.DRILLING, COMPLETIONS, PRODUCTION, RESERVOIR, ENUIRONMENTAL, ETC., AND IDENTIFY THE MOST PROMISING RESEARCH TOPICS.

d) DEVELOP A PROGRAM THAT PERIODICALLY WILL PRESENT TO INDUSTRY, GOVERNMENT AGENCIES AND OTHER GROUPS THE ACADEMIC COMMUNITY'S ASSESSMENT OF RESEARCH OPPORTUNITIES AND NEEDS.

e) ENCOURAGE THE SOCIETY OF PETROLEUM ENGINEERS TO EXPLORE THE POSSIBILITY OF ADOPTING A NAME THAT MORE ADEQUATELY DESCRIBES THE PETROLEUM ENGINEERING PROFESSION.

f) ENCOURAGE THE SOCIETY OF PETROLEUM ENGINEERS TO ESTABLISH A COMMITTEE FOR THE OVERVIEW OF RESEARCH.

g) ENCOURAGE THE NATIONAL SCIENCE FOUNDATION TO SUPPORT A STUDY TO IDENTIFY THE UNIQUENESS OF THE TECHNOLOGY THAT PERTAINS TO THE USE AND DEVELOPMENT OF SUBSURFACE RESOURCES THROUGH WELLS AND WELL SYSTEMS, WHICH MIGHT BE CATEGORIZED GENERALLY AS "SUBSURFACE WELL SYSTEMS ENGINEERING".

6.2 A long standing deficioncy with respect to academic research in petroleum ongineering has been the lack of a stable funding base, particularly one that involves adequate public funding. In contrast to the situation in other engineering fields, industry has provided the largest share of funding for research in petroleum englneoring. The level of industrial support has been short term and has varied with the fortunes of the industry. The direct industrial support is often categorized as "support to education" rather than as funding for research activities. Independent operators and service companies, for the most part, do not contribute to research, the industry support being concentrated in the "major" producing companies.

There is a virtual absence of any recognition of the need for or justification of public funding for petroleum engineering through federal agencies. The National Science Foundation, which is the principal source of research funds for fundamental technology, does not recognize petroleum technology for program funding purposes. The Department of Energy has been the major source of federal support for petroleum engineering research. Funding for oil and natural gas programs in the DOE, however, has been focused on limited topics, e.g. Enhanced 0il Recovery, has not been conceived for the broad advancement of petroloum technology and has favored the use of National Laboratories for conducting the research.

Some research funding in recent years has emerged through the programs of the Gas Research Institute. These funds are derived through the mechanism of regulating the rates that are charged to the consumers of natural gas. Although there have been suggestions that a rosearch group similar to GRI je established for petroleum, industry appears to be against the idea. The industry still maintains a program of support for research through the American Petroleum Institute, but the scope is limited. 
There are a growing number of attempts to consolidate industrial support of research programs in the petroleum engineering departments through consortium type arrangements and thereby ensure longer term fnding. In addition, the petroleum enpineering departments have developed a potential access to new DOE funds through assistance in the efforts of the geoscience community to encourage DOE to support research related to geosciences through the formation and implementation of the Geosciences Institute for 011 and Gas Research. Industry has also enhanced the channels through which universities may make presentations of new resuarch proposals to representatives of industry. Groups such as the Drilling Engineering Association, the rompletions Engineering Association,etc.serve this purpose. These growing communication channels and cooperative rolationships are a positive development.

Even with a low level of funding, petroleum engineering departments have been able to maintain a high visibility and reputation in the international community. Potroloum engineoring is a uniquely American technology, probably more so than any other technology. It has been exported for the development of hydrocarbon resource throughout the world and it has contributed to a dominant international position for the nation's petroleum industry.

The balance of competitiveness between domestic and international petroleum technology is rapidly changing, however. The number of potroleum engineering academic programs overseas oxceeds our own. Rasearch leberatordes in other countries now rival those in the United States. Research on the total technology, so essential to maintaining a leadership position, has given way in the United 5tates to applications that are directed at short term problems. There appears to be $11+t l e$ attention to this issue of international techological competitiveness within oither the industry or DOE. The academic departments are a medium through which this problem could be addressed.

A principal conclusion, based on this background, is that steps need to be taken to address the long term continuity of research funding for the academic field of petroleum engineering, not only for domestic reasons but also as a means of sustaining the nation's leadership in this technological field. Statements of the primary needs and recommendations follow.

* There is a need for the National Science Foundation to recognize, as a separate system of technology for research support, those engineering activities that are germane to the development, conservation and use of the resources of the earth through the wells and well systems that penetrate the formations and reservoirs of the earth. This technology is found in the fields of petroleum hydrocarbon resources, water resources, geothermal resources, mineral resources, coal resources, waste disposal systems, scientific exploration of the earth and other activities that involve the subsurface. The field of technology is conceptually eqivalent to other technological systems that are funded by NSF as separate programs, such as those for bio-engineering or ocean resources.

* There is a need for devoloping mochanisms that will broaden the funding 
support for rosearch in potroloum engineoring to the entire industry, e.g.the independent operators, the service companies and royalty owners as well as the major producing companies. The idea is to provide broad support somewhat similar to the concepts that form the bases of support for the Gas Research Institute and the Electric Power Research Institute through contributions from all consumers of hydrocarbon fuels.

* There is need for improved communication among petroleum engineering faculty groups and petroleum industry groups with respect to the asseosment of research needs, the avallability of field data and facilitios for research purposes, the formulation of cooperative and consortia type arrangements, and the long term funding of research programs at universities.

* There is a need to improve the support of academic research in petroleum engineering departments as an important mothod of sustaining the nation's international position of leadership in this field of technology, not only with respect to the technology itself but also with respect to the education of technological leaders.

As a response to meeting these needs, appropriate positive actions can be visualized on the part of several government agencies, industrial groups or organizations that have a concern. The following statements are offered as examples of what such actions might be.

THE NATIONAL SCIENCE FOUNDATION SHOULD HAVE, WITHIN ITS DIVISION OF BIOLOGICAL AND CRITICAL SYSTEMS, A PROGRAM SPECIFICALLY DEDICATED TO ADVANCING THE SYSTEM OF TECHNOLOGY THAT IS CONCERNED WITH THE DEVELOPMENT, CONSERVATION AND USE OF THE RESOURCES OF THE EARTH THROUGH WELL SYSTEMS.

THE DEPARTMENT OF ENERGY SHOULD ESTABLISH A RESEARCH PROGRAM DIRECTED AT SUSTAINING THE INTERNATIONAL LEADERSHIP ROLE OF THE NATION WITH RESPECT TO PETROLEUM TECHNOLOGY, MAKING PRIMARY USE OF THE PETROLEUM ENGINEERING DEPARTMENTS OF THE NATION, NOT ONLY TO CONDUCT RESEARCH TOWARD THAT END BUT ALSO TO EDUCATE THOSE WHO WILL BE FUTURE LEADERS IN THE TECHNOLOGY.

THE SOCIETY OF PETROLEUM ENGINEERS SHOULD HAVE AN INTERNAL MECHANISM THROUGH WHICH THE PROFESSION WILL PERIODICALLY REVIEW THE NEEDS FOR RESEARCH IN THE TECHNOLOGY OF THE PROFESSION, THE COMMUNICATION CHANNELS THAT EXIST RELATIVE TO THE ASSESSMENT AND IMPLEMENTATION OF RESEARCH AND THE POSTURE OF PUBLIC AND PRIVATE FUNDING SOURCES FOR RESEARCH.

THE PETROLEUM INDUSTRY THROUGH ONE OR MORE OF ITS INTEGRATING ARMS, THE AMERICAN PETROLEUM INSTITUTE, FOR EXAMPLE, OUGHT TO SEEK BETTER MECHANISMS AND PROCEDURES BY MEANS OF WHICH ALL ELEMENTS OF THE INDUSTRY WILL CONTRIBUTE TO THE SUPPORT OF RESEARCH IN PETROLEUM TECHNOLOGY AND THROUGH WHICH ALL ELEMENTS OF THE INDUSTRY AND THE ACADEMIC COMMUNITY CAN COOPERATE IN THE ASSESSMENT OF RESEARCH NEEDS, IN THE DEVELOPMENT OF COOPERATIVE RESEARCH PROGRAMS AND IN THE 
MORE EFFICIENT USE OF RESOURCES THAT ARE AVAILABLE FOR RESEARCH.

6.3 The emphasis on academic petroleum engineering research within the last quarter century has been in the direction of mathematical and theoretical analyses backed up by computer simulations and modeling. The trend developed for a variety of reasons, among them being the interest of the industry to apply to real reservoirs the principles that had been developed through laboratory work using simple systems, an approach mado possible by the powerful analytical tools that emerged through the use of computers. It was also less expensive for academic departments to supply computing capabilities than to maintain expensive laboratory complexes. Although some laboratory work continued with reference to enhanced oil recovery, the capabilities of petroloum engineering academic departments, until the last few years, has focused for the most part on computerized analyses.

It is fundamental to all phases of petroleum production that there be basic and comprehensive knowledge of the petrophysical behavior of the environment within which hydrocarbons occur and from which the hydrocarbons will be recovered, but the current situation is one in which there exists a poor understanding of this physical system. Physical constants and boundary values for theoretical analyses are unknown and are typically estimated from empirical correlations or from extrapolatiolis based on prior laboratory work. Current measurements are limited to the well bore or its immediate vicinity, leaving the greater portion of the reservoir devoid of direct measurements. Added to the paucity of data is the fact that the current data available from cores or logs may not be of high quality.

There is a need for a roturn to academic research that seeks to elucidate the physical system of concern to petroloum engineering. The fact that this physical system is controllod by goological parameters has led to the suggestion that the research is therefore a geosciences problem. The focus needed is not that of the geosciences per se, but is rather the way in which the concepts of geoscience pertain to our understanding of the manner in which hydrocarbons, or other fluids, are distributed and can be moved within a subsurface situation. The specifc needs encompass the measurements of subsurface properties as thay would be in place, the statistical variations in these properties and the averaging of properties for analyzing a total subsurface system. Obviously, the research needs to have a strong input from the geological sciences, but the thrust should be the development of concepts and measurements that will provide the petroleum engineer with the boundary conditions and constants that he now lacks for engineering solutions, mathematical simulations and theoretical analyses.

The general name that might be applied to this area of research is petrophysics and there is a broad need for a concentrated research program into all aspects of petrophysics. The scope of needed understanding ranges from microscopic to macroscopic levels, from concepts that apply to porous rocks as 
structural systems or as fluid containing systems, and from systems with a single fluid to those with multiple fluids. The development of new measuring

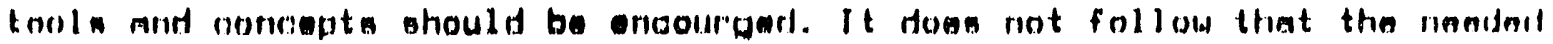
research should be based complotely in either the laboratory or the field. What is indicated is the need for a combined field, laboratory and simulation approach, multi-disciplinary in nature and with a strong emphasis upon geostatistics. Unfortunately, the academic petroloum engineering departments do not have the assemblage of sophisticated modern equipment that will be noeded to undertake these tasks.

Some of the more specific noeds that can be indentified are-

* There is need for a systematic re-examination and analysis of coring methods and of the techniques used for making measurements on cores, including the manner in which those samples that are selected for measurements will be representative of the distribution of measured properties within the reservoir.

- The technology on which some of the older logging techniques are based should be upgraded and the quality improved. .

* There is a need to apply statistical mothods in the broadest sense to the procedures for measuring and analyzing the subsurface parameters, whether through coring, logging, or other methods.

* Wettability, particularly as it exists in place, is poorly understood. Methods for determining in-situ conditions are lacking.

* There is need for measurement mothods that will probe the portion of the reservoir between wells.

* There is need for upgrading the assemblage of sophisticated laboratory equipment that is avallable within the academic departments for conducting petrophysical research.

* There is need for better access on the part of the academic research community to field data and to actual subsurface situations within which petrophysical research may be conducted or verified.

In order to meet these needs, the following types of actions are recommended-

THE NATIONAL SCIENCE FOUNDATION SHOULD BE ENCOURAGED TO INITIATE A RESEARCH SUPPORT PROGRAM THAT WILL FOCUS UPON PETROPHYSICS, E.G. AN ENGINEERING APPROACH TO MEASURING AND CORRELATING PARAMETERS OF THE SUBSURFACE ENUIRONMENT AS THEY MAY RELATE TO ALL USES OF THE SUBSURFACE FOR RESOURCE DEVEL OPMENT.

THE UNIVERSITIES WITH PETROLEUM ENGINEERING PROGRAMS SHOULD CREATE, INDIVIDUALLY OR COLLECTIVELY, ONE OR MORE CENTERS FOR PETROPHYSICS FOR THE PURPOSE OF FOCUSING MULTIDISCIPLINARY RESEARCH ACTIVITIES IN THIS IMPORTANT AREA AND FOR ASSEMBLING THE LARGE SOPHISTICATED EQUIPMENT ITEMS THAT MAY BE NEEDED TO SUSTAIN SUCH A PROGRAM. 
THE ASSOCIATION OF HEADS OF PETROLEUM ENGINEERING SCHOOLS SHOULD INITIATE CONVERSATIONS WITH INDUSTRY, INCLUDING THE COMPANIES THAT PROVIDE LOGGING AND CORING SERUICES, WITH THE GOAL OF CREATING MECHANISMS THROUGH WHICH FACULTY MEMAFRS WOUI D BE ARI F TO CONDUCT RESEARCH USING PETROPHYSICAL MEASUREMENTS ON ACTUAL WELLS AND RESERVOIRS AND THROUGH WHICH CRITICAL EXPERIMENTS RLLAIIVE TO MAKING SUCH MEASUREMENTS WOULD BE DESIGNED AND CONDUCTED.

6.4 The need for research on fundamental concepts applies al so the operational systems that are germane to wells, among them being drilling, multiphase flow, well bore completions and well behavior. The dynamics of drilling systems are poorly understood and, as a result, drilling events can not be analyzed fully. The design of equipment for moving fluids, both within the vertical well bore and through pipes systems will depend upon basic knowledge pertaining to multiphase flow. The dynamics of rock behavior, material and fluids transport and other processes in the near well bore rogion are fundamental to handling formation damage, stimulation and other matters which affect the performance of a successful well.

Drilling is a high cost activity and any reduction in costs with respect to a single element can be extremely helpful. Drilling is carried out within ill-defined boundary conditions, in a medium that is anisotropic and with stresses, both around the well bore and within the reservoir, that may vary from time to time. Although numerical models are used for the analysis of drilling operations, they are virtually impossible to validate. Bore hole hydraulics and bore hole dynamics need to be understood in a more fundamental sense than they are at present. Predictive models need to be developed and verifted for tension, torque and state of stress in a drilling string (and in casing strings,also).

The approaches that are now used for predicting multiphase flow in pipes, both vertical and horizontal, are empirical in nature, based for the most part on experiments that have been run under controlled conditions for speciific types of installations. Steady state flow conditions and limited ranges of variables are inherent within such experiments. The need is to develop a research program based on physical principles supported with mechanistic modeling, so that prodictions for unsteady state conditions can be arrived at. In order to validate these predictive methods it will be necessary to assemble data bases from the field.

The lack of understanding with respect to dynamic processes also extends to the operations that are concerned with ensuring fluid movement between the well and the reservoir, such as stimulation through fracturing and acidizing. avoidance or removal of solid materials from the porous structure, and creating or closing perforations through pipe and cement. All of these processes, like those for multiphase flow and drilling. are based on empirical observations. 
Research is needed that is based on a recognition of the physical principles that are germane, coupled with the assemblage of data bases from the field to permit the validation of the predictive analyses that are generated through the research.

In all of these areas, there is a need to couple laboratory research with theoretical research and modeling offorts. Diagnostic systems are needed that will woint to enginaring solutione for enecifir: nituntions. There in nand. III all cases, for the assembling of field data, with appropriate field instrumentation to validate the predictive analyses. There are a wide variety of field operations of interest and it is desirable that research focus on those physical principles and validations that might he pertinent to the broadest possible range of such operations.

In order to meet these $k$ inds of research needs, the recommendations that follow are suggested as a course of action.

THE PETROLEUM ENGINEERING ACADEMIC DEPARTMENTS SHOULD DEVELOP AN INVENTORY OF THEIR EXISTING FACILITIES FOR CONDUCTING RESEARCH IN THE FUNDAMENTAL ASPECTS OF MULTIPHASE FLUID DYNAMICS, DRILLING DYNAMICS, BORE HOLE DYNAMICS AND NEAR BORE-HOLE DYNAMICS AND SHOULD PROPOSE TO DOE OR OTHER FEDERAL FUNDING AGENCIES THE CREATION OF NEW UNIVERSITY FACILITIES THAT ARE NEEDED TO APPROPRIATELY ADDRESS THESE AREAS OF RESEARCH.

THE DOE OR OTHER AGENCIES THAT FUND RESEARCH FOR SUBSURFACE TECHNOLOGY SHOULD BE ENCOURAGED TO ESTABLISH ONE OR MORE FIELD RESEARCH LABORATORIES, OF A NATIONAL TYPE, TO ADDRESS RESEARCH NEEDS IN DRILLING, HYDRAULIC FRACTURING, WELL COMPLETIONS, AND SIMILAR SUBJECTS, INCLUDING APPROPRIATE TIES TO UNIVERSITY AND INDUSTRIAL LABORATORIES THAT ARE DEVELOPING DIAGNOSTIC TOOLS. THESE LABORATORIES SHOULD HAVE THE CAPABILITIES TO DRILL, INSTRUMENT AND OPERATE WELLS IN A RESEARCH MODE.

6.5 A wide variety of problems associated with petroleum engineering technology are concerned with individual components or single operations. Such problems do not exist in isolation, however. They can of ten be grouped into sub-sets of problems that, as a whole, contribute to the efficiency of the total technological matrix. Rosearch that is limited to a particular component may miss the target because of overriding systom relationships. It may be more fruitful to approach such rosearch within a systems context. Several such approaches can be identified among the opportunities for departments of petroleum engineering,o.g. horizontal bore holes, aging wells, reservoir management technology, drilling systems and natural gas supply.

It is not often that a technological advance appears to have the potential for changing an activity in a fundamental way. Such an appoarance in the past was fracturing. A current appearance is the use of horizontal well bores. This 
omerging should be accompanied by a research program that treats the technology of horizontal wells in a systematic manner, with the research on various uses being highly integrated. The goal should be to understand as we proceed with the technology, so that down the road we will know why things did or did not work as predicted.

The use of horizontal wells may not require research into now fundamental concepts but it will require a better understanding of the specific boundary values that are applicable. Three dimensional variations of the properties of the reservoir and well bore environments will be critical. Dynamics of the reservoir rock and of the fluid transfers may require different treatment than for vertical well bores. Although tho fundamental research needs that were described above for drilling. well completions and multiphase flow are applicable also to horizontal well bores, there is a separate need for predictions and validetions that cover horizontal well situations.

Another set of problems for which a systomatic research program is needed is that pertaining to wells that are aging. It is important to the future national production of hydrocarbons to maintain existing wells in operation as long as is possible. There is a population of "geriatric" wells the composite life of which might be prolonged through research. The need may be more for a systematic application of existing technology rather than for an elucidation of now principles, but the application itself requires a research approach, i.e. new types of information that should be obtained, options that may exist for re-completions, schedules of monitoring that will insure maximum longevity of production, and the priority identification of the key operational impediments against continued productivity. In different reservoir and different producing situations, the specific engineering solutions might differ, but a research approach could identify the most common elements among such differing situations and, more importantly, olucidate an appropriate methodology for dealing with aging well situations.

The technology for managing a petroleum reservoir is another area which should be approached with a systomatic rosearch propram. Managoment in this context means the combination of technological and operational decisions made over the life of the reservoir. The continued woll being of the reservoir as a productive entity depends upon the consistency and soundness of the management posture. Each reservoir is an individual and although the management process should take this individuality into consideration, it should be possible also to establish an organized approach to the elements that are involved in the management that would apply to reservairs in general. This might involve the appropriate manner of assembling reservoir and production data, of determining the analytical and diagnostic techniques that will be routinely applied, of ostablishing schedules to be used for monitoring well and reservoir changes, of deciding the types of $f(0)$ / investigations and/or pilot operations that might be undertaken, of identify,ng the decision strategy for operational decisions, otc. A rosearch program on this mattor might encompass, for example, an examination of existing reservoirs and the decision processes that brought them 
to their current status, combined with analytical, modeling and predictive techniques through which alternate paths of management might be explored.

Some of the special research needs that are related to natural gas production include the technology of dealing with tight reservoirs, shales, coal seams and hydrates. Fundamental questions concern such elements as the chemistry of hydrates and the adsorption/desorption cycles of coals. Application questions concern such items as diagnostic techniques for stimulation technology on tight reservoir materials and methods of producing hydrate gas. The petroleum ongineering academic community should work closely with the Gas Research Institute which has developed a relatively large, ongoing research program related to the system of natural gas supply.

The development of improved or different systems for drilling wells has long captured the attention of those interested in petroleum engineering and related fields. Production of hydrocarbon resources can grow and be extended by increasing the amount of hole that it is possible to drill with the current expenditure of resources. Potential research topics would encompass a variety of techniques for breaking and removing rock. Past approaches have been based on concepts involving high pressure systems, nozzle action, cavitation, vibration, etc. Research in this area might also relate to materials problems on drill bits or tubular steels and to the high temperature environments that must be endured. Research needs include dealing with the high gravity forces that must be ondured by down hole telemetry systems and computers.

Research programs that are based on a systems approach will not exist unless they are planned and organized as such, with appropriate funding. Toward such a goal, the following conclusions are formulated.

THE DEPARTMENT OF ENERGY SHOULD PROUIDE FOR RESEARCH SUPPORT THAT WILL ENABLE DEPARTMENTS OF PETROLEUH ENGINEERING TO UNDERTAKE RESEARCH PROGRAMS THAT ATTACK BROAD SYSTEMATIC PROBLEMS THAT ARE IMPORTANT TO OIL AND GAS PRODUCTION, SUCH AS THE TECHNOLOGY PERTAINING TO HORIZONTAL WELL BORES, IMPROVED DRILLING SYSTEMS, THE EXTENSION OF PRODUCTIVE LIFE FOR OLDER WELLS AND THE DEVELOPMENT OF TECHNOLOGICAL SYSTEMS FOR IMPROVING PETROLEUM RESERVOIR MANAGEMENT.

THE DEPARTMENTS OF PETROLEUM ENGINEERING SHOULD EXAMINE THE SCOPE OF PETROLEUM TECHNOLOGY AND PRACTICES OF PETROLEUM PRODUCTION TO IDENTIFY AREAS IN WHICH A SYSTERATIC APPROACH TO RESEARCH CAN TAKE THE PLACE OF ISOLATED RESEARCH ON INDIVIDUAL COMPONENTS OF THE SYSTEM.

THE DEPARTMENTS OF PETROLEUM ENGINEERING SHOULD EXPLORE THE NEED FOR FACILITIES TO UNDERTAKE RESEARCH PROGRAMS THAT ARE SYSTEM ORIENTED, WITH THE POSSIBILITY OF PROPOSING THE ESTABLISHMENT OF COOPERATIVE FACILITIES OR OF FACILITIES HAVING "NATIONAL" CHARACTERISTICS.

\subsection{The larpe amount of romaining oil in known reservoirs continues to be a}


challenge. The emphasis should not be on enhenced oll recovery in the sense of some new or esoteric method yot unknown, but in terms of applying that which is known to the fullest. In most situations, the location of the hydrocarbons that remain in the reservoir is not known. Techniques are needed to identifying those locations specifically. In some instances, the latest diagnostic technology is not applied because the basic reservoir information is lacking. Current measurements on old reservoirs are needed, particularly measurements that can be made in place. In some situations, operational methods have created local anomolies of fluid distribution, formation damage, etc which need to be corrected.

The Geosciences Research Institute for $\mathrm{O} i l$ and Gas Research has laid out a potential rosearch program that will be directed at recovering additional oil from known situations. They propose to identify different classes of reservoirs, characterize thom fully using both existing and new measurements, and perform complete suites of diagnostic tests with respect to performance. Computer mothods will be used to match and predict behavior. Analytical approaches will be utilized to assess the most promising technological steps for increasing recovery, not only with respect to individual well operations but also with respect to improved recovery methods, including EOR techniques.

This type of comprehensive program is not only to be commended but it should serve as an example of the broad $k$ ind of research approach that should be funded for some of the other research topics described earlier. The conclusion that is expressed with respect to this approach is-

THE DEPARTMENT OF ENERGY SHOULD BE ENCOURAGED TO FUND FULLY THE RESEARCH PROGRAM TO RECOVER ADDI TONAL OIL FROM EXISTING RESERVOIRS AS HAS BEEN PROPOSED BY THE GEOSCIENCES INSTITUTE FOR OIL AND GAS RECOVERY.

6.7 Petroleum engineering deals with the design and operation of large and complex systems to develop subsurface resources. In instances, such as off-shore operations, where the capital investments are very large, or in the development of large reservoirs where there are many variables that require a large number of interlocking decisions, optimization techniques have been helpful in reducing costs. By and large current optimization systems are based on correlations pertaining to drilling, operating and recovery systems rather than on physical understanding. Consequently, research into a better understanding of the physical concepts will improve optimization. There is a more general need for research on optimization techniques in several respects, and some of the specifics might be-

- Research should be directed at the use of optimization techniques for the development of marginal hydrocarbon resources. When the difference between success and failure may be small it is very important that the most applicable technology be used to optimize the end result. There should be a clear 
distinction made between appraaches for optimizing the amount of oil production that can be maintained, optimizing the amount of reserves that can be maintained, or optimizing the profit that can be realized.

- There should be research for the improvement of optimization techniques

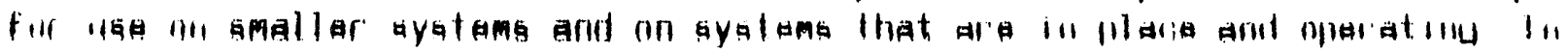
principle, optimization will apply to any size operation, but the attention has been directed to its use on large systems. Optimization may also apply to an operation at any stage, even though the amount of freedom to optimize may be limited for a system that is in operation. Such optimization techniques may assist in increasing the number of smaller production operations and in continuing operations that might otherwise be abandoned.

- Knowledge of various aspects of petroleum technology should be captured in the form of expert systems to be used in consort with optimization techniques. In short, if the amount of knowledge on which optimization decisions are based can be placed into computer format as expert systems, the possibilites for greater use are enhanced.

* Optimization methods should be directed at the total national goals of reserves and the ability of the nation to produce oil. What are the resources available to the nation? What would it take to make them economically useful to the nation? What form should the new requirements take. i.e. changes in technology, changes in practices of exploration and drilling, changes in taxes or subsidies, otc.

- Research attention should be given to the latest developments in numerical modeling, machine intelligence, pattern recognition, neural networks, etc, with the goal of making a direct application of such developments to petroleum technology at the earliest times.

Based on these needs, it is suggested that action along the following 1 ines would be appropriate-

THE PETROLEUM ENGINEERING ACADEMIC DEPARTMENTS SHOULD SEEK TO CREATE AMONG THEMSELVES A FOCUS FOR CONSIDERING RESEARCH INTO ALL THE ASPECTS OF OPTIMIZATION IN THE APPLICATIONS OF PETROLEUM TECHNOLOGY, INCLUDING THE USE OF EXPERT SYSTEMS AND MACHINE INTELLIGENCE, WITH A VIEW TOWARD ENHANCING THE DEVELOPMENT OF MARGINAL HYDROCARBON PRODUCTION ENTERPRISES AND CONTINUING THE LIFE OF OLDER OPERATING SYSTEMS.

6.8 A group of research issues that has been recognized for many years, and which is ever increasing in importance, is that concerned with the enviroriment. So far as petroleum technolgy is concerned there are at least four facets to be considered. These are (1) the direct application of petroleum technology in the design and operation of subsurface waste disposal systems; $(2)$ the amelioration of negative environmental aspects $r$ ising out of current petroloum technology practices; (3) the evaluation of potential negative environmental impacts 
remaining from past petroleum technology practices; and (4) the re-structuring of petroleum technology in a manner that will avoid negative environmental impacts and/or enhance onvironmental attributes.

The onvironmental aspects of petroleum technology relate to many types of nrobloms. Among the obvious are rosidual probloms from salt water disposal

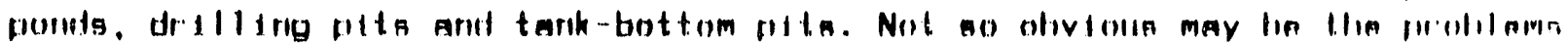
related to surface subsidence from subsurface withdrawals or the use of old pipe from oil field installations for a wide variety of purposes. Air quality problems have been cited with respect to noxious gases, radon and benzene as well as with respect to contributions to acid rain through high levels of combustion at compressor stations.

Perhaps of greatest environmental concern to petroleum engineering are those factors that relate to the potential dispersion of unwanted materials throughout the geologic environment, e.g. movement of materials from the surface to the subsurface or from one part of the subsurface to another part through fluid movement and transfor, adsorption/desorption cycles, distillation and condensation,ion exchange or other means. This topic involves the manner in which well bores are sealed from or are coupled with subsurface formations and pertains to injection wells for production operations, wells for disposal purposes, observation wells, and wells for any other purpose, such as grourid water recovery.

Separate environmental rosearch topics might lie in almost any aspect of petroleum technology, e.g in drilling, well completions, well abandonment, corrosion and scaling, cementing, petrophysics, fracturing, well analysis, etc. Petroleum engineering, by definition, is concerned with the movement of fluids into and out of the subsurface through well systems and with the control of these fluids. How they interact among themselves and with the subsurface and how they may be gathered from or dispersed within the subsurface environment are knowledge areas that are fundamental to petroleum technology.

There is a need to recognize and use the fundamental expertise of petroloum engineering with respect to the environmental issues that exist or may arise. There is also need to use the petroleum engineering academic programs as catalysts in the redirection of potroleum engineering to recognize environmental factors, which also has the additional advantage of bringing environmental concepts into the oducational process for future petroleum engineers. An impetus is necessary, however, to catalyze the petroleum engineering academic programs to undertake the needed aspects of environmental research. The suggestion that is made toward such a goal is as follows-

THE DEPARTMENT OF ENERGY AND/OR THE ENVIRONMENTAL PROTECTION AGENCY SHOULD ESTABLISH AND FUND ONE OR MORE OIL AND GAS ENVIRONMENTAL MANAGEMENT CENTERS AT UNIVERSITIES FOR THE PURPOSE OF UTILIZING PETROLEUM ENGINEERING TECHNOLOGY, IN CONJUNCTION WITH OTHER ACADEMIC FIELDS, TO ADDRESS IN A COMPREHENSIVE MANNER THE ENUIRONMENTAL ISSUES RELATED TO OIL AND GSS PRODUCTION AND TO APPLY PETROLEUM ENGINEERING TECHNOLOGY BROADLY TO THE DISPOSAL AND 

SUBSEQUENT DISPERSION OF MATERIALS THROUGH WELLS INTO THE SUBSURFACE
ENUIRONMENT.

6.9 Although not a research topic per se, the matter of technology transfer is allied to research. The research equation should include the use and application of the technological advances that are made. In discussions about the research agenda, deficiencies in the current mechanisms for technology transfer were recognized. Encompassed within this matter are such subjects as textbooks, continuing education courses, state-of-the-art papers, packaging of software, consulting, clinics and technology centers, service company activities, and related mechanisms.

A large amount of petroleum engineering technology has not been recorded in a summary form that is availablo generally to any seeker. It may exist in company or consulting organizations or in faculty notes. The recent personnel cutbacks and reorganizations within the petroleum industry have resulted in a loss of many experienced practitioners and some note this to be a potential loss of technological knowledge to the industry. One possible way of capturing this resource might be through the development of expert systems dealing with special subjects.

A deficiency in the amount of text material or of papers that deal with summarizations of the state-of-the-art has long been recognized. One difficulty in stimulating new text material is that the rewards are not great. Another difficulty is that those who control publication outlets do not favor papers that are directed at technology transfer contributions. A general suggestion is that the Society of Potroleum Engineers could do more to encourage publications of this type.

Clearly, the service companies and consulting organizations play a role in technology transfer. The question arises as to how well these channels are coupled to the research systom. What is needed are more foci that perform the function of interfacing research advances with applications. The existing research laboratories of the petroloum producing industry are performing this function to a greater extent than they did in the past. Some give the opinion that they have moved completely into the application mode. These laboratories serve only the major companies, however.

There is a need for technology centers that exist apart from any one company and which are coupled closely to the academic research community. They should be able to bridge the gap between field operations and research, in some instances extending the academic research program into the field and in other instances bringing the problems of the field into the laboratory. Such foci would not be unlike the "clinical" centers that exist in human and animal medicine for bridging the gap between research laboratories and the realm of medical practice. Such centers might be offshoots of petroleum engineering academic departments, of consulting organizations or of service companies, or 
they might be independent organizations. They must be capable, however, of

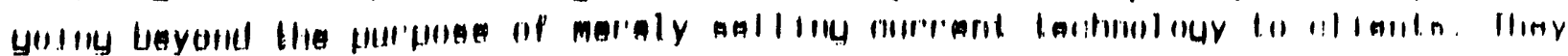
must be able to deal with the real world problems of clients from a diagriostic base and a perspective of research.

Several courses of action seem to be indicated, among them being the foll owing.

PETROLEUM ENGINEERING DEPARTMENTS SHOULD SEEK TO WORK MORE CLOSELY WITH THE MAJOR INDUSTRIAL RESEARCH LABORATORIES, SERVICE COMPANIES, CONSULTING ORGANIZATIONS AND THE SOCIETY OF PETROLEUM ENGINEERS TOWARD THE GOAL OF DEVELOPING BETTER TECHNOLOGY TRANSFER MECHANISMS FOR APPLYING AND UTILIZING THE RESULTS OF ACADEMIC RESEARCH PROGRAMS .

THE PETROLEUM ENGINEERING DEPARTMENTS SHOULD EXPLORE THE POSSIBILITY OF CREATING INDEPENDENT TECHNOLOGY CENTERS FOR THE PURPOSES OF ENSURING THE EXISTENCE OF CHANNELS THROUGH WHICH THE ACADEMIC RESEARCH PROGRAMS CAN BE COUPLED WITH RESEARCH IN FIELD SITUATIONS, PARTICULARLY FOR THAT SEGMENT OF THE INDUSTRY THAT IS NOT SERVED BY THE MAJOR COMPANIES.

THE DEPARTMENT OF ENERGY SHOULD PROUIDE FUNDING MECHANISMS THAT WILL ENCOURAGE PETROLEUM ENGINEERING DEPARTMENTS TO BECOME MORE HEAVILY INUOLVED IN TECHNOLOGY TRANSFER ACTIVITIES. 
APPENDIX $1-1$

A RESEARCH AGENDA FOR ACADEMIC PETROLEUM ENGINEERING PROGRAMS

STEERING COMMITTEE

1. Zaki Bassouni, Chairman

Petroleum Engineering Department

Louisiana State University

Baton Rouge, Loulsiana 70803

504/388-6040

2. E.T.Guerrero, Chairman

Petroleum Engineering Department

Tulsa University

600 South College

Tulsa, Ok lahoma 74104

918/592-1319

3. Gary A.Pope, Chairman

Petroleum Engineering Department

University of Texas at Austin

Room 2.502 6/4.118A

Austin, Texas 78712

$512 / 471-3235$

4. Henry J. Ramey, Jr.

Keleen and Carlton Beal Professor

Department of Petroleum Engineering

Stanford University

Mitchell Building

Stanford, Cal if ornia 94305

415/723-1774

5. W. Douglas Von Gonten, Head

Petroleum Engineering Department

201 Doherty Building

Texas A\&M University

College Station, Texas 77843

409/845-2255 
APPENDIX $1-2$

\begin{abstract}
SUMMARY OF STEERING COMMITTEE MEETING
PETROLEUM ENGINEERING RESEARCH AGENDA

SPE HEADQUARTERS, RICHARDSON, TEXAS
\end{abstract}

APRIL 25, 1989

1. In attendance were Z.Bassount, E.T.Guerrero, G.Pope, H.J.Ramey, Jr, W.D.Von Gonten, John Calhoun and David Martin.

2. A.R.Jennings of Mobil made a presentation about the Completion Engineering Association and Frank Shuh of Drilling Technology Inc.made a presentation about the Drilling Engineering Association. The nature of these Associations was described and explanatory material was distributed. They indicated that there were two other Associations, for Reservoir and Environmental topics. These Associations are open to all who wish to inquire, through any Association member who will be a sponsor. The sense was that the Associations discussed existing projects and ideas and considered new project proposals but did not adddress the general question of what a total research program should be. The sense was that the Associations would welcome participation by the academic groups. They encouraged the distribution of information to department heads.

3. Shuh discussed some of the opportunities for advances in drilling. He touched on the importance of safety, an increased emphasis on the operational side, an understanding of what's going on in the reservoir, horizontal drilling, MWD at the bit, bottom hole assembly failures in deep holes, torque and drag measurements (coefficients of friction), buckling in curved holes and drilling wastes. He touched briefly on the possibility of a major research facility that would evaluate tubular connections.

4. Dave Martin gave a summary of the activities underway in two IOCC Committees (Research and EOR) to assess rosearch status and need. Four subcommittees have been formed- environmental, economics, residual saturation, and funding \& programs. Martin has beeil using the data being collected from the research agenda project. He indicated a willingness to share the information that is developed by his group.

5. Notice was taken of the many other groups with which a liaison would be useful. These included the Gooscience Research Institute, the newly organized SPE Council on Education, and the Bartlesville project office of DOE ( TOM Wesson of that office should bo invited to an oarly meeting). References were made to such groups as NEDHO (nuclear engineering department heads), the AAPG and AGU, the various NRC Committees, ACCORD (Chas Mankin), and the GRI. 
6. The possibility of inputs from industry was discussed. Contact with the Associations seems to be an appropriate place to start. It was suggested that much would be gained by visiting with key industrial persons, $\theta .9$.

"graybeards". Key points to inquire about include any changes in objectives and the role of university versus that of industry. Some names that were suggested included Blackwell (Exxon), Pratz (Shell), Stacey (Amoco), Nedom (Phillips), Odeh (Mobil), Timur (Chevron). There was a particular note that conversations should be held with top oil company executives who have had some first hand experience in doctoral and research work (0.g. Little of Shell, Stegemeier of Chevronl

7. A possible outline for a report on the project was distributed and comments were requested. The following points were made-

* There should be section on the importance of doctoral education in the research posture that is germane to academic departments.

* There should be some exposition related to the demonstrated value of the research product, if possible. Some candidates are fracturing, thermal processes, EOR, pressure transient analysis.

* The changing nature of the industrial research picture should be noted. (Reference to the NPC report. The growing need. The greater rolo today of research)

* Note the things that universities can assume from industry to make industry's role more effective.

* Stress the need for technical information as an investment for the future.

* There is a need for a national research focus dealing with movement of fluids within the earth and in and out through well bores. 
APPENDIX 1-3

DRAFT REPORT

A RESEARCH AGENDA FOR ACADEMIC PETROLEUM ENGINEERING P'ROGRAMS

PREPARED BY

JOHN C. CALHOUN, JR.

This report is intended as a basis for discussion among petroleum engineering faculty members, department heads, and members of the petroleum engineering profession. Several workshops are planned for the specific purpose of receiving suggestions for additions, deletions and corrections, and for focusing on pertinent conclusions and recommendations. However, comments will be welcomed from any sourco. A final report will be prepared after discussion groups are held and comments are received.

SEPTEMBER $\quad 12,1989$ 


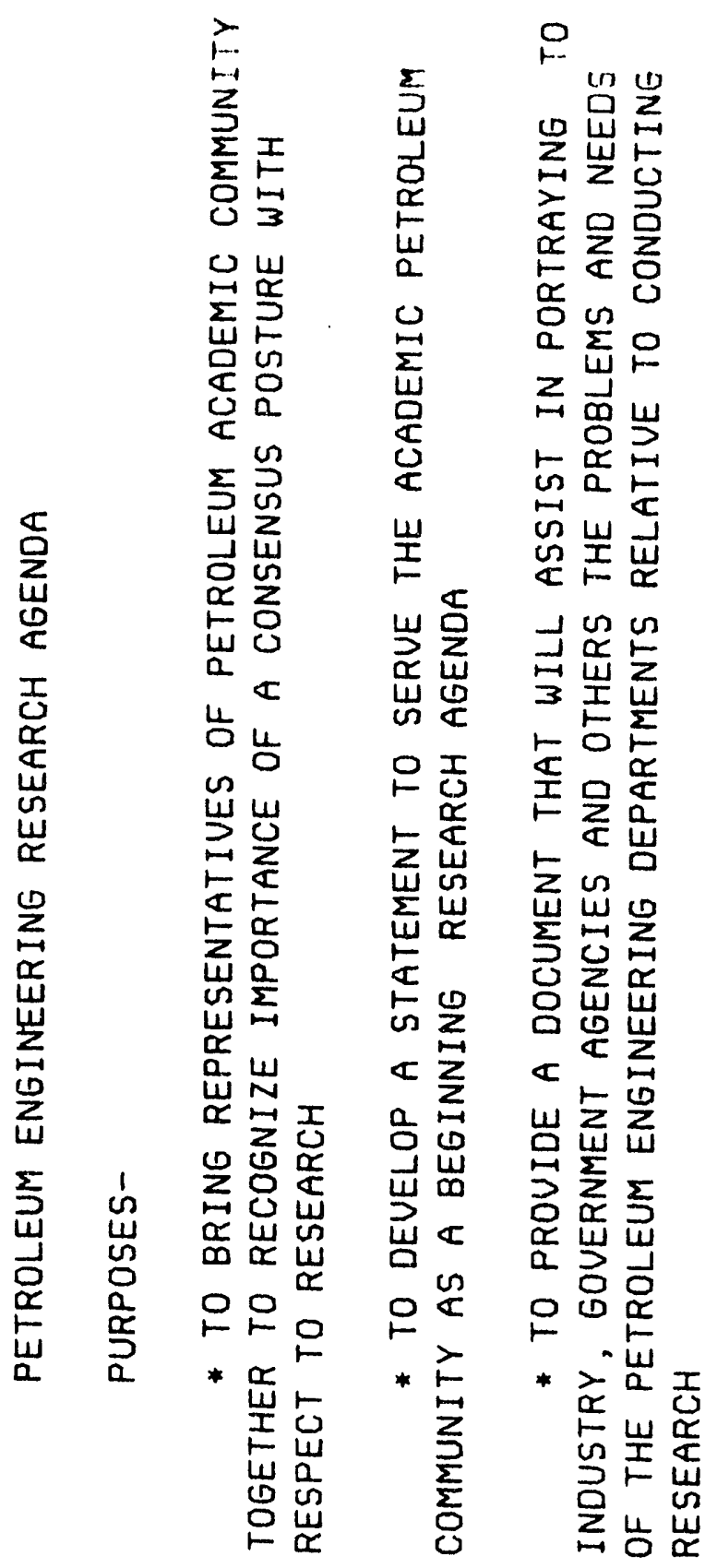


LEVEL OF ACADEMIC PETROLEUM ENGINEERING RESEARCH

The relative amount of petroleum engineering research done in universities is less than in other fields of national concern.

* For all US the average is 13\% in universities, $69 \%$ in industry. Based on industry amount, university amount would be $\$ 150$ million. (page 16)

* US average for basic research is $13 \%$ of total. If total is $\$ 800 \mathrm{million}$, basic part would be over $\$ 100$ million. If over half of basic is done in universities, university total should be over $\$ 50$ million. (page 17)

* $6.3 \%$ of total national R\&D is separately budgeted academic research. Hence total in p.e. academic should be $\$ 50-82$ million (page 17)

* Pet. Engr. programs are about 0.5-0.75\% of total industrial expenditures(page 17) 


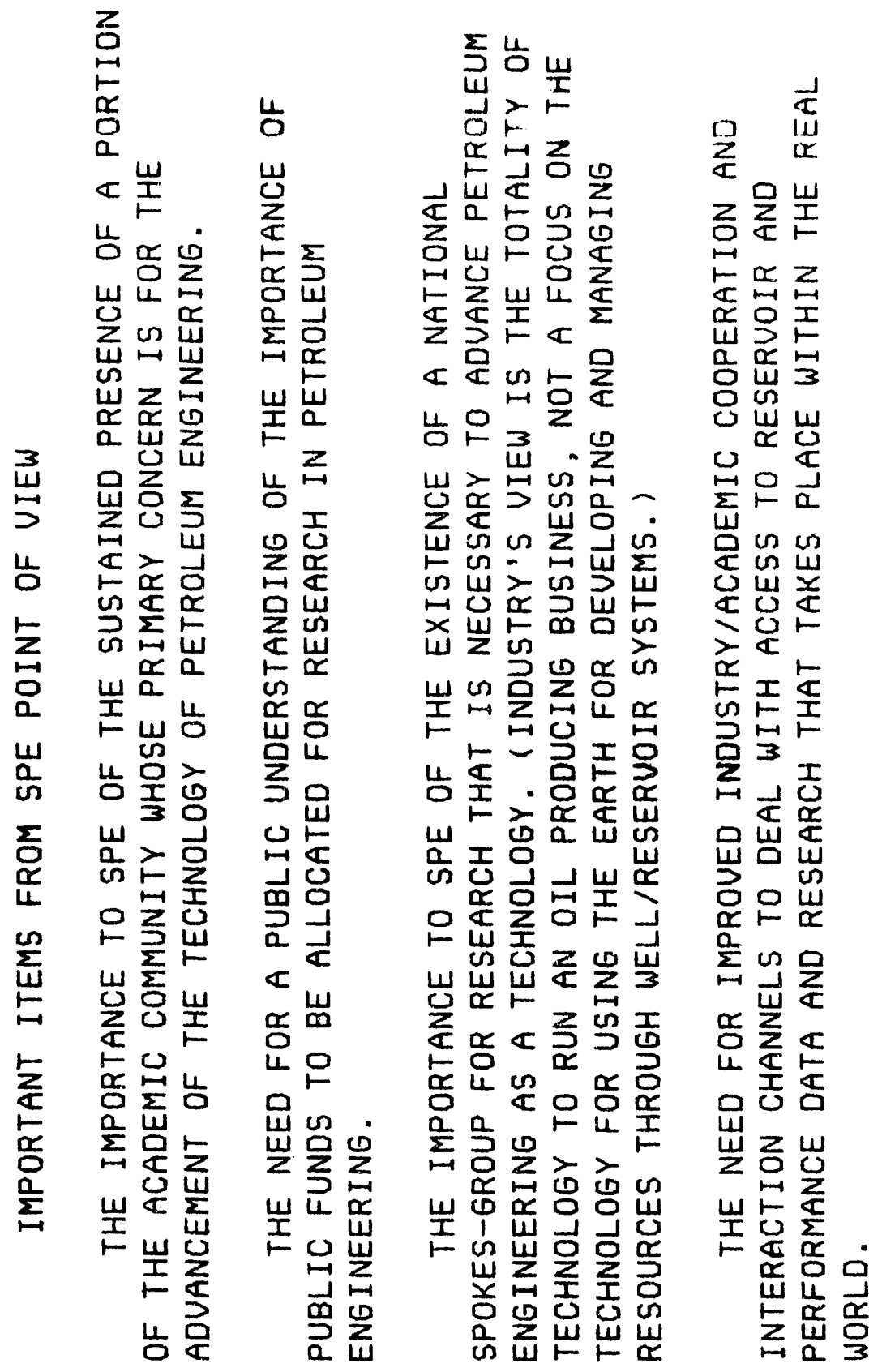




\section{TEXAS A\&M UNIVERSITY \\ DEPARTMENT OF PETROLEUM ENGINEERING \\ COLLEGE STATION TEXAS 77843.3116 \\ 409/845.2241 FAX: 409/845.1397}

November 14, 1989

Dr. Leonard R. Koedertiz

Department Head

Petroleum Engineering Department

University of Missouri

Rolla, MO 65401

Dear Dr. Koedertiz:

I am in the process of scheduling group meetings involving a limited number of faculty and industrial representatives to discuss and revise the Draft Report, A RESEARCH AGENDA FOR ACADEMIC PETROLEUM ENGINEERING PROGRAMS. Specifically, I am scheduling a meeting on Tuesday, January 9, 1990, to consider the issues and needs relative to the area of Logging, Characterization and Evaluation. A faculty member from your institution is invited to be present.

I would like to ask you to designate an appropriate faculty member from your departmeht (or yourself) to participate in this meeting. Please hand this letter, with its enclosures, to whomever you designate. The enclosures include (1) a copy of the draft report, (2) a statement about the logistics for the meeting and the payment of expenses, and (3) a form that asks for information about the designated participant so that I may provide additional information reganding the meeting. I ask that the form be returned promptly.

Revision of material in Chapters 3 and 4 of the draft report will be a particular goal of this meeting. However, I wish to stress that input from the participants to any part of the report will be welcome. I am particularly interested in obtaining strong opinions about any research matter that should be included as a key recommendation in the report.

The participation of your institution in this project will be greatly appreciated.

Sincerely yours,

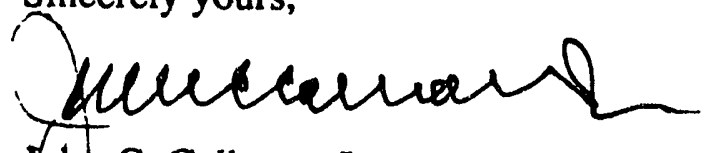

John C. Calhoun, Jr.

Deputy Chancellor for Engineering-Emeritus

JCC:edh

Enclosures 


\section{TEXAS A\&M UNIVERSITY}

DEPARTMENT OF PETROLEUM ENGINEERING

COLLEGE STATION TEXAS 77843-3116

409/845-2241 FAX: 409/845.1307

November 30,1489

MEMORANDUM

T0: $\quad$ Petroleum Engineering Department Heads

FROM: John C. Calnoun, Jr

SUBJECT: $\quad$ Schedule of Meetings IA January To Discuss Research Agenda

I have sent letters to most of you asking that you designate persons to attend group meetings in January at SPE Headquarters to discuss the draft report on the Research Agenda. Inasmuch as my allocation for travel funds is limited, I could not extend invitations to all departments for a 11 groups, so I made the best judgement I could on distribution among institutions.

It occurs to me that some of you may want to have your faculty participate in these discussions even though I cannot pay travel expenses. It also occurs to me that some may be interested in participating for two days instead of one because I have separate meetings scheduled for Mondays and Tuesdays. For these reasons, I give you the entire schedule of meetings, as follows:

January (Tuesday) Logging, Characterization \& Formation Evaluation January 15 (Monday) Reservoir \& We 11 Systems

January 16 (Tuesday) Recovery Processes \& EOR

January 22 (Monday) Drilling \& Completions

January 23 (Tuesday) Production

January 29 (Monday) Environment, Economics \& Related Matters

January 30 (Tuesday) Optimization, Expert Systems \& Data Organization

All meetings will be at SPE Headquarters in Richardson. They will starting at 9:00 a.m. and try to conclude by 4:00 p.m.

If any of your faculty want to participate in meetings other than those for which I have agreed to pay travel, they will de welcome. Please have them notify me ahead of time, indicating the meeting date, and I will see that they receive appropriate background material.

$\mathrm{JCC} / \mathrm{Dp}$ 


\section{GROUP MEETING ATTENDANCE}

January 9, 1990

Robert Desbrandes

Mark Miller

Tarek Ahmed

Paul Willhite

Elmond Claridge
LSU

UT

Montana Tech

KU

U. of Houston

January 15,1990

Lyman Handy

Faruk Civan

John Lee

Robert Lee

Ekwere J. Peters

Aziz Odeh

Donald L. Whitfill

Turgay Ertikin

Daopu Numbere
USC

U. of Oklahoma

TAMU

New Mexico Tech

UT

Consultant

Conoco/Reservoir \& Rec. Forum

Penn State University

University of Missouri-Rolla

January 16.1990

Robert Lee

Fred Stalkup

Don Menzie

Lyman Handy

Don Green
New Mexico Tech

ARCO

OU

USC

University of Kansas

\section{January 22.1990}

Hans C. Juvkam-Wold

Jean-Claude Roegiers

Stefan Miska

Adam T. Bourgoyne, Jr.

J. J. Azar

F. T. Al-Saadoon

Gerald Coulter

Frank J. Schuh

Jack Evers

Claude Cooke

\section{TAMU}

University of Oklahoma

New Mexico Tech

LSU

University of Tulsa

Texas A\&I University

Oryx Energy

Drilling Technology Inc.

University of Wyoming

Self \& Kirk, Bissex 
January 23,1990

F. T. Al-Saadoon

Ted Bourgoyne

7elimir Schmidt

Claude Cooke

Ron Evans

Ovadia Shoham

Carlos F. Alcocer

Philip T. Wall

Lanuary 29. 1990

Bob Bretz

Andrew Wojtanowier

John Lohrenz

Fred Arnold

Bob Chase

January 30.1990

Lloyd Heinze

Dick Startzman

Michael Adewumi

Bob Bretz

Bob Chase

Ed Blick
Texas A\&I University

LSU

Tulsa University

Self \& Kirk, Bissex

University of Oklahoma

Tulsa University

USL

Oryx Energy

New Mexico Tech

LSU

L. Tech. U.

University of Oklahoma

Marietta

University of Missouri-Rolla

TAMU

Penn State

NM Tech

Marietta

$\mathrm{U}$ of $\mathrm{OK}$ 
70

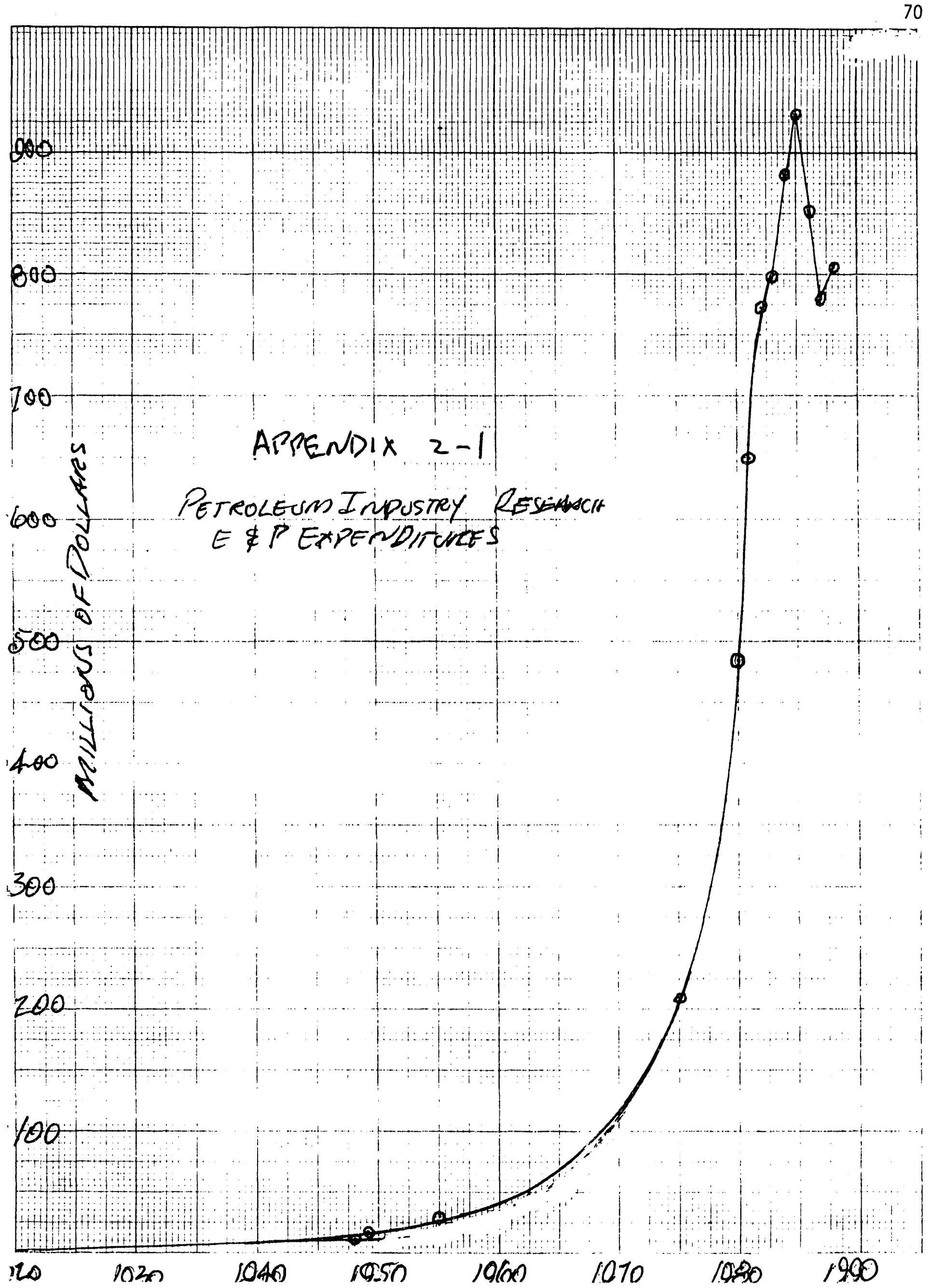


APPENDIX Z-2

PETROLEUM ENGINEERING DOCTORAL DEGREE HISTORY

I. Dearees \& Enrolments By year

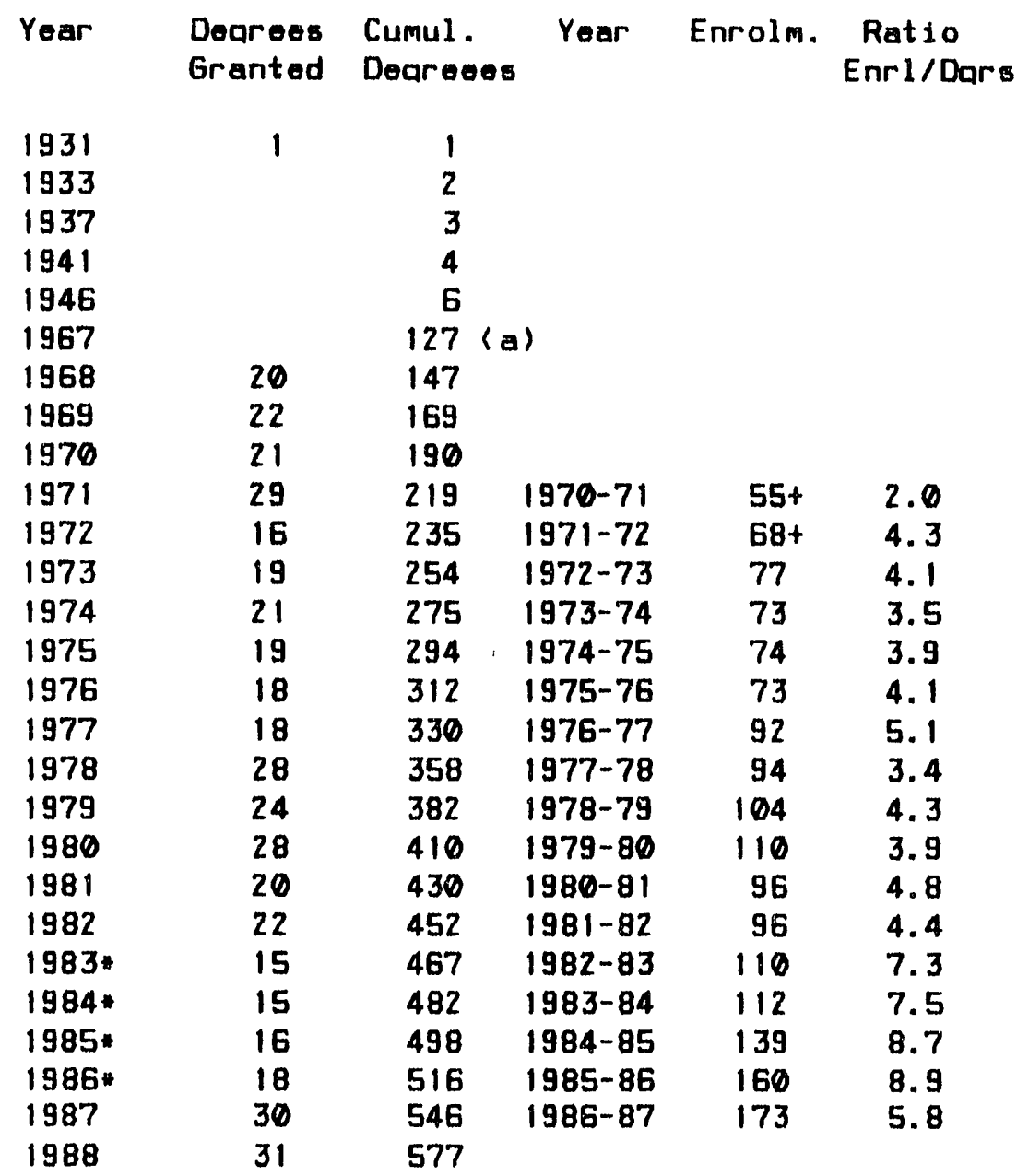

* Does not include degees and enrolments from U. Kansas

(a) this number was comouted by subtracting known dearees from totals aiven 1 ater. 
APPENDIX 2-3

PETROLEUM ENGINEERING RESEARCH PROJECTS, ASEE ENGINEERING EDUCATION, MARCH 1989

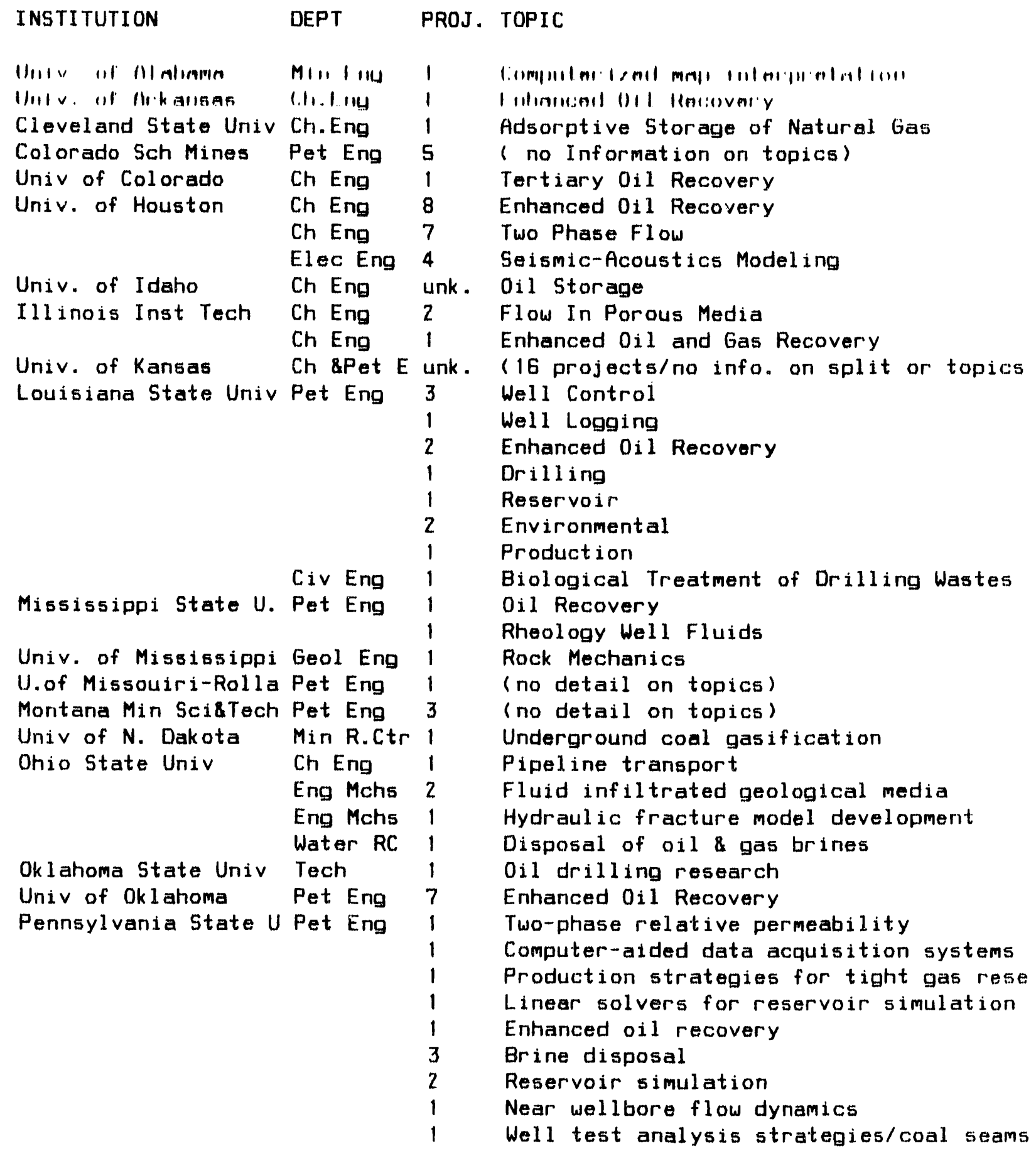




\section{9}

PETROLEUM ENGINEERING RESEARCH PROJECTS, ASEE ENGINEERING EDUCATION, MARCH

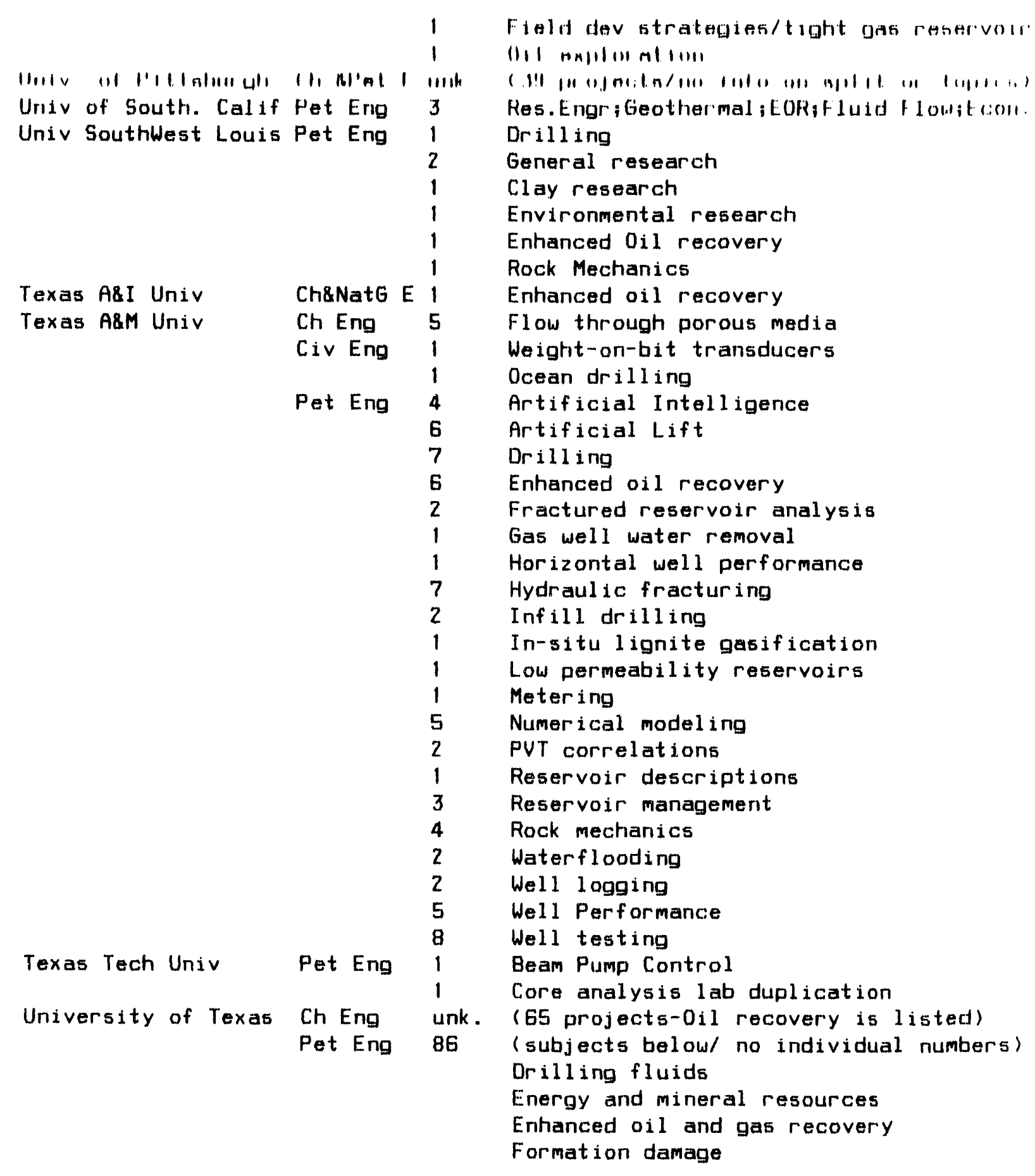


1989

PETROLEUM ENGINEERING RESEARCH PROJECTS, ASEE ENGINEERING EDUCATION, MARCH

\begin{tabular}{|c|c|c|c|}
\hline & & & $\begin{array}{l}\text { Geopressured/geothermal energy } \\
\text { Logging and petrophysics } \\
\text { Mobility control } \\
\text { Multiphase flow in pipes } \\
\text { Pressure transient testing } \\
\text { Production logging } \\
\text { Reservoir characterization } \\
\text { Rock mechanics } \\
\text { Solution mining } \\
\text { Well stimulation }\end{array}$ \\
\hline $\begin{array}{l}\text { Tulane University } \\
\text { University of Tulsa }\end{array}$ & $\begin{array}{l}\text { Ch Eng } \\
\text { Ch Eng } \\
\text { Chem } \\
\text { Pet Eng }\end{array}$ & $\begin{array}{l}1 \\
\text { unk } \\
\text { unk } \\
7\end{array}$ & $\begin{array}{l}\text { Deformable drops through porous media } \\
\text { ( } 18 \text { projects. EOR is a topic) } \\
\text { ( } 4 \text { projects. Drilling fluids is a topic) } \\
\text { (No individual numbers. Topics below) } \\
\text { Drilling } \\
\text { Multiphase fluid flow } \\
\text { Artificial lift }\end{array}$ \\
\hline $\begin{array}{l}\text { University of Utah } \\
\text { Univ of Wyoming }\end{array}$ & $\begin{array}{l}\text { Fuels E } \\
\text { Ch Eng } \\
\text { Pet Eng }\end{array}$ & $\begin{array}{l}1 \\
2 \\
2 \\
3 \\
2 \\
1\end{array}$ & $\begin{array}{l}\text { Tar sands research } \\
\text { Enhanced oil recovery } \\
\text { Drilling technology } \\
\text { Enhanced oil recovery } \\
\text { Multiphase fluid flow } \\
\text { Secondary recovery }\end{array}$ \\
\hline
\end{tabular}


APPENDIX 2-5 RESEARCH SURUEY DATA-JULY, 1989

$\begin{array}{ccc}\text { INSTITUTION } & \text { RESEARCH } & \text { SOURCE } \\ & \text { IN PETR.ENGR } & \end{array}$

COLORADO MINES

UNIU KANSAS

LOUISIANA ST.U.

MISSISSIPI STATE

U.MISSOURI-ROLLA

MARIETTA COLLEGE

MONTANA MIN SCI

NEW MEXICO TECH

U OKLAHOMA

PENNSYLUANIA ST

UNIU PITTSBURGH

U.SO.CALIFORNIA

U.SW.LOUISIANA

STANFORD UNIV

TEXAS A\&M UNIV

TEXAS TECH UNIU

U.TEXAS AUSTIN

UNIU TULSA

U. WYOMING

WEST VIRGINIA U

$\begin{array}{rr}68308 & \text { ASEE } \\ 486000 & \text { INQUIRY } \\ 2250000 & \text { ASEE } \\ 6106 & \text { ASEE } \\ 20728 & \text { ASEE } \\ 7400 & \text { INQUIRY } \\ 44616 & \text { ASEE } \\ 2328000 & \text { INQUIRY } \\ 432355 & \text { ASEE } \\ 212000 & \text { ASEE } \\ 70000 & \text { INQUIRY } \\ 117084 & \text { ASEE } \\ 80000 & \text { ASEE } \\ 2210728 & \text { INQUIRY } \\ 1800000 & \text { ASEE } \\ 181000 & \text { ASEE } \\ 3769000 & \text { ASEE } \\ 1203738 & \text { ASEE } \\ 90000 & \text { ASEE } \\ 120000 & \text { INQUIRY }\end{array}$

15497063

13561466

1935597

NO RESEARCH REPORTED

U. ALABAMA

ASEE

U. ALASKA

ASEE

U.CALIFORNIA

ASEE

LOUISIANA TECH U

ASEE

MICHIGAN TECH

ASEE

OHIO STATE UNIU

ASEE

TULANE UNIV

ASEE

TO BE HEARD FROM

U. HOUSTON

TEXAS A\&I UNIV 


\section{Summary of Data}

The approximate tovals are given from the data reported by the 230 Engineering and Technical College and Affiliate Members of ASEE who responded to the questionnaire. The respondents include 220 American and 10 Canadian universities.

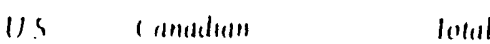

2a. Number of Faculty, 1987-88

Combined tocal of full-time engineering teaching and research

faculty in the three professorial ranks

$20.500 \quad 1.252$

21,752

Combined total of full-time.

part-time, and other faculty

$27,906 \quad 1,542$

29,448

$2 b$ and 5. Enrollment and Degrees Granted

Enrollments in all engineering degree programs, fall 1988

Undergraduate

Total master's

Part-ime master's

Professional

Doctoral

$\begin{array}{rr}393,029 & 21,005 \\ 79,997 & 2,659 \\ 29,975 & 888 \\ 988 & 318 \\ 30,983 & 1,169\end{array}$

414,034

82,656

30,863

1,306

32,152

Degrees granted in all degree

programs, 1987-88

Undergraduate

Master's

Professional

Doctoral

$\begin{array}{rr}70,643 & 3,800 \\ 25.494 & 750 \\ 628 & 30 \\ 4,538 & 177\end{array}$

74,443

26,244

658

4,715

8. Total Personnel Engaged in Separately

Budgeted Research, 1987-88

Professorial

Other faculty

Postdoctoral fellows

Graduate students

Undergraduate students

Nonteaching research personnel

Total

\begin{tabular}{rr}
13,050 & 66 \\
962 & - \\
1,492 & 16 \\
35,886 & 137 \\
10.053 & 12 \\
4,430 & 18 \\
\hline 65,873 &
\end{tabular}

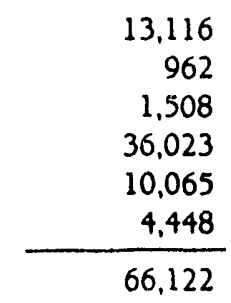

9a. Expenditures for a Total of 36,191 (Tables 9b and c) Research Projects by Source of Support, 1987-88

Federal government

Canadian national government

State and local govemment

Canadian provincial government

Other governments.

Private, nonprofit organizations

Business and indusiry

Other

Total*

$$
\begin{aligned}
& 1,294,125,291 \\
& \text { - } \\
& 209,912,477 \\
& 38, \overline{10}, 973 \\
& 16,504,72 \\
& \text { 1,556,263 } \\
& 2,362,207 \\
& 91,714,330 \\
& 280,506,204 \\
& 122,673 \\
& 4,616,038 \\
& 42,300,764 \\
& 3,300,254 \\
& \$ 1,965,996,430 \quad \$ 66,719,871
\end{aligned}
$$

$\begin{array}{r}1,294,125,291 \\ 38,410,973 \\ 209,912,477 \\ 16,504,726 \\ 3,918,470 \\ 92,936,003 \\ 285,122,242 \\ 45,601,018 \\ \hline \$ 2,032,716,301\end{array}$

- Because some schools did not break down total expendirures, the totals do not equal the sum of all categories.

Note: Five more institutions responded to the 1987-88 survey than the year before-two U.S. schools and three Canadian.
Góvernment \&

Industry Members of ASEE's Engineering Research Council in

- Government Members and Their Representatives

Air Force Office of Scientific Research: Colonel J. Bialecki

National Aeronautics and Space Administration: F. Owens

National Institute of Standards and Technology: G. Sinnott

\section{Industry Members and Their Representatives}

Allied-Signal, Incorporated: B. Robbins Alcoa: M. Rawlinson

Bell Communications Research: B. F. Blair

Control Data Corporation: J.V. Boettcher

Digital Equipment Corporation: D.A. Rogers

General Electric Company: R.M. Anderson

GTE Corporation: F. Riley

Honeywell, Incorporated: C.A. Rhodes

Intel Corporation: J. Carruthers

Newport News Shipbuilding: W.B.

Weaver

Siemens Aktiengesellschaft: $\mathrm{K} . \mathrm{H}$.

Zaininger

Technovate, Incorporated: C. McMahan Westinghouse: J.B. Kruger 
APPENDIX 2-7

\section{RESERVOIR AND RECOVERY FORUM \\ Apr11 13, 1989}

The Reservolr and Recovery Forum was uryanized at a meeting hald in Mouston on January 26, 1989. L'the purposes and objectives of the Forum are to advance the state-of-the-art in reservolr and recuvely research by providing a forum for:

1. The presentation of proposals for industry reservolr-rolated projecta

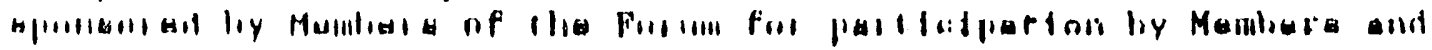

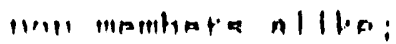

2. exploring the levels of lulutust of Membets in potential reservoli related probleins to ald in developlub future industry oponsored projects;

3. advising academic orgarlizacions and other reservoir research oriented groups of the needs and intoroata of Members.

Members of hise organization are Amuco Production Company, Arco oll and Gas Company, Breragne, British Pelruleun Cu., Chevion oil Field Research Company, Conoco Inc., fif Aquitaine, Exxun Pruduction Research Company, Japan Nationa1 Oil Corp.,Kerr-Mrciee Corporation, Meclulas O11 Company, Mobl1 Research and Development Corporation, OXY USA INC., Phill1ps Petrolewn Curmany, Shell Development Company, Sun Explutaliun and Froduction Company, Texaco and UNOCAL. Membership is open lo ally ludividual, firm, partnership, association or corporation mellig the requirements of the Forum charter.

This Forum is urginized and expects to operate in a mannar similar to the Drilling Enginecring Associaliull (DEA), Completions Engineering Association (CEA) and the Petroleun Envirurulental Research Forum (PERF).

An important point about this organization is that it does not financially suppore jolnt. Industry research projucls, but serves as the focal point for Member companies ro hear and acl un puopusuls. Both interected Members and non-members acl indepericlesilly lu ulgamize the profects once the proposals have been presented. Any propusal lo lu presented to the Forum by a non-member at a quarterly meeting must be sponsored by ullit of the Members. The Forum Members are intcrested in hearing of potential projects for conslderation to be presented at their quarterly meetings.

Orflcers for the Reservoir and Recuvery Forwn, to serve a two year term, are: Donald L. Whitfill, Conoco Inc., Chalrman; Lori G. Johnson, Shell Development Co., Vice Chalsmus: J. R. Barnett, Arpoco Froduction Co., Secretary/Treasurcr; and Dlrecturs R, Ehrlich, Chevron OLl Fleld Research Co.; A. K. Hagedorn, Exxon Producclon Research Co.; Jim EksLrand, OXY USA INC.; and Ford Griggs, lhillips Petroloum Co.

FOR FURTIER INFORMATTON CONTACT:

Dorlald L. Whitfil1

Cha I rman

Conoco Inc

P. O. Box 126/

ronca City, OK 7/,603

(405) $767-3975$
Lori G. Joshusium

Vice Chairman

Slic11 Development Co.

P. O. Box 481

Houscon, TX 77001

(713) $663-2702$
J. R. Barnett

Secretary/Trcasurer

Amoco Production Co.

P. O. Box 3385

Tulsa, OK 74102

$9 1 8 \longdiv { 6 6 0 \cdot 3 1 0 3 }$ 
APPENDIX 2-8

\title{
COMPLETION ENGINEERING ASSOCIATION CHARTER
}

\author{
Article I \\ (Name, Purposes and Objectives)
}

The name of this organization is the Completion Fngineering Association.

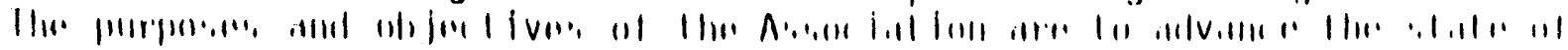

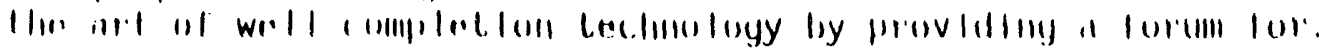

1. The oresentation of proposals for completion-related projects sponsored by Members of the Association for participation by Members and non-members alike.

2. Exploring the levels of interest of Members in potential completion related problems to aid in developing future industry sponsored projects.

3. Advising academic organizations and other industry groups of the needs and interests of Members.

4. This organization is not organized for profit or organized to engage in an activity ordinarily carried on for profit. No part of any net earnings of this organization shall inure to the benefit of, or be distributed to, its members, trustees, officers or other private persons; provided however, that the Association shall be authorized and empowered to reimburse its members, trustees, officers or other private persons for reasonable expenses incurred by these persons in furtherance of the purpose for which the Association was organized.

\section{Article II \\ (Membership)}

1. MEMBER: Any individual, firm, partnership, association or corporation engaged in the production of oil and gas may become a Member of the Association by (a) paying the then current Initial Fee, (b) accepting this Charter, (c) appointing a Representative and an Alternate Representative who shall have the power and authority to represent such Member in all matters relating to the Association and (d) paying a pro rata share of the routine expenses of the Association as determined by the Advisory Committee. Any such Representative or Alternate Representative may be replaced at any time by the particular Member. Memberships may not be transferred. A Membership shall continue so long as the Member complies with the terms and provisions hereto and continues to pay its share of fees and assessments as provided for herein. 
2. INITIAL FEE: Members joining the Association on or before October 6 , 1988, shall pay one time, an Initial Fee of Five Hundred Dollars $(\$ 500.00)$. After October 6, 1988, the one time Initial Fee for new Members joining the Association shall be established annually by the Advisory Committee.

\author{
Ari.is.lis 111
}

(Uryanization)

1. OFFICERS: The officers of the Association shall consist of a Chairman, Vice-Chairman, and Secretary-Treasurer. Candidates shall be a Representative or an Alternate Representative nominated by a Nominating Committee of at least three (3) Member representatives selected by the Chairman at least sixty (60) days prior to the Annual Meeting. Additional candidates may be nominated from the floor. Officers shall be elected by majority vote of the Members present and voting at the Annual Meeting and shall take office on the first day of the following calendar year. Their term of office shall be for two (2) years or until the next set of officers takes office, unless earlier removed for cause by vote representing at least eighty percent ( $80 \%$ ) of all of the Members.

a. The Chairman shall preside at and conduct meetings of the Association and appoint such task forces, special and standing committees as he deems necessary and advisable to carry out the purposes and objectives of the Association. The Chairman may appoint individuals to such task forces or committees or he may invite Members to furnish individuals to serve on such task forces and committees.

b. The Vice-Chairman shall act in the absence of the Chairman.

c. The Secretary-Treasurer shall prepare and distribute a meeting agenda prior to each meeting of the Association or any committee or task force, maintain the minutes, records, and files of the Association, pay routine expenses as authorized by the Advisory Committee by checks drawn on the account of the Association, file financial and tax forms with appropriate governmental agencies as needed, and furnish at least an annual accounting statement to the Membership

2. CHAPTERS: A chapter of the Association may be formed with the approval of the Membership. The approved resolution creating the chapter shall constitute the Charter of the chapter and define the chapter and its scope. No chapter shall have the power to obligate the Association. The Charter of the chapter may be modified or revoked by the Membership.

a. The chapter charter shall include provision for a chapter Chairman, whose responsibilities and authority are as follows: 
1. Schedule and conduct chapter meetings, and otherwise direct chapter activities.

2. Represent the chapter with the Association

3. Approve chapter expenditures within the currently approved annual budget and chapter reserve

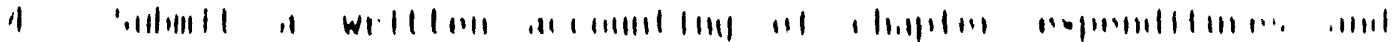
financial status to the Association Chairman and SecretaryTreasurer, along with a proposed annual budget and chapter reserve for the next annual period. These shall be submitted two weeks prior to the Association Annual meeting.

b. Procedures for the election of the Chapter Chairman and any other chapter officers shall be included in the chapter charter. The Association Chairman shall have the power to appoint a temporary Chapter Chairman unless an acting Chapter Chairman is otherwise provided.

c. Each Association Member may name one Chapter Representative and one Alternate Chapter Representative for each active Association chapter. These Representatives may be either different or the same as the Association representatives.

3. ADVISORY COMMITTEE: In addition to the various task force(s) and committee(s) which the Chairman is authorized to appoint, there shall be an Advisory Committee. No Member shall have more than one representative on the Advisory Committee.

a. Advisory Committee Members shall be as follows:

1. One shall be the current Chairman of the Association who shall also be the Chairman of the Advisory Committee.

2. One shall be the current Vice-Chairman of the Association who shall also be Vice-Chairman of the Advisory Committee.

3. One shall be the current Secretary-Treasurer of the Association who shall ilso be the Secretary of the Advisory Committee.

4. Four (4) shall be elected from Member or Alternate Representatives by the Membership. The tenure of office of these committee members shall be concurrent with the Association officers unless earlier removed by a vote representing at least eighty percent ( $80 \%$ ) of all the Members.

5. Each current Chapter Chairman. 
b. Duties of the Advisory Committee shall include the following:

1. Provide advice and consultation to the Chairman with respect to the performance of his duties in meeting the purposes and objectives of the Association.

2. Establish guidelines and procedures for the submittal of programs and/or projects to be considered by the Association.

3. Establish the current Initial Fee at the first meeting of each calendar year and administer the expenditure of funds as set forth in Article VI of the Charter. Such Initial Fee shall not exceed an amount approved by a vote of two-thirds (2/3) of the voting Members of the Association.

4. Elect interim replacements for officers of the Association or Members of the Advisory Committee who resign or are removed prior to the completion of their term of office. Such interim replacements shall hold office until the next regularly elected officers take office.

5. Such other duties as may be authorized by the Association.

c. Six or more members of the Advisory Committee shall constitute a quorum. All actions of the Advisory Committee shall be approved by the votes of a majority of members present at a meeting at which a quorum is obtained; or in the absence of a quorum, by the votes of a majority of all the members of the Advisory Committee.

d. The Advisory Committee may act, within its scope of authority, without a convened meeting by telephone, telex, or letter.

\author{
Article IV \\ (Rights of Members)
}

1. The right of each Member of the Association to act individually and independently concerning any matter within the scope of the Association's activities shall not be impaired or restricted by the action of the Association. Each member shall have the right individually to take such action as it deems advisable, whether or not such aciion conflicts with the action of the Association. Such individual action shall not purport to represent action of the Association.

2. Association business will be conducted on a non-confidential basis.

3. At reasonable times upon reasonable notice, each Member shall have access to and the right to inspect for any proper purpose the books and records of the Association and to make copies or extracts thereof. 
4. Any Member may withdraw from the Association by giving notice in writing to the current chairman of the Association, and such party shall not be liable for any costs or expenses incurred subsequent to receipt of such notice of withdrawal by the Secretary-Treasurer. However, such party shall continue to be liable for its proportionate part of all costs and expenses incurred or committed to prior to Association receipt of notice of withdrawal. Such party shall not be entitled to a refund of all or any portion of the initial for or any annual tee.

Article $V$

(Conduct of Business)

1. Except as otherwise specifically provided herein, all matters coming before the Association shall be decided by the vote of a majority of the total voting Members present.

2. Prior to the conduct of business at a meeting of the Association, a quorum of at least fifty percent (50\%) of the Members must be present, but a lesser number may adjourn the meeting. Members present at a duly called or held meeting at which a quorum is present may continue to do business until adjournment notwithstanding the departure of Members leaving less than a quorum. Each Member present shall be entitled to one vote. A Member may issue a written power of proxy to one of its employees to exercise in person. No other form of proxy shall be permitted.

a. If a quorum is not present, the attending Members at a regular Association meeting may direct that a mail ballot be conducted on a proposal of Association business.

3. By direction of the Chairman, the Advisory Committee, or as provided in Article V.2.a, a vote of all of the Members may be taken by mail or telex but requests for such mail or telex votes must be accompanied by as much notice and supporting information as the time and circumstances will reasonably permit. If a majority of all of the Members approve any matter by vote taken by mail or telex, the matter shall be considered as approved the same as if voted on in a meeting of the Association. The SecretaryTreasurer shall promptly advise the Members of the results of all such mail or telex votes and any action taken pursuant thereto.

4. This Charter may be amended by affirmative vote of at least seventyfive percent (75\%) of all of the Members.

5. The Association shall not itself participate in joint industry projects. Each Member who participates in a joint industry project presentëd 
by the Association hereby agrens to indemnify, dofond, and hold hormlla, ,

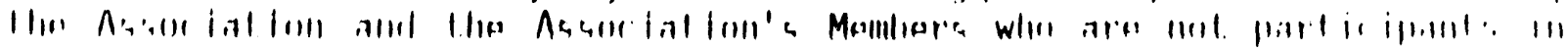
such project of and from any liability of any kind whatsoever in any way resulting from any contract, agreement, understanding, or dealing in connection with such projects, which indemnity and obligations shall survive the withdrawal or expulsion of the Member from the Association.

\section{Article VI}

(Funding)

1. Funding will be the responsibility of the Advisory Committee through an annual budgeting process which anticipates routine and incidental administrative expenses. Such funds shall be raised by equal assessments to the Members.

2. The annual budget for the coming year shall be presented to the Membership for approval by majority vote at the Annual Meeting. The budget will include anticipated expenditures and revenues, and will state the proposed Annual Fee.

a. The Annual Budget shall include provision for chapter budgets and reserves for Membership approval. Once approved, these funds shall be transferred to the Chapter, and may be disbursed under the authority of the Chapter Chairman.

3. If additional funds are required by the Association during the year due to increased expenditures, needs and/or a decrease in the membership count, an updated budget will be submitted for approval by a majority vote of the Members. Such approved funding not covered by the Annual Fee may be acquired by assessment of the Members. The Association or its officers are prohibited from making commitments that would exceed the approved budget and reserves. The Annual Fee shall be in addition to the one time Initial Fee.

4. No member is required to pay any annual fee or assessment which has not been approved by a majority vote of all members.

5. If additional funds are required by a chapter during the year, these may be approved by the Advisory Committee, but in no event exceeding the authority in paragraph 3 of this Article. The Advisory Committee shall advise the Membership of such action at the next Regular Association meeting.

\section{Article VII}

(Meetings)

The Association will meet as often as deemed necessary by the Chairman or Advisory Committee to carry out the purposes and objectives of the Association. In any event, however, no less than one (1) meeting shall be held in any calendar year, the Annual Meeting. Written notice of any 
meeting will be given at least fourteen (14) days prior to such meeting unless a shorter notice is unavoidable. All notices shall contain the reason for the meeting, the date, place, and time it is to br held, and an

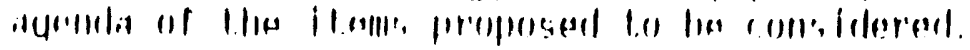

Article VIII

(Payment Delinquency)

In the event a Member has not paid any assessment within ninety (90) days after receipt of billing from the Secretary-Treasurer, the account of such Member shall be considered delinquent. At the expiration of ninety (90) days after receipt of billing from the Secretary-Treasurer, the SecretaryTreasurer shall mail notice of delinquency to such Member by Registered or Certified Mail. In the event the Secretary-Treasurer has not received payment within thirty (30) days after the mailing of notice of delinquency, such Member shall be dropped automatically from the Membership as of the end of such thirty (30) day period. Such Member, however, shall continue to be liable for its obligations accrued prior to such termination of its Membership.

\section{Article IX \\ (Dissolution)}

1. This Association may be dissolved upon the affirmative vote of at least seventy-five percent ( $75 \%$ ) of all the Members.

2. Upon the dissolution of the Association, the Advisory Committee shall, after paying or making provision for the payment of all of the liabilities of the Association, dispose of all of the assets of the Association to such organization or organizations organized and operated exclusively for charitable, educational, religious, or scientific purposes as shall at the time qualify as an exempt organization or organizations under Section $501(c)(3)$ of the Internal Revenue Code of 1954 (or the corresponding provision of any future United States Internal Revenue Law), as the Advisory Committee shall determine. Any such assets not so disposed of shall be disposed of by the appropriate court of the county in which the principal office of the Association is then located, exclusively for such purposes or to such organization or organizations, as said court shall determine, which are organized and operated exclusively for such purposes. 
Article $x$

(Effective Date)

The Effective Date of this Charter shall be October 6, 1988.

This Charter is hereby approved and accepted this 19

MEMBERS:

Signature

Company 


\section{APPENDIX 4-1}

LISTING OF SPE FORUM SERIES TOPICS $1979-89$

I. Drilling

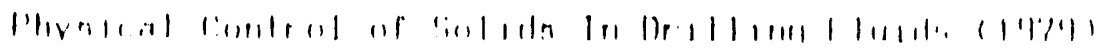

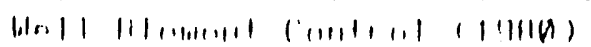

Mecharics of Drilling at the Bit (|YG|)

Directional Orilling (1983)

Measurement While Drilling (1984)

Well Blowout Control (1985)

Application of Simulators and Computers to the Drilling Process (1986).

Horizontal Drilling (1987)

Application of Rock Mechanics to Orilling and Comoletion Practices (1988)

\section{Reservoir Definition}

Properties of Saturated Rocks of Interest To Petrophysicists and Geophysicists (1979)

Reservair Definition (1983)

Open Hole Logaing (1985)

Improved Resérvoir Description (1987)

\section{Reservoir and Well Performance}

Earth Stresses- Their Relationship to Petroleum Production (1980)

Residual 0 il Saturation Determination (1980)

Relative Permeability and Wettability (1981)

In-Situ Combustion (1982)

Analysis and Production of Miscible Flood Performance (1984)

Naturally Fractured Reservoirs (1985)

Design and Interpretation of Pllots (1985)

Use of Steam for Enhanced Oil Recovery (1985)

Well Testing (1986)

Reservoir Mechanics of Chemical Flooding (1986)

The Use of Reservoir Simulators (1986)

Wet tability and Relative Permeability (1987)

Monitoring Performance of Full Scale Carbon Dioxide Projects (1987)

Reservoir Conformance Enhancement-Polymers: Gels and Foams (1988)

Naturally Fractured Reservoirs (1989)

Advances In Reservoir Management and Field Applications (1989)

Reservoir Engineering and Completion Aspects of Hor.ionti1) Wells (1989) 
IV. Completions and Production

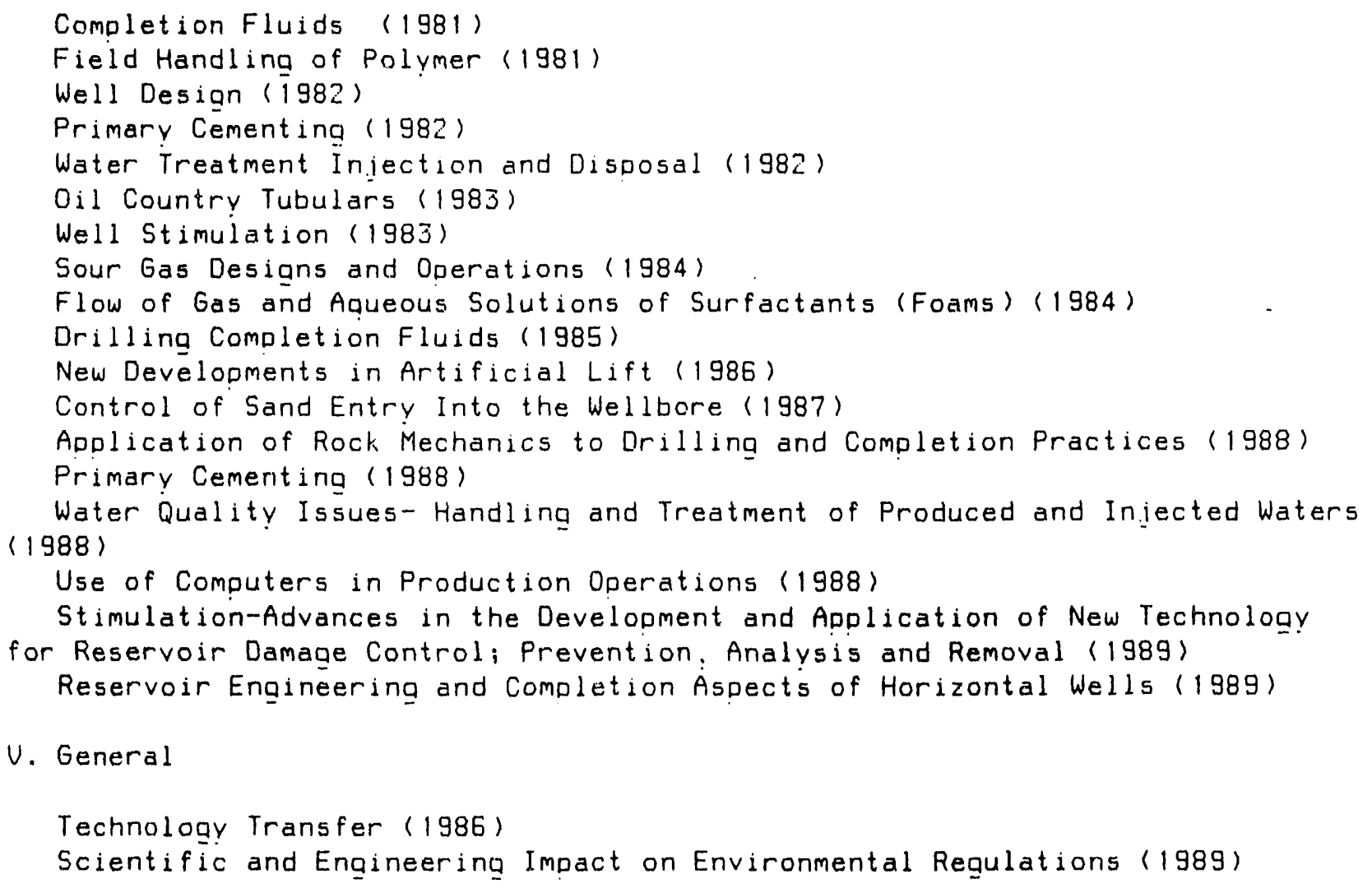




\section{TEXAS A\&M UNIVERSITY \\ DEPARTMENT OF PETROLEUM ENGINEERING \\ COLLEGE STATION TEXAS $77843-3116$ \\ 409/845-2241}

May 5, 1989

TO:

Faculty Members of U. S. Petroleum Engineering Programs

SUBJECT: Survey of Important Research Topics and Issues The petroleum engineering academic community has an obligation to advise others
as to the status of the technology of which it claims to be the academic guardian.
Faculty members normally discharge this obligation through
programs, publications, programs, publications, continuing education activigation through their graduate Survey Form which I am sending you with this collective thinking on this subject from all those letter is an attempt to assess the the SPE Schools Booklet. The survey is" part of an effort to formulate a petroleum engineering research
agenda that can be used by the petroleum engineering departments, as a group, in
presenting the importance of their activities and needs before
funding agencies, industry and the needed to round out instry and the public at large. Such a refore government been expressed, in recent viewpoints about petroleum technology research agenda is that the petroleum recent times, by geoscientists and olher engineers. Nown case.

No individual who responds to this survey will be quoted. If you give your name, it sent to every department. and issues that may form the compiled results will also be used to identify topics propose to convene.

Your early response will be appreciated.

JCC:gh

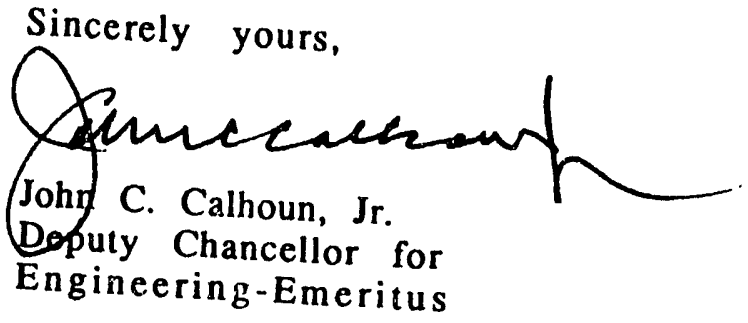

Enclosure: Survey Form 
RETURN THIS COMPLETED SURUEY FORM TO

JOHN C. CALHOUN, JR

PETROLEUM ENG INEERING DEPARTMENT

TEXAS A\&M UNIUERSITY

COLLEGE STATION:TEXAS: 77843

PETROLEUM ENGINEERING FACULTY SURUEY OF IMPORTANT RESEARCH TOPICS AND ISSUES

A. What do you consider to be the most important technical problems that exist relative to the improvement of petroleum production?

1 .

2.

3.

4 .

A. Please qive a brief description of the three most important research topics that you think should be of concern to the petroleum engineering faculties of the nation.

1 .

2 .

3.

B. Describe briefly any general problems you identify (e.q. quality of graduate students: Low level of funding: lack of equipment, etc) that restrict the ability of the petroleum engineering faculties to address the most important research topics. 
C. Do you feel that there is a critical need for petroleum engineering faculties to have better access to field data for conducting their research programs? Yes - No - If yes : explain

D. Do you feel that there is a need for petroleum engineering faculties to work cooperatively among institutions on general research programs? Yes No - If yes : explain

E. In many academic areas there are larqe facilities, of a "national" nature, such as cyclotrons, computers, etc: that are available to the faculties from all universities for conducting research. Do you think that any such facilities of a "national" character are needed by the petroleum enqineering faculties in order to address the important research problems that exist.? Yes No - If yes: please decribe briefly what facilities you may have in mind.

F. In your own area(s) of research: is the total level of activity of all the petroleum engineering faculties of the nation as great as it should be, and if not: how much of an increase in activity is needed? 1 . Area

Level is OK - The increase needed is

2.Area

Level is OK - The increase needed is

3. Area

Level is OK - The increase needed is 


\section{APPENDIX 4-3}

Summary of $8 / 18 / 189$

PETROLEUM ENGINEERING FACULTY SURUEY OF IMPORTANT RESEARCH TOPICS AND ISSUES

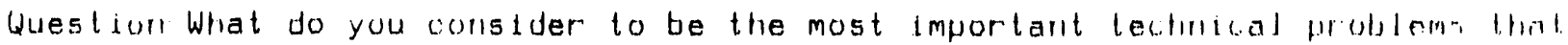
exist relative to the improvement of petroleum production?

1. RESERUOIR CHARACTERIZATION AND HETEROGENEITY

a. Reservoir characterization (4)

b. Reservoir description (2)

c. Reservoir definition

d. Reservoir heterogeneities

e. Characterizing reservoir heterogeneities (2)

f. Understanding reservoir heterogeneity

g. Understanding and exploiting reservoir heterogeneity

h. Ability to adequately define and account for heterogeneities in the reservoir (fractals are helping)

i. Better formation evaluation methods

J. Measure petrophysical properties between wells

$k$. Not being able to describe the inter-well reservoir

1. Developing better measurement techniques to detect reservoir properties

$m$. Well log evaluation in complex enviroments and cased holes

n. Collecting core and $l o g$ data on horizontal wells

o. Obtainment of improved reservoir data

p. To bring down the price of high resolution seismic and multiple sensor well log data

Q. Understanding geometry (large and small scale) of reervoirs

2. DRILLING

a. Horizontal drilling

b. Horizontal drilling- reduction of costs

c. Reduce drilling costs

d. Cheaper drilling methods

e. Better and less expensive drilling techniques. How to access more of the reservoir.

f. Inadequate drilling techniques

g. High cost of drilling and completions

h. Improvements in MWD

1. Logging, casing and cementing horizontal wells

j. Improved cement placement techniques and procedures

$k$. Deep water drilling

1. Drilling deeper off-shore wells 
m. Capabilities to drill in deep off-shore environments

$n$. Environmental aspects of drilling

\section{COMPLETION TECHNOLOGY}

a. Formation damage

b. Formation damage during drilling/completion operations

c. Reduction or elimination of formation damage in drilling and completions in mature reservoirs

d. Improved drilling and well completion technologies for vertical and horizontal wellbores which minimize formation damage and which will lead to a more thorough understanding of stimulation processes.

e. Better methods in identifying fracture orientations in gas and oil reservoirs

f.Better design for non-homogeneous reservoir fracturing

g. Better understanding of the role of solid (rock) mechanics in petroleum exploitation

4. PRODUCTION OPERATIONS

a. Methods to improve production for older wells

b. Maintainance of stripper well production

c. Artificial lift improvements

d. Artificial lift for horizontal wells

e. Improved reliability and broader use of computers in field operations

$f$. Developing software for production optimization workstations

g. Understanding multi-phase flow behavior, especially in deviated wells

h. Multiphas flow metering

i. Corrosion

j. Sour gas design

k. Improved lightning protection for field facilities

1. Lack of understanding of fundamentals by operators, etc

$m$. Integration of production engineering with reservoir management

$n$. How to avoid the well damage by hot fluids, sanding,etc

o. Quality control of field operations

p. Off shore production in deep water

q. Capabilities to produce in deep offshore environments

$r$. Environmental aspects of production

5. Low efficiency of production

5. RESERUOIR

a. Integration of engineering and geolog: in developing and adding to reserves in known producing fields

b. Better geoscience understanding of petroleum reservoir systems 
c. Better understanding of the effect of reservoir heterogeneity on oil recovery process performance

d. Reservoir characte lzation and multiphase flow in heterogeneous, natural fractured systems

e. Fundamental behavior of rock-fluid systems

$f$. Multi-phase flow measurements

9. Developing and/or defining the proper relative permeability relationships

$h$. Determine the real flow channels which exist in a reservoir

1. Wettability-determining the true ceservoir wettability and its effect on production

j. Improving the application of reservoir models

$k$. Better techniques to incorporate correctly the physics in reservoir simulators

1. Inability to scale from lab to field

m. Methods to improve vertical sweep

n. Improved volumetric sweep efficiencies (not microscopic displacement)

0 . Poor sweep efficlency in secondary and tertiary recovery

p. Development of novel mobility control and mobilization agents

a. Reservoir pressure maintainence-conservation of reservoir energy for

fluid production

$r$. Developing reservoir engineering procedures for horizontal holes

6.OIL RECOVERY AND EOR

a. Removal of residual oil

b. Reducing residual oil saturation

c. Increase recovery of oil

d. Low recovery of resource base

e. Not being able to recover $100 \%$ of initial 011 in place

f. Saturation distribution after primary depletion

g. Cost of recovering residual or by-passed oil in existing reservoirs

h. Heavy oil

1. Recovery of very low gravity crude oil

j. Forecast accurately recovery rates from assisted recovery operations

$k$. New process development

1. Improved EOR methods

$m$. New EOR processes that build on geoscience understanding, rock mechanics and behavior of rock-fluid systems

$n$. Find a general EOR method that actually works

0 . Reducing the cost of EOR Methods

$p$. Economic and efficient enhanced oil and gas recovery

q. Enhanced oil recovery/general reservoir engineering

$r$. More accurate quantitative predictions of EOR process performance at field scale

5. Improved mobility control for EOR in non-homogeneous reservoirs 
t. How to reduce the tendency of the injected agents to override the (3il

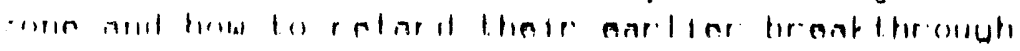

u. Surfactant systems matching a large variety of reservoir coridition,

$v$. Improved stimulation metiods for low permeability formations

\section{GENERAL}

a. Public education on the need for additional exploration and development in the US

b. Technology transfer-applying what we know

c. Technology transfer

d. Present straight forward solutions to practical problems

e. Organization of existing technical data

$f$. Cooperation of specialties among existing universities

g. Time available

h. More economical exploration methods

1. More emphasis on improved economics

j. Improved transportation methods to improve the overall economics

$k$. Better understanding of error analysis and risk analysis in petroleun engineering generally 
APPENDIX 4-4

Summary of $8 / 18 / 89$

PETROLEUM ENGINEERING FACULTY SURUEY OF IMPORTANT RESEARCH TOPICS AND ISSUES

Question-Please give a brief description of the three most important research

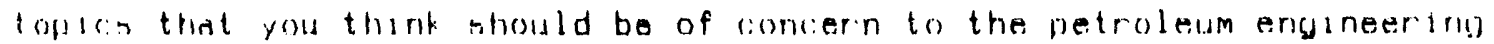

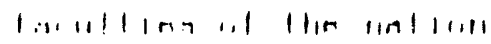

1. RESERUCIR CHARACTERIZATION, HETEROGENEITY \& FORMATION EUALUATION

a. Reservoir characterization and description

b. Reservoir characterization: This topic includes the correct physical description of the reservoir. Included are permeability distribution, layering, communication, etc.

c. Reservoir characterization at all scales for all operations

d. Reservoir characterization- how much is needed for various types of reservoir engineering problems

e. Reservoir characterization- reliability of various techniques

f. Geosciences/reservoir characterization to improve understanding of reservoir systems and the effectiveness of displacement processes in heterogeneous systems

9. Reservoir definition, well tests, tracers, logging, monitoring techniques

$h$. New ways to measure and characterize heterogeneity, including physical instrumentation and mathematical models

1. Reservoir heterogeneity- how to detect relevant scales of variability in both the near well bore region and in the inter well region. How to represent the variability in a tractable way for 011 recovery performance predictions.

j. Measuring and using directional permeability, 1.e. the different permeabilities in the various horizontal directions as well as vertical.

$k$. Develop new and improved wellbore diagnostic procedures and try to measure rock properties, in-situ stress conditions, and stimulation quality in a cost effective manner.

1. Development of inexpensive logging techniques to be used to characterize fracture orientation and aperture (?) opening in mature low pressure reservoirs

$m$. More reliable formation evaluation techniques through casing are needed. Near term exploration will largely consist of finding by-passed oll and gas formations in existing wells.

$n$. Formation Evaluation- More emphasis should be placed on formation evaluation since this data is used to evaluate and predict the performance of a reservoir. Specific emphasis should be placed on geologic interpretation skills, well testing and core analysis.

2. DRILLING

a. Improved drilling methods \& technology 
b. Improvement in dril1ing and completion techniques in older mature low pressure reservoirs

c. Novel drilling techniques: Rotary drilling was introduced over 80 years ago, and we haven't developed any other method of drilling since then. If drilling wells was cheaper, we could find more oil.

d. Developing drilling technology that can reduce drilling costs so that well density can be increased.

e. Deep water drilling- risers and control

$f$. Addressing the challenges of drilling in deeper and deeper waters

g. Computer controlled drilling

h. Horizontal (parallel) drilling

1. Drilling technology-horizontally drilled wells could dramatically improve the domestic state of reservoirs in the US. Also, deepwater and hostile environment technologies should be thoroughly reviewed.

j. Rig safety/ environmental safety

k. Geomechanics applications to improve drilling and well completions, including horizontal wellbores

1. Logging, casing and cementing horizontal wells

m. Improvements in MWO

\section{PRODUCTION}

a. Improved production $(2)$

b. Optimization of production operations

c. Reduce drilling and development costs, especially in off-shore areas and hostile environments through the use of mathematical optimization methods

d. Reduce lifting costs through (1) better design of facilities, ( 2 ) more efficient mechanical lifting and ( 3 ) process automation/monitoring

e. Cost effective expert systems development for real time monitoring and evaluation of production systems for increasing the recovery and production of hydrocarbon mesources.

$f$. Ways to produce oil from off-shore without a platform and the problems of mult i-phase flow in long, sub-sea plpelines

9. Addressing the challenges of production activities in deeper and deeper waters

h. Development of production equipment to be used in horizontal boreholes

i. Modeling multiphase flow behavior in deviated wells ought to be attempted. Two phase oil/water flow needs to be understood as well as three phase flow of oil/water and gas.

j. Something better than a spinner must be developed for metering multiphase flow, especially in deviated welis.

k. Multiphase flow in wellbores and pipelines.

1. Formation damage: We should attempt not just to minimize damage, but eliminate it. We don't really understand the long term economic and technical consequences of drilling and/or completion damage. 
m. Formation damage prevention and control. Quantitative methodologies need to be developed to predict and control formation damage and fines generation and transport.

$n$. Methods for preventing, measuring or overcoming formation damage

o. Well stimulation technology needs to be improved. Fracture simulation computer models, fracture fluids and proppants, and field use of computers and automated equipment all need to be improved

p. Sour gas design

Q. Corrosion

$r$. Field demonstration project- need to be able to put ideas into practice without interfering with "economic" operations.

5. Developing technology that w111 allow operations in populated environmentally sensitive areas. Perhaps mining \& tunnelling techniques can be applied to develop underground space techniques from which field development can be done from the subsurface.

$t$. Water production problems noed to be addressed. Effective water shut off techniques are needed or uses for produced water need to be developed.

\section{RESERUOIR}

a. Fundamental petrophysics and the interactions of rocks and pore fluids, especially at their interfaces.

b. Properties of fluids in porous media, e.g. measurements of low wetting phase saturations at high capillary pressures

c. Fundamentals of fluids in porous media (reservoir and drilling); fluids and rock behavior; rock mechanical properties.

d. Better understanding of in-situ petrophysical properties (wettability, microfracture development, etc) and how these relate to measured properties (in cores) and inferred properties (from well logs)

e. Wettability: reservoir engineering relies heavily on simulation which inherently assumes water wet reservoirs. The results calculated by simulators are strongly affected by the wettability effects on multiphase flow relations.

$f$. Study of non-equilibrium and time-dependent processes in disordered media. Emphastze the surface science aspects of petroleum production.

g. Heterogeneous (complex) reservoirs need to be investigated using teams of geologists, geophysicists, petrophysicists and petroleum engineers

h. Reservoir simulation.

i. Better simulation tools for modeling complex reservoirs. Currently, the 3-D, 3-phase model only runs effectively on a supercomputer.

J. Scale up: The pore level-to-core level-to-field level integration. Proper averaging of properties and phenomena

$k$. Scaling-how to translate experimental results from iaboratory scale to fjeld scale in heterogeneous reservoir flow systems. How to blend descriptions of processes that operate a the pore level with flows that occur at the field scale. 
1. The major problem in any recovery project is the successful determination of the true flow directions and channels in a reservoir. Insufficient research has been conducted in this area.

$m$. Development of improved methods to monitor fluid movements in reservoirs by cased hole logging, interwell tomography, etc.

$n$. General reservoir engineering and enhanced oil recovery -EOR will be the future of the domestic oil industry and should be heavily emphasized even though the current economic environment is not conducive to many large scale EOR projects.

o. Performance of horizontal wells versus fractured wells, with consideration of economics

p. Integrated reservoir management- how to design production facilities and operations to mesh well with complex flow in heterogeneous reservoirs.

q. Development of Denp Gas Reservoirs

\section{OIL RECOUERY}

a. Field scale enhanced recovery. We displace oll very well in cores in the lab, but we do not do so well in the fleld. We must develop the technology to improve recovery in the field, and do so economically.

b. New ideas on mobilizing oil from by-passed zones

c. How to reduce the oil saturation in unswept areas of a water flooded reservoir.

d. Determining ways to reduce residual oil saturation or improve recovery

e. Develop cross-well logging methods that will locate by-passed oll

$f$. Detection of domestic untapped oil originally availablegeological/geophysical models

9. Enhanced 011 recovery methods (2)

h. Earlier implementation of the EOR method in the life of a reservoir (e.g. polymer water flocding)

1. Gas and water injection might be the only affordable EOR techniques for the next decade. We have to improve our understanding of their performance in heterogeneous reservoirs.

$\mathrm{J}$. Better understanding and classiflcation of economically "reasonable" recovery methods, ranked as to cost/ubl or cost/mmcf, as opposed to exotic methods such as tertiary recovery, production of gas in formation water in superpressured reservoirs, etc, so effort can be channeled to research problems with best expected present worth

$k$. Vertical sweep: EOR methods, their success or failure, are strongly impacted by vertical sweep. We need to pursue research-foam, etc, which will lead to improvements in the vertical sweep

1. Development of EOR technique that is not afected by heterogeneity of rock. formations.

$m$. Use of reservoir data efficiently so as to improve the oil recovery using enhanced techniques- how to integrate data from various sources. 


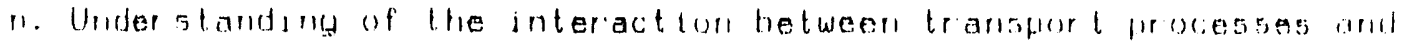

heterogeneity at various scales

o. Foam as sweeping agent

p. Heavy oil and tar sands production. Improved thermal recovery methods.

q. Heavy oil

$r$. Recovery of very low gravity crude oil

5. Combination of petroleum and chemical engineering principles, e.g.

underground gasification of coal and the use of produced gases to synthesize compounds such as methanol at the well site.

$t$. Detalled survey of each of the existing 011 reservoirs in the United States regarding their real potential to increase the oil recoveryl past history, recovery mecharisms, actual status, conventional and EOR methods)

\section{GENERAL}

a. Many professors think "bigger and better" computers programs are the answer. We need to solve problems with the data we have avallable.

b. Apply human expertise increasingly with expert systems and computers

c. Improved use of computers in education, complete integration into classrooms and labs.

d. How to incorporate environmental considerations in engineering profitability analysis?

e. How to improve environmental safety and vigilance for the oil fields?

$f$. Additional study of fault tectonics around high stress structures ( piercement salt domes, thrust faults, etc) with the alm of finding new fault traps in known areas of oil production. 
APPENDIX $4-5$

Summary of $8 / 18 / 89$

PETROLEUM ENGINEERING FACULTY SURUEY OF IMPORTANT RESEARCH TOPICS AND ISSUES

Question B. Describe briefly any general problems you identify (e.g. quality of graduate students, low level of funding, lack of equipment, etc) that restrict the ability of the petroleum engineering faculties to address the most important research topics.

1. Funding

a. Low level of funding (4)

b. Low level of federal and state funding (2)

c. Low level of funding-first for student support; second for equipmerit; third for released time

d. Lack of funding

to attract quality graduate students

- to do fundamental resarch

- to renovate and upgrade laboratories

e. Lack of long term ( $>5$ years) funding. Impossible to hire research 5 taff and technicians

$f$. Research funding

g. Funding level. Present projects seem to be in the $\$ 10,000-50,000$ range. Think 10 to 50 million

h. Lack of funding (government) ( 2 )

1. Lack of funding (industry)

J. Low level of funding for applied research

$k$. Due to changing focus of major industries ( from domestic to international) makes it difficult to obtain research money from these 01 companies

1. Increasing difficulty of getting continuing longer term funding from industry for really innovative research, plus having to contend with a slow, unimaginative DOE bureaucracy for significant amounts of government funding.

2. Federal Support

a. Petroleum engineering faculty get very little support from NSF

b. The federal research dollars are controlled and spent by EOR groups primarlly staffed by chemical engineeris who do not have a grasp of the other areas of petroleum enguneering. The federal government should support drilling and production research as well as EOR research.

c. There is little recognition that iny process that improves recovery efficiency adds to economically recoverable reserves.

d. My outsiders ( $51 \mathrm{c}$, a geologist in an enginering program) view of Geofing in 
general is that it has no "home" in major funding organizations such as NSF while DOE funding for schools outside the oll patch 15 enceedingly hard to get. In addition, in harmony with the economic times, industry support is iery errat:c. Establishing a stable funding base for GeoEng in general, includiria Pet Eng, should be a priority.

e. Petroleum engineering is not recognized as a stand alone discipline by NSF and other government agencies. As a result, there is the perception by persorinel of these agencies that if any relevant petroleum enguneering research reeds to be done it will always be done by the industry or should be supported cintarely by the industry. Unfortunately, this is a misconception which hampers petroleum engineering faculty from obtaining funds for their research ideas.

3. Students

a. Students

b. I perceive student quality as a problem

c. Quality of students is adequate.

d. Quality of craduate students is poor, in general, compared to other disciplines. Graduate study in PTE generally not considered of high quality liy both industry arid academia. This is both an image and a real problem. Standiads must increase in all levels of PTE education and curricula must be strengtheried in more basic courses.

e. I see a future crisis regarding good quality graduate students. This ls part of the engineering science problem in the US. Funding is also a factur.

$f$. Not enough good students (inadequate basic engineering and math bach grounds)

פ. Many petroleum engineering graduate students lack a strong background in mathematics, fluid mechanics, thermodynamics, solid body mechanics and transport phenomena to attack some of the more complex problems which need tis be researched.

h. Inability to attract numbers of nighly qualified grad students there is no premium to a masters over a BS in industry.

1. Low number of graduate 5 tudents now that jobs are becoming avallable. Lul auality results from shortage

3. Quality of graduate students relative to other disciplines and low riuriber of U.S. students is a problem.

r. Shortage of petroleumengineering students.

1. Low undergraduate enroliments reduce the pool of qualified grad studerits. FE dises not have a strong enough tradition of the best students continuing on to graduate school. For our department, at least, research support is adequate but we need a steady flow of good students. The perception of PE as a narrow field with employment opportunities limited to a flagging oil industry is part of the problem.

$m$. Low undergraduate enroliments and an improving industry environment lall ll create a shortage of candidates for graduate school within $2-3$ years 
n. Funding for graduate students ( If we had dependable sources and funds, we would have little trouble with student quality

- Need for several graduate fellowships of significant duration and level (\$15,000 plus) to attract quality graduate students, especially those with faw years of practical experience.

p. Majority of graduate students are foreign. They are smart but often poor communicators and most of them will return to their homes abroad after finishing graduate work instead of working in US

q. Insufficient supply of PhD students

$r$. Small number of job openings for PhDs in P.E has a negative effect on the recruitment of high ability individuals to PE

4. Industrial Relationships

a. Access to industrial production results

b. Lack of good data (what data is available is proprietary)

c. Lack of access to reservoir history data.

d. Inadequate interaction with industry on applied research programs

e. Lack of cooperative research support from industry. They will donate money but not research.

$f$. More industrial joint involvement in R\&D. In particular, involvement of service companies

g. Normally, (the exception being industrial consortiums) industry support for petroleum engineeering faculty is at a relative low level where compareu with the government support available for other disciplines of engineering.

5. Administrative

a. I believe consistency of long term commitment is the most pervasive and damaging problem. This leads to a host of difficulties. The ones that concern me most right now are student quality and lack of institutional understanding of the mission of our program within the university. I understand the institution's inconsistency, however, because it is a result of inconsistent signals from the private sector and other public sectors.

b. University administration is only interested in research gran's

\section{Research Program}

a. Much research today in universities tends to be very applied, with formal reporting, budgeting, etc. that does not take into account that much of the work w1ll be done by graduate students who are really" researchers in training"-their productivity is low. When they are trained-they leave the university. They are the real product of our research. The papers and specific contributions are useful, but are definitely by-products. This 15 not reallzed by many (most?) funding agencies. 
b. Lack of time. Emphasis is on quantity of research papers in shortest time span

c. Number of faculty has been reduced $25 \%$ because of low undergraduate enrolment. Amount of research that $c a n$ be done has thus been reduced.

d. More research chairs are needed to fund a constant level of research into specific areas. Writing proposals keeps one alert, but requires a great deal of time and effort.

e. A unified direction of research among faculty who perform research in similar areas

f. Lack of coordinated program to bring new ideas to field to test

g. Lack of well focused national petroleum research program results in unreliable funding and cyclical effects on research priorities

7. Equipment

a. Lack of equipment(2)

b. Lack of expensive, sophisticated equipment (e.g. cat-scan, etc) prohibits intelligent experimental studies.

8. General

a. Lack of consensus national energy policy

b. We have a difficult time getting low cost "public domain" seismic data to work with 
APPENDIX 4-6

Summary of $8 / 18 / 89$

PETROLEUM ENGINEERING FACULTY SURUEY $\quad{ }^{\circ}$ IMPORTANT RESEARCH TOPICS AND ISSUES

Question C. Do you feel that there is a critical need for petroleum engineering faculties to have better access to field data for conducting their research programs? If yes, explain.

Yes 24 No 9 Undecided 2

1. Most companies will provide data when asked, however

2. Academic work is looked down upon unless supplemented by "real" data. Isee a need to prove the desirability of academic research through the use of field data.

3. To be productive, rosearch in PE should be applied. Only companies can operate fields. Technology transfer is weak. Needs to be improved.

4. The proof of the pudding is in eating. Until models developed from lab data can represent field data, they are of no use.

5. It is not critical but it certainly stimulates research activities tremendously

6. Such field data is critical in the development process. Joint university -industry programs would be ideal. The DEA pattern works well, but needs direct involvement of service companies

7. I think we have become too "scientific" and have focused on the analysis of laboratory and theoretical studies. As a result of this attention on the micro and synthetic worlds we have strayed in both research and instruction from the real world of exploitation of resources.

8. Laboratory scale tests do not necessarily reflect real problems. There is not enough funding for univergities to collect their own field data.

9. We could always use more data. We have reasonably good access now.

10. By integrating field data into both the classroom and research, the quality of the educational system will be improved. I know this for sure because I do it consistently.

11. One must gotothe actual field office and well files to get all the 
information. This is not practical except on a particular field basis.

12. Need information from actual drilling wells. Some sort of daily data base should be set up.

13. Core data base for analysis and possible correlation develpment. Field data for EOR and well testing research

14. llany production research projects cannot be reduced to lab size and require full scale equipment

15. Not necessorily, although in many instances it would help. It would clearly allow for a more critical evaluation of conducted research.

16. The three research piojects I described ( reservoir characterization, wettability and vertical sueepl are meaningful if they are tested on actual reservoirs. Pilot tests and field interactions are necessary for these projects.

17. If research is to focus on problems that are of use in petroleum production, real data is absolutely necessary to avold going off on academic tangents.

18. The need is quite obvious. Data are needed for seismic exploration, well logs and unconventional techniques such as well logging.

19. I only need this rarely but do have a present need for information on location and condition of depleted natural gas fields.

20. Unless individual faculty members have a direct tie to a particular company the availability of field data to support faculty research projects is sorely lacking.

21. Cant work in a vacuum.

22. We have good cooperation from companies in this area

23. The student learning is improved when the theory is enforced with field data applied research.

24. End products of research are usually models used to enhance our understanding of a physical set-up. To test the validity and fieldapplicability

of these models one needs current data that are owned and controlled by industry and usually nonaccessible.

25. Usually have to resort to published data which may include bias of previous 
investigator.

26. Need to spend time working on real problems rather than academic artifacts.

27. I find it difficult to believe good research can be done without adequate field data. 
APPENDIX 4-7

Summary of $8 / 18 / 89$

PETROLEUM ENGINEERING FACULTY SURUEY OF IMPORTANT RESEARCH TOPICS AND ISSUES

Question D- Do you feel that there is a need for petroleum engineering

faculties to work cooperatively among institutions on general research programs? If yes, explain.

Yes 25 No 8 Uncertain 2

1. Our institution does not have a graduate program, so cooperative research would te beneficial and logistics would be tough

2. Depends. Superficially it is a good idea- logistically may not be very convenient unless the institutes are in close vicinity

3. There is a lot to be learned from other institutions. Cooperative work is a good way to do that.

4.Cross pollination is good anytime. Even at large departments, stagnation of ideas is always a possibility.

5. Although, presently they see themselves in competition for the same, practically speaking. limited resources and limited number of interested PTE graduate ( and undergraduate) students

6. This must be done with industry, not federal programs. Most federal programs are oriented toward the "enhanced" recovery (liquid flooding) club. This is not petroleum engineering, it's petrophysics. Leave the feds out unless they change their priorities.

7. This is particularly true for PE faculty. We have more in common with each other than with the faculty at our respective universities. We are generally small in numbers and need cocperation to be able to establigh "critical masses" to work on any specific problem.

8. Not necessarily. The bottleneck is field data.

9. I feel strongly that geology and engineering should be better integrated in our research. This could be within a single university, or between universities (usually less efficient) 
10. Not really. It would be useful at times but is not a necessity

11. More diverse ideas solve problems

12. Make better use of specialized knowledge to solve large national problems

13. Not only among universities, but also with

IAODC and ASME petroleum division

14. In general, I would say it has to be on a project by project basis

15. Both parties can contribute to ideas and solutions

16. Definitely. That would enhance communication betwen petroleum and other engineers and scientists, a badly needed interaction

17. Though some cooperation is desirable

18. Cooperation is needed for large research projects

13. The need to share resources, equipment data and brain power is obvious

20. How can we find out easily and without a lot more paper work what other faculties are working on currently, i.e. before the papers based on the work are presented at a meeting.

21. Cooperative efforts between petroleum engineering faculties at different institutions are healthy and permits individual faculty to pool their talents to attack much larger and more complex research projects.

22. Sometimes- it might be more officient use of taxpayers \$. -also contributes to the "good ole boy" club and stagnation of ideas,- need provision for independent effort.

23. I am reluctant to commit more time to coordination exercises that consume a lot of time and don't produce much in the way of actual results. The bureaucratic overhead is just too high.

24. The experience acquired in one area could be useful in solving problems in other areas (analogy synergism)

25. Theroetically, there is synergy to be gained from cooperative research. Practically, logistics makes close cooperation on specific resoarch projects difficult. Shared facilities would entance the capabilities of cooperative research. 
26. Competition between institutions has to be maintained to keep faculty motivated to tackle complex problems. Cooperative programs are usually hard to manage and are stale.

27. Very inefficient if each school has to have expertise in all areaj.

28. To minimize duplicative efforts if for no other reason. And to relieve companies from having to choose between schools when providing funding support. 
APPENDIX 4-8

Summary of $8 / 18 / 89$

PETROLEUM ENGINEERING FACULTY SIIRUEY OF IMPORTANT RESEARCH TOPICS AND ISSUES

Question E- In many academic areas there are large facilities, of a "national" nature, such as cyclotrons, computers, etc that are available to the faculties from all universities for conducting research. Do you think that any such facilities of a "national" character are needed by the petroleum engineering facultios in order to address important research problems that exist? If yes, describe briefly.

$\begin{array}{lllll}\text { Yes } & 15 & \text { No } & 15 & \text { Undecided } 4\end{array}$

1. A national lab would not be desirable

2. One more level of bureaucracy

3. There are excellent facilities for multiphase flow at the U of Tulsa (unfortunately not a state University). Access to such facilities would be great for anybody working in that area. Computer facilities (especially for reservoir simulation) also should be available to all faculties

4. We should have an abandoned oil field to learhow to implement EOR processes

5. I am not well informed on this matter

6. There are computer facilities that are of use, also some chemical analysis facilities. However, there is little in the DOE National Lab structure that we need. If we let them run the new funding for joint

university/industry/government projects, the universities will get 1 ittle or no funds. The national labs will simply expand their programs on our backs.

7. I'm not sure of the form and use of such "national"facilities. One may simply be to focus public attention and add "glitz and excitement" to our profession.

8. Full scale pipe-line, subsea, with multiphase flow instrumentation. Cored wells with known heterogeneities to run new logs and formation evaluation tools

9. Don't foresee this need generally. An exception may be access to large 
"supercomputers."

10. We need to improve our mathematical modelling capabilities. Computer sclentists would be helpful

11. NMR/CAT imaging

12. Not at present because most of this equipment is available locally

13. Dedication of a producing field by several oil companies to be available for testing, dat: gathering by them and universities

14. CAT Scans, NMR equipment, Supercomputers

15. Possibly. Supercomputers is an obvious example. Expensive surface science equipment and image analyzers may also be cited.

16. Possibly access to a major computational facility, given the trends in research at present.

17. Stanford has a "model" facllity for petroleum geophysics, for example, Jon Clarbout's vast amount of data and programs would be very useful if it were available to others.

18. I don't think such large facilities are necessary for really innovative research.

19. This is a difficult question to address. Unless petroleum engineering faculty from those schools which have a lack of research facilities are somehow integrated into the research programs of the more "elite" research oriented petroleum engineering programs, it is highly unlikely that large facilities of a national nature will create additional individual faculty research at the lesser institutions. There are some large scale research facilities of a national character that are needed to foster quality, petroleum engineering research. Facilities such as large scale computerized multiphase fluid flow loops and drilling simulators, rock mechanics and large scale hydraulic fracture simulation facilities, fully instrumented well bore simulators equipped with automated computer-based data acquisition and data analysis systems, large scale laboratory reservoir models which can be used to evaluate enhanced oil recovery processes, large scale state of the art computer systems with three dimensional graphics capability, computer automated scanning $x-r a y$ equipment for rapid scanning acquisition, assessment, and evaluation of rock and fluid properties of large scale cores at restored state in-situ reservoir conditions. 
20. Field site for testing

21. A large scale, high pressure facility to study multiphase flow behavior.

22. Full scale facility simulating well hole geometry during drilling and productionoperations.

23. State of the art, expensive analytical tools.

24. Data base only. If a national data base could be developed and maintained it would alleviate problem $C$ abovele.g. the problem of access to field data)

25. Industry scale drilling facilities, i.e. Terra Tek, otc. Underground space facilities for evaluating stimulation effectiveness, sweep etc., i.e. something like the Nevada test site, AGSTRA's UTF site, etc. 
APPENDIX 4-9

Summary of $8 / 18 / 89$

PETROLEUM ENGINEERING FACULTY SURUEY OF IMPORTANT RESEARCH TOPICS AND ISSUES

Question F- In your special areas(s) of research, is the total level of activity of all the petroleum engineering faculties of the nation as great as it should be, and if not, how much of an increase in activity is needed?

1. RESERUOIR CHARACTERIZATION/FORMATION EVALUATION

a. Reservoir definition. 100\%

b. Reservoir definition. Five fold

c. Reservoir characterization/simulation. Substantial and the largest five programs need to lead the way.

d. Heterogeneous reservoirs. Funding for new tools and ways to process data.

e. Formation evaluetion. Very few faculty work this area

$f$. Formation evaluation. More institutions needed in conducting this type research.

9. Well logging. Level is ok? In complex computer based well logging interpretation, the user must be aware of what is going on- assumptions made, approximations used,etc. and not just take computer output as gospel.

h. Formation Evaluation/well testing. Level is OK

i. Characterization of reservoir heterogeneities. Level is OK

j. Reservoir characterization- 50\%

$k$. Reservoir characterization- double

1. Characterization of fluids. Questionable that current level is OK. Needed are new approaches to EOS.

m. Imaging. Level is OK

n. Fracture orientation characterization. Needs to be supported diractly by the service industry

2. DRILLING

a. Drilling. 400\% . We need to drill more holes cheaper and find more oil. We act like there is no oil left to be found, and that we are simply prolonging production. The oil industry is bound to die with this attitude.

b. Air and gas drilling and completions. Five times.

c. Drilling -Fifty Percent

d. Drilling research - double

3. PRODUCTION

a. Multiphase flow. $50 \%$

b. Multiphase flow in pipes and well bores. $200 \%$ 
c. Production and completion techniques in horizontals. Needs to be supported directly by service industry

d. Deep off-shore production. Need funding to study problem and find solutions. Better access to existing field data

e. Well stimulation. Very few faculty work this area.

f. Well stimulation-300\%

g. Fracturing. More innnovative research

h. Rock mechanics and stimulation technology development. Petroleum engineering faculty need to increase their level of activity in this area by at least $300 \%$. Most of the research in this area is not being done by petroleum engineering faculty.

1. Development of a cost effective and reliable wellbore diagnostic package for real-time monitoring and evaluation of stimulation quality. The present monitoring and evaluation systems are unreliable and many timies are based on "art" rather than good engineering science. The increase needed is at $10 a s t 300 \%$

j. Production. Twenty five percent

$k$. Production. Level is OK

1. Gas well deliverability testing. Level is OK

$m$. Horizontal wells charactorization. It is difficult to assign a number but more analytical work is needed

n. Production-artificial lift. 100x

o. Artificial lift rosearch - doublo

p. New methods of petroleun transportation, e.g. in the arctic. This vital area is hardly addressed at all and could be

q. Supplementary sources of natural gas beyond what DOE thinks are important.

$r$. Production system analysis, design, implementation and operatons. The increase needed is at least $200 x$ since any imporvements in production enhancement is an immediate benefit to an organization

5. Production logging. 100\%

4. RESERUOIR

a. Additives to improve mobility control. $300 \%$

b. Reservoir engineering. Level OK, but more fundamental research on reservoir characteristics and reservoir homogeneities

c. Reservoir numerical simulation. Level OK

d. Pressure Analysis. Increase needed in the area of heterogeneous reservoirs and hot and high pressure gas reservoirs

e. Fluid Flow. Level is OK

f. Petrophysics. Level is OK

9. Coal degasification. Level is OK

h. Pressure transient processes. Level is OK

i. Fractured and Heterogeneous reservoirs. LEvel is OK.

j. Wettability- $100 \%$

k. Fluid Mixing and flow through porous media. Questionable that level is 
OK. Experimental data are sparse on core samples, sparser on field scale.

1. Reservoir engineering-conventional and EOR projects. Increase eeded is for more interest of companies and individuals regarding our research potential.

$m$. Reservoir management. More effort is nooded in defining economic ( $\$ 15-20 / b b 1$ ) means of EOR

5. EOR

a. Thermal recovery. $200 \%$

b. EOR. Substantial both from the public and private sector

c. New ideas for cheap EOR. Level OK. Industrial funding is reasonable at lab scale

d. EOR. Three fold

e. Improved techniques for EOR. Level is OK

$f$. Underground heating of heavy oil sands by new mothods of using microwave energy.

9. Alternate EOR methods. Questionable that current level is OK. Field data are needed

h. Miscible flooding research. About triple the current level. The number of viable unoversity research programs is very small.

6. GENERAL

a. Petroleum economics. Increase needed in economics and risk evaluation to make engineers (and the public) more aware of the "facts of life"

b. Optimization. About triple

c. Expert systems. About double

d. Artifical intelligence. More applications in all areas

e. I do not think it is a question of activity as much as it is one of focus and quality. I would like to see higher quality and a focus toward more basic research.

$f$. This is hard to say. Just now, even though faculties are operating with a "skeleton crew", the supply of graduates and the industrial demand are just about in balance. 


\section{APPENDIX 4-10}

\section{SUMMARY OF COMMENTS FROM NAE MEMBERS}

VERSION OF $9 / 6 / 89$

\section{Important Ressearch Topics}

1. How can wo make major atrides in reducing cost of drilling? The basic process has changed little since rotary drilling bogarl. Is there a bettar wisy to excavate rock? How can we speed up the exploitation of horizontal drilling?

2. Engineering, logging and materials research to develop a low-cost infill well technology (perhaps a slim hole that could be drilled very rapidly, logged while drilling, completed with tubing, and even thrown away when workovers are needed).

3. Better definition and understanding of mechanical-force-rock interaction in the drilling process from a system perspective (inclusive of pressure, temperature, in-situ and introduced fluids, rock heterogeneity, density, mass transfer of cut material). Compositing sections of strata to be drilled to adjust cutting geometries and hydraulics would have obvious value.

4. Molecular physio-chemical relationships of oil-water-gas mixtures as they affect particle size, distribution and concentration, with the objective of effecting a clean separation ( thus diminishing environmental impacts) and developing new methods of separation or equipment.

5. Reduction in size and weight are critical variables in certain oil field development economics.

6. There is need to study and understand the origins of the heterogeneities of geologic formations and their effects on production.

7. Accurate reservoir characterization is essential to engineering recovery processes.

8. Reservoir characterization using a combination of geological, geophysical, geochemical, geomechanical and geohydrological methods. Reservoir characterization should be pointed at developing 30 models of 0 il and gas reservoirs that are consistent with all sources of information. This means a comprehensive anals is of a number of sources of data that petroleum engineers may not be familiar with. For example, seismic tomography should be used to get a 30 picture of the velocity distribution. Electric magnetic tomography. which is just being developed, should be used to got a 3D picture of the electrical conductivity distribution. Conventional logging and core data provide the 
geological picture. Pressure buildup data provide the hydraulic data, and rock mechanic measurements in the laboratory can provide the gecomecharical picture, especially on fractured rocks. To combine these varied sources of data into a consistent model of a petroleum reservoir obviously requires the development of a team of experts that includes the petroleum engineer. This, in my view, is THE fundamental problem.

9. An engineering. geological, goophysical effort to develop 30 selsmic, cross borohole tomography, or other 1 maging techniques to characterize the flow structure of any given reservoir in the detail that is needed for flow predictions, to locate mobile oil and to trace the sweepout of injection fluid,

- develop more accurate conceptual geological/engineering models of permeability heterogeneity for various depositional types from outcrop studies and subsurface studies in fields with closely spaced wells,

-pursue geostatistical approaches to "fill in the blanks".

10. Potential of energy modulation into seismic evaluation methods to definitively carry high frequency wave energy superimposed on the seismically active low frequency wave spectrum, with the expectation of achieving much better thin bed definition, identifying fluid content, and determining certain rock properties. Could become a macro reservir cvaluation system, geometry, reserves, discontinuities, otc.

11. I have become deeply concerned about the lack of fundamental studies on rocks that constitute the world's petroleum reservoirs... If we are ever to really simulate reservoir behavior, much more definitive ground truth of rocks' petrology, petrography, lithology, geochemistry, petrofabrics, ect, as related to petrophysical parameters, will certainly form the foundation. I know of no laboratory that is really pursuing the research in any sort of basic fashion. Academia should show the way.... This effort, however, calls for a level of interdisciplinary research that I have not yet seen professors willing to undertake.

12. Wettability. Its research should be in two parts. The first concerns determining wettability in situ. The second is to quantify the effect of wettability on multiphase flow behavior and on log interpretation.

13. Research on flow in fractured rocks is still far from complete. Most work to date has been concerned with single phase flow and we do not have a good understanding of multi-phase flow in fractures. Current investigations on the internal geometry of fracture space have revealed that the topography of this space controls the distribution of wetting and non-wetting phases. Thus, it should be possible to develop an understanding of relative permeabilities from appropriate laboratory investigations of single fractures. Since the fracture 
space (or aperture distribution) is stress dependent, this becomes a coupled problem between the mechanical and hydraulic behavior of the fracture.

14. Understanding the three phase flow dynamics involved in producing naturally and hydraulically fractured tight reservoirs. What is the true area of drainage? What are its dimensions? How is the flow conducted vertically in the reservoir? What is the offect and areal extent of vertical permeability barriers?

15. A mathematical-engineering effort in mathematical techniques, computing techniques, and averaging techniques to develop improved reservoir simulators.

16. Enhanced oil recovery is receiving more and more attention and these investigations should be pursued. On the assumption that the correct characterization of the oil reservoir has been made, what is the appropriate method of exploitation to be used? I think mobility control is the key problem and the application of foams appears to have considerable promise. Steam foam appears to be giving good results for the heavy viscous oils. Carbon dioxide foam is another possibility that needs to be investigated. But further work to develop other methods of mobility control are also needed.

17. EOR research should devote significant effort to improving vertical sweep. This has been one of the most important factors in the failure of EOR processes.

18. Chemical flooding has been a failure. Is there an alternative ror crudes where steam or carbon dioxide are not applicable.

19. Tight gas reservoirs will become very important in the future. How do we find them, identify them while drilling and produce them.

20. Most U.S tar sands are not producible economically. Is there a new approach?

\section{Non-Technical Issues}

1. Nearly ali of the major oll companies have cut and sized their research expenditures in proportion to their operational budgets. This action demonstrates that these organizations consider research as an operational support area and not as a generator of new technology to solve the changing and more difficult business environment. To significantly improve the environment for academic research will require that the major industrial concerns recognize and support such efforts. Finding a way to communicate with and sell today's leaders will be an enormous problem.

2. I see focusing on relevant problems as ar issue. It seems to me that a 
university research project ought to be (1) relevant and important to do, 2) useful for teaching the student, and 3) capable of being completed in a suitable time frame. My impression is that too may projects accomplish the latter two objectives but fall short of the first. I think it is a shame to see a project finished, written up, and then completely ignored and forgotten by everyone.

6. Some very relevant and meaningful research has come out of the university/industry consortia. Perhaps this approach should be pursued more or perhaps other avenues should be explored to focus on outstanding issues. Would development of an overall plan by the academic community with industry input be useful or even possible?

4. I wonder whether curront graduates in petroleum engineering, at any level, will understand the methodology required to carry out what I have tried to describe above as reservoir characterization. Of course, the academic community may not agree with my viow of the importance of reservoir characterization, but if they do, then the question can be raised whether the curricula in petroleum enginoering need to be reviewed and revised. It seems to me that engineers with a thorough training in the basic courses in engineering and science will be better prepared for the $k$ ind of petroleum engineering that $I$ envision.

\section{Access to Field Data}

1. The kind of reservoir characterization that I envision can only be carried out by having access to field data. 011 companies are able to provide such data, and where necessary. steps can be taken to prevent revealing the source. This means that a collaborative effort will be needed so that the student can be trained in a realistic manner.

2. Yes, there is a critical need. However, securing access to company data will be difficult to achieve. It will take staff time and may require study before release. Could companies organize for summer studies by students and faculty?

3. I believe university research cannot be conducted effectively without field data and field trials. I recognize that early one may be concentrating on developing ideas and testing them in the lab. However, eventually there is no substitute for trying the ldee on field data.

4. All research programs must eventually leave the lab and get to the field. Since most of our technical work oversimplifies the complex mechanisms that occur in the field, it is generally a significant technical effort to apply new technology in the field. The field processes are probably as important as applications. 
5. My view here is a resounding yes. Although it is the university's appropriate role to develop generic solutions to the extent possible, this doesn't mean the universities should only attack problems that sometimes are so idealized that they are not very useful. I think you can only get a good appreciation of what the real problems are by working on non-generic problems specific to a given reservoir, etc.

6. If actual field data are needed to further develop, verify or refine an engineering concept that has been previously identified, then yes, it could be critical- otherwise, no. Quality of field data enters into this. Also, one could get into sticky problems as to application, ownership or interpretation of performance such that it might subordinate the added value.

\section{Observations}

1. Most fields in the U.S. are in the EOR mode. Therefore, we should be concentrating on the research programs pertaining to EOR. That is the reason why I believe wettability and reservoir characterization are very important. Equally important is the incorporation of the correct physics in reservoir simulators, such as the effect of wottability, frontal instabilities or viscous fingering, etc.

2. Selecting an effective research agenda should be viewed as one of the most important steps in this program. At least $10 \%$ of the total research expenditures should be devoted to evaluating and selecting the appropriate projects. With the general disdain that the major companies hold true research, I doubt that you can look to them for the most informed guidance. The operating people in these companies are not generally useful in identifying research issues as their day to day activities, at best, generally cause them to focus on symptoms rather than the inherent problems. Therefore, it is the smaller companies in most industries that identify the key research areas and create the technical breakthroughs that shape the future. The universities need to $f$ ind a way to encourage interaction with those companies. The best method I can identify for causing such interaction would be to offer free or highly subsidized support to these institutions in return for their guidance in directing research programs. This would be an ideal way to utilize DOE funds. If it were adequately packaged, the scope could be highly appealing to DOE. The direction would be strongly focused towards areas of greatest potential value and with reasonable luck would stay on the leading edge of technology for the industry.

3. I think that in most areas of petroleum engineering, university research can lead to worthwhile improvements in technology that are evolutionary in nature. 
That is to say, we would become incrementally better and better. The chance of achieving these incremental imnprovements should be high. I gather, though, that this is not the sort of thing that you are asking for. To make a revolutionary impact. I think we are somohow going to have to drastically change the way we manage and produce oil reservoirs. I certainly don't have a formula for doing this, but it seems to me that some of the elements have to be 1) more realistic description of the "plumbing" of reservoirs so we will know where fluids are flowing and what we are dealing with, 2) direct detection, or at least a lot more insightful inference, of where the remaining oil is, 3 ) much improved methods for making fieldwide predictions of reservoir performance that account for the important details of reservoir description, and 4) much lower cost methods to drill up fields on close spacing.

4. Much of petroleum engineering is empirical and statistically derived, mak. ing it difficult to further devolop the technology on first principles in a building block manner. Since its bases are wells and well systems in which randomness is a given, it seoms destined to roly heavily on indirect measurements and a substantial amount of abstract reasoning. Further. application of a singular idea or concept embodied within a complex system may be difficult to say the least, and often cannot be easily verifled because of multivariable effects. Consequently, bottom line verification often must be on a system or field trial basis. This is costly and generally takes on an extended period. Nevertheless, the discipline must move forward 50 a better or concensus definition of research needs should be beneficial. 
APPENDIX 4-11

SURVEY OF SURUEY OF SELECTED SPE FORUM LEADERS

VERSION OF $8 / 18 / 89$

\section{Important Topics}

1. Scaling up of laboratory experimental results to field applications. Laboratory results cannot be duplicated or achieved in the field because heterogeneities are not simulated or accounted for adequately.

2. Production geology must become more quantitative and reservoir engineering must include science of production goology in its fabris. Research is needed to bring these two areas closer.

3. Dilute aqueous surfactant systems have the best hope to contact uncontacted oil and reduce its interfacial tension. A search for viable, low viscosity, surfactant flooding systems is in order. The old viscous slug cannot contact much of the oil. Surfactants can be injected in the secondary gas cap, steamflood, and with injected gas to form foam-like material to reduce mobility of gas or reduce oil-water and oil-gas interfacial tension to expedite oil recovery.

4. Methods of measuring reservoir properties in-situ must be improved. Major development decisions are made based on a scarcity of data. It is very difficult to analyze a problem when we have many uncertainties in the data. Petroleum ongineering is much difforent from other engineering disciplines because it is not only dificult to obtain the necessary parameters for engineering analyses but it is also difficult to evaluate the success or failure of a project.

5. Reservoir description. Development of new and improved techniques to enhance our understanding of reservoir structure and how this structure relates to ultimate recovery. This is all the way from seismic to special core analysis and modelling the results.

6. Drilling technology enhancement. The major portion of operating companies exploration budgets go into drilling exploration wells. How do e do it more efficiently?

7. Improved oll recovery. Can techniques be developed for application to small reservoirs? Can ultimate recovery be improved by implementation earlier in the reservoir life? Does horizontal drilling offer a new or different perspective on this? 
II. Non-technological issues

1. How do we interest a broad spectrum of faculty to go into petroleum engineering education? P.E. is a multidisciplinary activity. Industry must support with grants, chairs, otc.

2. Industry and academic community must work closer together to plan their technical goals and the funding of such goals.

\section{Access to field data}

1. Academic programs must be consistent with the goals and needs of the industry. We need more funding of research, and more leadership from the academic institutions than wo are getting now.

2. Access to field data is extremely important to work on "real" problems.

IV. Observations

1. Need more bright, research oriented professors at the petroleum engineering departments. We also need moro long range research programs with competent leadership at the petroloum englneering departments. Better programs and better professors can bring the students to our petroleum engineering departments.

2. There will be no single answer, or easy answer, for the individual departments. Each will have to take the information provided as guidance- and develop their program to fit their gtrengths. They cannot be everything for everyone. 

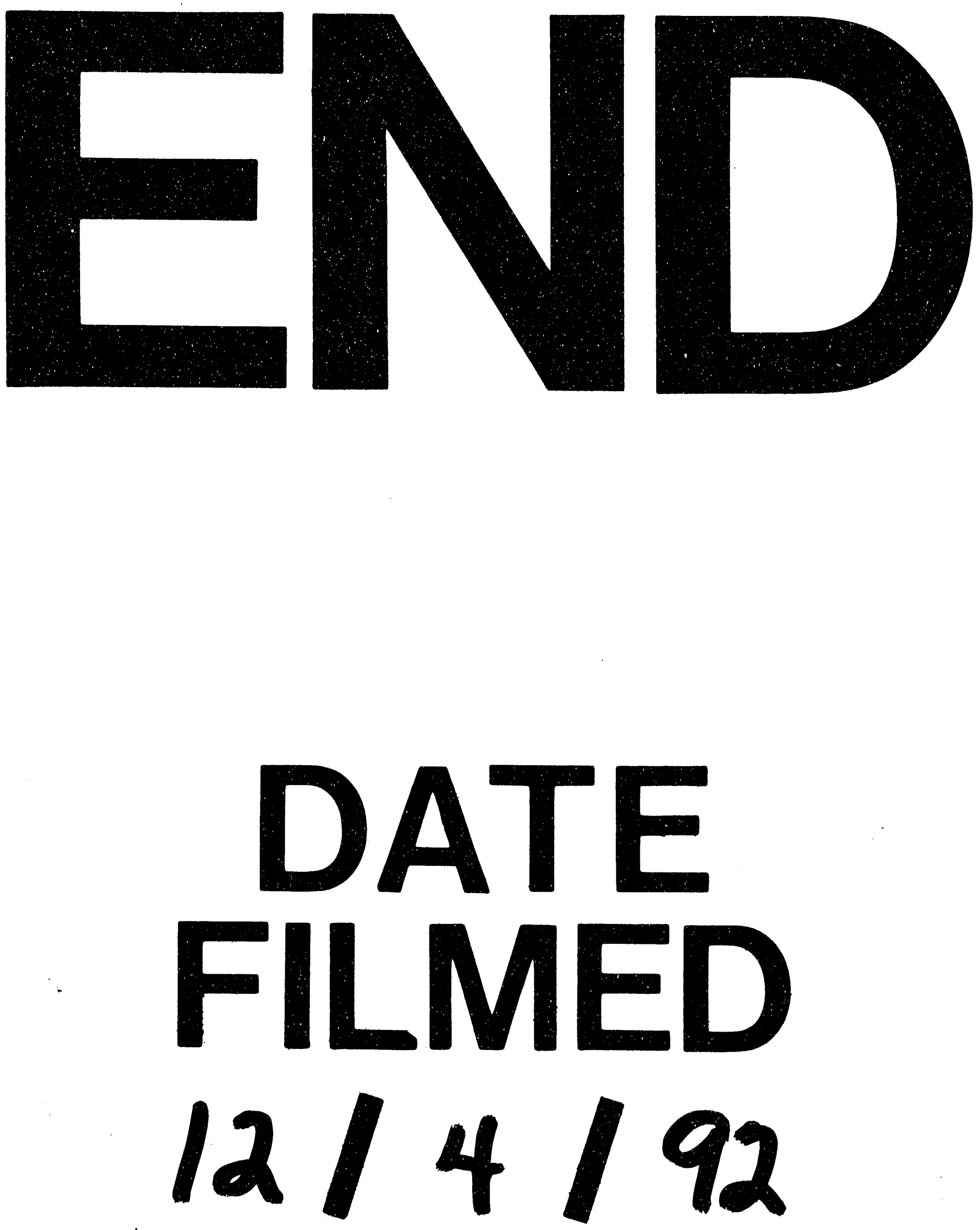
